\title{
Mammals from the earliest Uintan (middle Eocene) Turtle Bluff Member, Bridger Formation, southwestern Wyoming, USA, Part 1: Primates and Rodentia
}

\author{
Thomas S. Kelly and Paul C. Murphey
}

\begin{abstract}
The Turtle Bluff Member (TBM) is the stratotype section for the earliest Uintan biochron, Ui1a, of the middle Eocene Uintan North American Land Mammal age. For more than a century, the TBM had yielded only a few fragmentary specimens. As the result of many years of field work, numerous mammal fossils have now been recovered and provide an unprecedented opportunity to better define this poorly known interval. This is the first in a series of papers that provide detailed descriptions and taxonomic revisions of the fauna of the TBM. Here we document the occurrence of the following taxa in the TBM: Uintasorex parvulus; Microsyops annectans; Notharctus robustior; Omomys carteri; Trogolemur myodes; Washakius insignis; Thisbemys corrugatus; Microparamys minutus; Microparamys sp.; Sciuravus nitidus; Tillomys senex; Tillomys? parvidens; Taxymys lucaris; Pauromys sp., cf. P. perditus; three informal sciuravid species (sp. A, B and C); cf. Pareumys sp.; Metanoiamys sp.; and Elymys? emryi new species. Except for the previously described Hemiacodon engardae, all of the primates from the TBM are holdover taxa from the earlier Bridgerian Land Mammal age, whereas the rodents exhibit a modest diversification during the earliest Uintan. Elymys? emryi and four additional informal rodent species (Microparamys sp., sciuravid sp. A, cf. Pareumys sp., and Metanoiamys sp.) make their appearances in the TBM and, as such, can be added to the list of index species characterizing biochron Ui1a.
\end{abstract}

Thomas S. Kelly. Research Associate, Vertebrate Paleontology Department, Natural History Museum of Los Angeles County, 900 Exposition Blvd., Los Angeles, California 90007, USA, tom@tskelly.gardnerville.nv.us Paul C. Murphey. Research Associate, Department of Paleontology, San Diego Museum of Natural History, 1788 El Prado, San Diego, California 92101, USA, pmurphey@sdnhm.org

Keywords: biostratigraphy; Eocene; mammals; new species; Uintan

http://zoobank.org/F05A22AE-8999-4E67-92B6-28ED7BAA3244

Kelly, Thomas S. and Murphey, Paul C. 2016. Mammals from the earliest Uintan (middle Eocene) Turtle Bluff Member, Bridger Formation, southwestern Wyoming, USA, Part 1: Primates and Rodentia. Palaeontologia Electronica 19.2.27A: 1-55 palaeo-electronica.org/content/2016/1518-earliest-uintan-mammals

Copyright: ( ) July 2016 Society of Vertebrate Paleontology. This is an open access article distributed under the terms of the Creative Commons Attribution License, which permits unrestricted use, distribution, and reproduction in any medium, provided the original author and source are credited.

creativecommons.org/licenses/by/4.0/ 


\section{INTRODUCTION}

The Bridger Formation of southwestern Wyoming has long been known for its middle Eocene fossil mammals (e.g., Leidy, 1873; Marsh, 1886; Granger, 1908; Matthew, 1909; Osborn, 1929; Gazin, 1934, 1946, 1949, 1955, 1957, 1958, 1968, 1976; Wood, 1934; McGrew, 1959; McKenna et al., 1962; Robinson, 1968a; McGrew and Sullivan, 1970; West and Akins, 1970; West, 1973, 1979, 1981, 1984; Krishtalka and West, 1977, 1979; West and Hutchison 1981; Evanoff et al., 1994; Gunnell and Bartels, 1994; Murphey, 1995, 2001; Gunnell, 1997, 1998, 2012; Murphey et al., 1999, 2001, 2011; Gunnell and Yarborough, 2000; Robinson et al., 2004; Murphey and Townsend, 2005; Murphey and Evanoff, 2007; Murphey and Walsh, 2007; Cuozzo, 2008; Gunnell et al., 2009; Murphey and Dunn, 2009). Comprehensive accounts on the history of investigations of the Bridger Formation have recently been documented elsewhere (Murphey and Evanoff, 2007; Murphey et al., 2011), so only a brief historical summary is provided here.

The Bridger Formation was initially divided into five stratigraphic subdivisions from oldest to youngest: Bridger A, B, C, D, and E (Matthew, 1909; Osborn, 1929). Subsequently, Wood (1934) divided the Bridger Formation into two members, the Blacks Fork Member (equivalent to Matthew's [1909] Bridger A and B) and the Twin Buttes Member (equivalent to Matthew's [1909] Bridger $C$ and D). The formation is currently divided into three members (Evanoff et al., 1998; also see Murphey and Evanoff, 2007; Murphey et al., 2011); the Blacks Fork Member (lower Bridger), the Twin Buttes Member (upper Bridger), and the Turtle Bluff Member (TBM = uppermost Bridger, equivalent to Matthew's [1909] Bridger E and the Cedar Mountain Member of West and Hutchinson [1981]). Strata of the Twin Buttes Member and TBM are today restricted to the southwestern part of the Green River Basin along (and in part including) the foothills of the Uinta Mountains (Figure 1). Although previous investigators introduced informal biostratigraphic zones for the Bridger Formation (Gunnell and Bartels, 1994; Gunnell, 1998), Gunnell et al. (2009) formally defined four biochrons (Br1a, Br1b, Br2, Br3) for the Bridgerian North American Land Mammal age. Murphey et al. (1999) initially provided an ${ }^{40} \mathrm{Ar} /{ }^{39} \mathrm{Ar}$ date of 46.16 $\pm 0.44 \mathrm{Ma}$ for a pumiceous sandstone bed (Basal $\mathrm{E}$ tuff) that occurs $8 \mathrm{~m}$ below the base of the TBM on Sage Creek Mountain. This and other dates were described in greater detail in a comprehensive report on the stratigraphy, fossil distribution, and depositional environments of the upper Bridger Formation (Murphey and Evanoff (2007). Based on 35 sanidine samples, Smith et al. (2008) redated this bed, which they refer to as the Sage Creek Mountain pumice, at $47.17 \pm 0.16 \mathrm{Ma}$ relative to the Taylor Creek rhyolite age of $28.34 \pm 0.28 \mathrm{Ma}$ (Renne et al., 1998). Following Smith et al. (2010), Tsukui and Clyde (2012) recalibrated Smith et al.'s (2008) date at $47.45 \pm 0.15 \mathrm{Ma}$ relative to the astronomically calibrated age of $28.201 \mathrm{Ma}$ for the Fish Canyon sanidine standard (Kuiper et al., 2008). However, because the base of the TBM is undulatory and possibly erosional, correlation between the TBM on Sage Creek Mountain and the TBM type section on Cedar Mountain five miles away has not yet been achieved with any degree of confidence. Dating of the TBM sequence on Cedar Mountain is needed in order to understand the TBM fauna in a precise temporal context.

Compared to the other members of the Bridger Formation, the TBM is sparsely fossiliferous. Matthew (1909, p. 296) initially described the Bridger $E$ as being $500 \mathrm{ft}$ thick, composed of "soft banded tuffs with heavy volcanic ash layers," and "nearly barren of fossils and with large gypsum content." He added that the few fragmentary mammal remains he found in the uppermost beds of the Bridger Formation (Bridger E), "sufficiently prove that they belong to the Bridger age." West and Hutchison (1981) documented the occurrence of three species of turtles (Baptemys wyomingensis, 'Rhinoclemys' terrestris, Echmatemys septaria) and three mammal taxa (Herpetotherium marsupium, Paramys sp., cf. P. delicator, Brontotheriidae) from Milwaukee Public Museum localities 2970 and 3077, which occur in the TBM on the southwest flank of Sage Creek Mountain. Murphey and Dunn (2009) described a new omomyid primate, Hemiacodon engardae, from Donna's locality (University of Colorado locality 92189), which occurs at the base of the TBM on the southwestern flank of Cedar Mountain.

Over the last 15 years, one of us (Murphey), often with the help of the late Stephen L. Walsh of the San Diego Museum of Natural History, collected large samples of bulk rock from many levels in the TBM. These bulk samples were liquid screen washed resulting in concentrates from which the fossils were separated by heavy liquid floatation. Their perseverance resulted in the discovery of six additional productive localities in the $131.5 \mathrm{~m}$ thick 


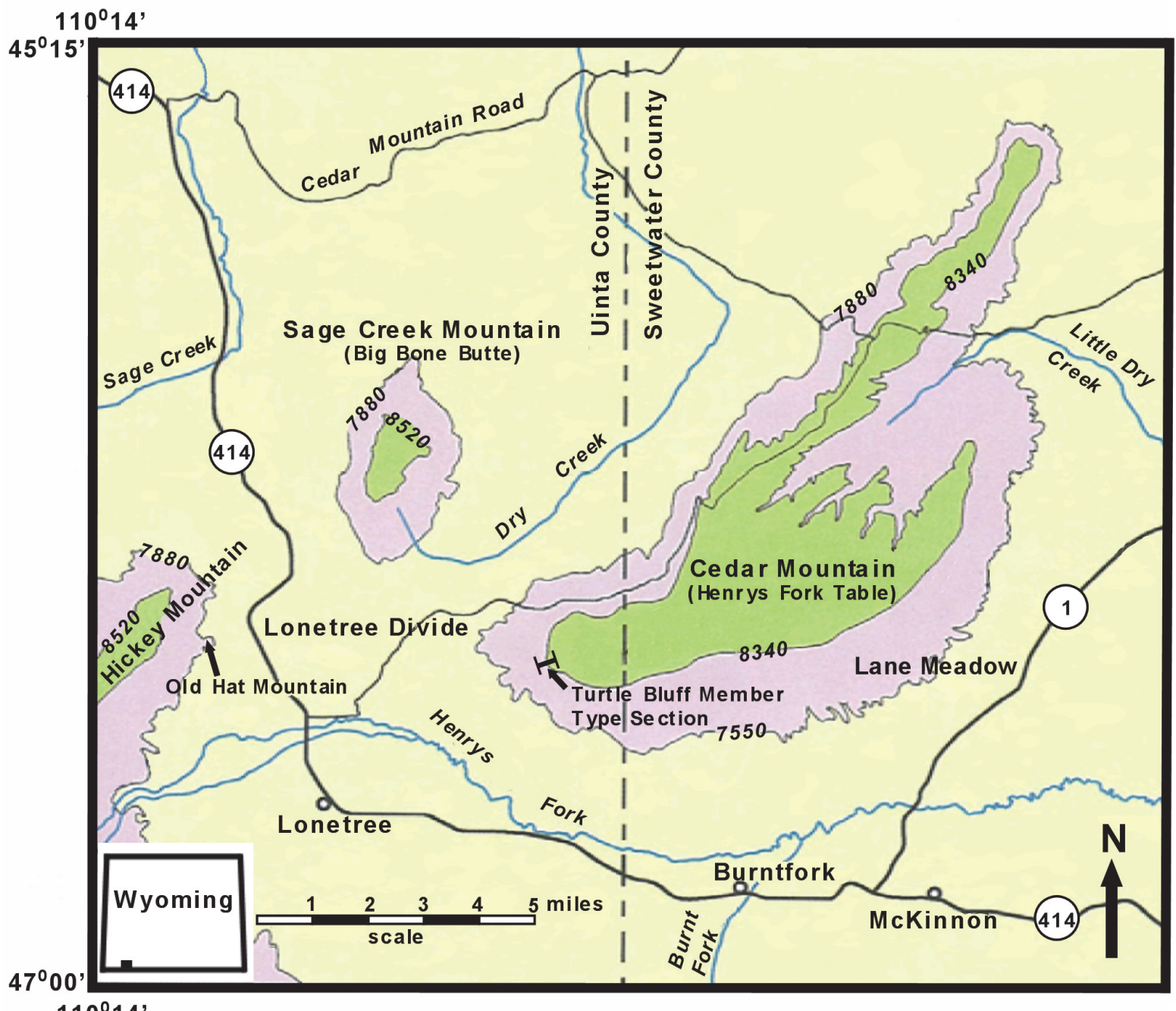

$110^{\circ} 14^{\prime}$

FIGURE 1. Map of study area showing modern and historical geographic terminology along with geographic position of type section of Turtle Bluff Member, Bridger Formation (modified after Murphey [2001]). The light purple shading represents areas on the lower slopes of the principal mountain landforms and the green shading represents areas above the base of the uppermost slopes for each landform (approximate elevations in feet are shown). Insert map shows location of study area in state of Wyoming.

TBM sequence. These localities yielded numerous small mammal teeth (Figure 2). Some of these localities also yielded large mammal taxa.

In addition to lower vertebrates, a wide variety of mammals are documented from these localities, including Marsupialia, Apatotheria, Lipotyphla, Primates, Rodentia, Condylartha, Dinocerata, Artiodactyla, and Perissodactyla. Many of these specimens have been included in published faunal lists, but with the exception of Hemiacodon engardae, they have never been formally described or illustrated.

A complete understanding of the faunal composition of the TBM is important because its strato- type section has been designated in the definition of the earliest Uintan (Ui1a) North American Land Mammal age (Evanoff et al., 1998; Gunnell et al., 2009; Murphey et al, 2011). The purpose of this paper is to document the Primates and Rodentia from the TBM. It is the first in a series of papers that will provide a comprehensive analysis and revision of the mammals of the TBM.

\section{METHODS}

Measurements of teeth were made with an optical micrometer to the nearest $0.01 \mathrm{~mm}$. Dental terminology for primates follows Szalay (1969a) 


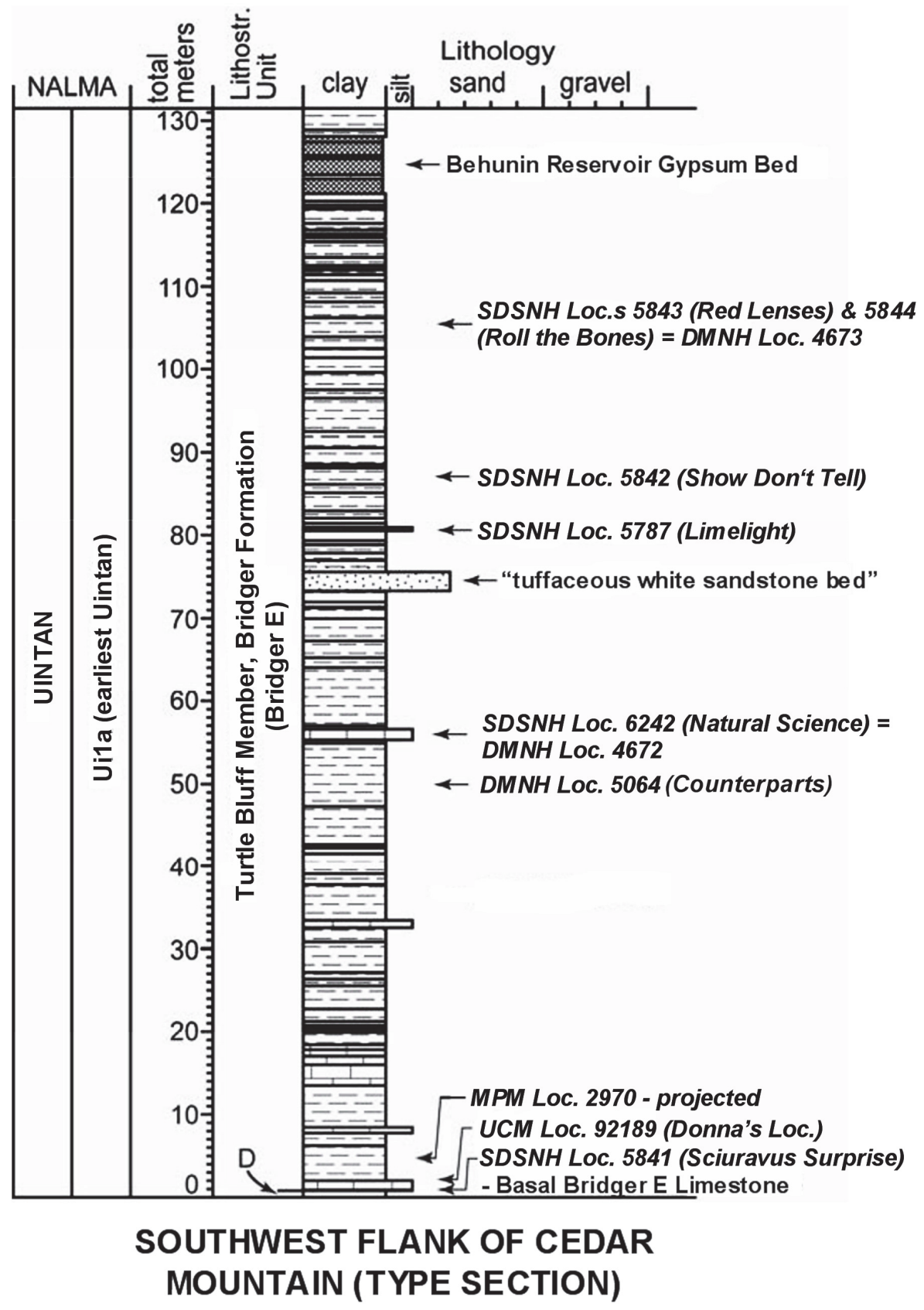

FIGURE 2. Schematic stratigraphic column of type section of Turtle Bluff Member on southwest flank of Cedar Mountain, Bridger Formation, showing relative stratigraphic positions of SDSNH, DMNH and UCM localities (along with the locality names in parentheses) that yielded the fossils described in this paper (modified and corrected after Gunnell et al., [2009]). Locality MPM 2970 occurs on southwest flank of Sage Creek Mountain and its approximate relative stratigraphic position is projected onto type section. Abbreviations are: Lithostr., lithostratigraphic; NALMA, North American Land Mammal age.

and for rodents follows Wood and Wilson (1936) with additional minor crest/cuspid terminology for Metanoiamys following Chiment and Korth (1996). Upper and lower teeth are designated by uppercase and lowercase letters, respectively. Open nomenclature qualifiers follow Bengtson (1988). All specimens described here are curated in the research collections at the Department of Paleontology at the San Diego Museum of Natural History, the Paleontology Section of the University of Colorado Natural History Museum, and the Department of Earth Sciences, Denver Museum of Nature and 


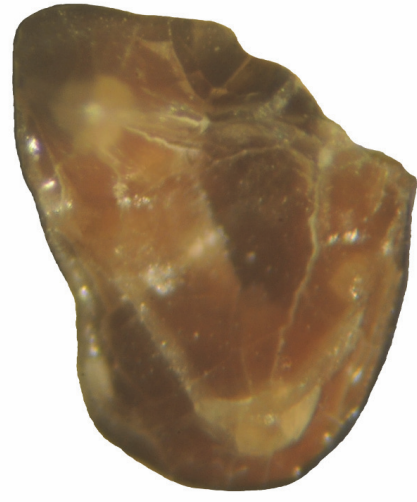

1
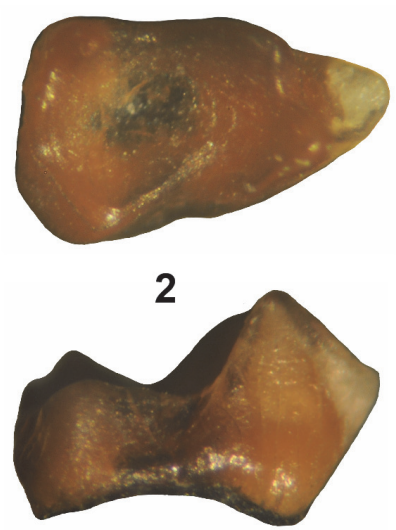

3

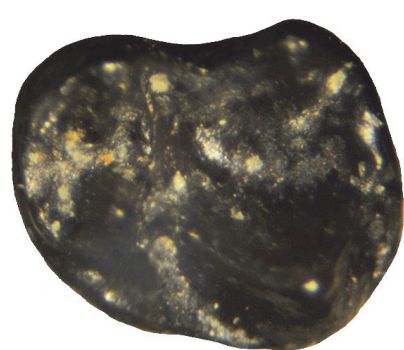

4
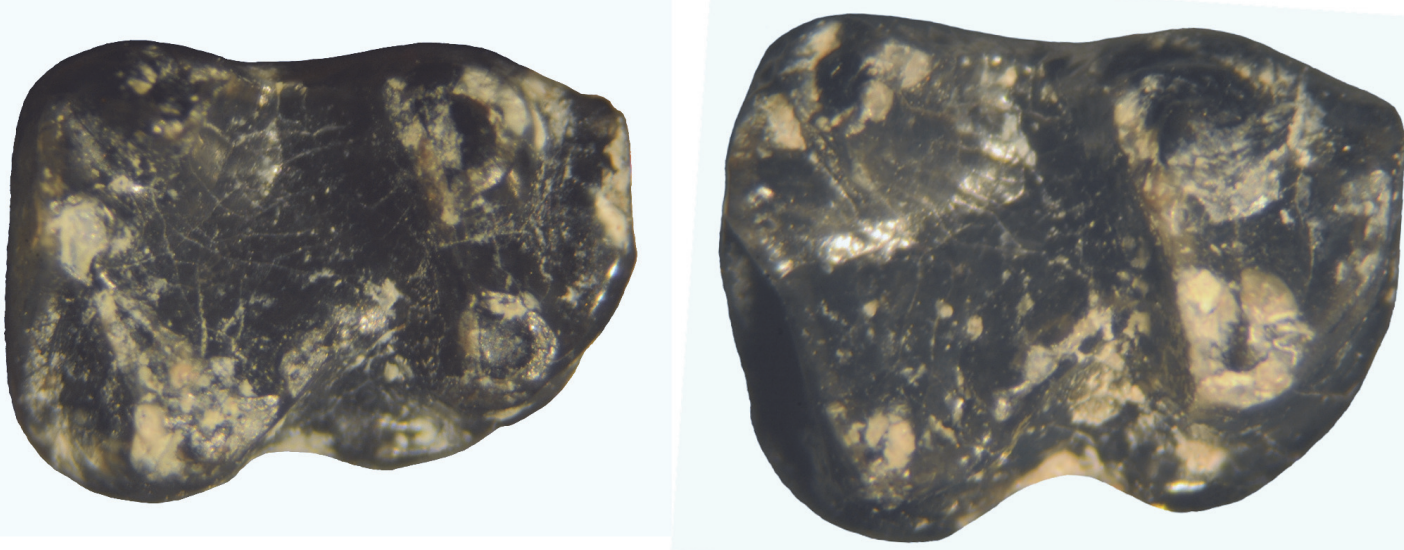

5

6

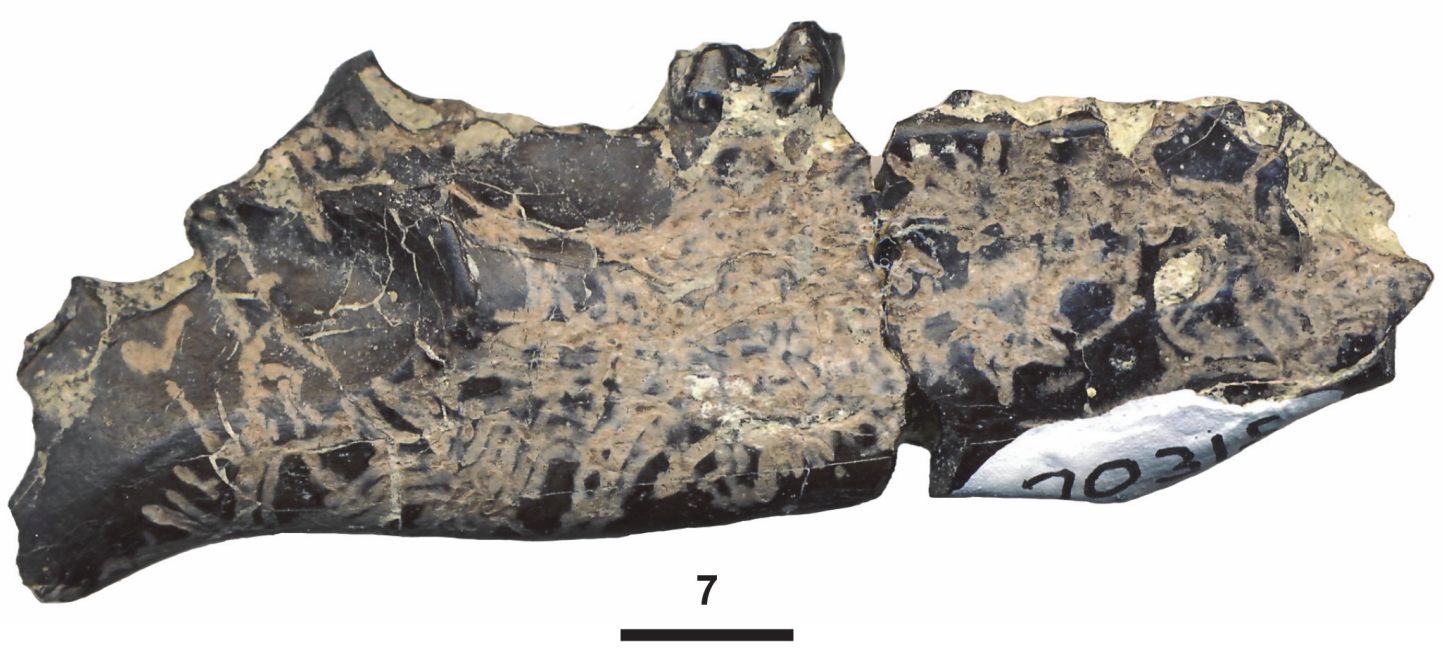

FIGURE 3. Microsyopidae from TBM. 1-4, Uintasorex parvulus: 1, RM1 or 2, SDSNH 110359; 2-3, Rdp4, SDSNH 110358; 4, Lm2, DMNH 75287. 5-7, Microsyops annectans: 5, Rm1, UCM 68541; 6-7, partial dentary with Rm2, UCM 70315. 1-2, 4-6, occlusal views. 3 and 7, labial views. Scale bars equal $1 \mathrm{~mm}$ for 1-6 and scale bar for 7 equals $5 \mathrm{~mm}$. 
TABLE 1. Measurements (in $\mathrm{mm}$ ) of Primates from TBM $(b=$ broken dimension, $p .=$ partial).

\begin{tabular}{|c|c|c|c|c|c|}
\hline Taxon/Specimen Number & Position & ap & $\operatorname{tr}$ & tra & $\operatorname{trp}$ \\
\hline \multicolumn{6}{|l|}{ Uintasorex parvulus } \\
\hline SDSNH 110359 & p. M2 & $1.18 b$ & $1.41 \mathrm{~b}$ & - & - \\
\hline SDSNH 110358 & dp4 & 1.08 & - & 0.52 & 0.64 \\
\hline DMNH 75287 & $\mathrm{~m} 2$ & 1.14 & - & 0.83 & 0.88 \\
\hline \multicolumn{6}{|l|}{ Microsyops annectans } \\
\hline UCM 67984 & $\mathrm{~m} 1$ & 4.59 & - & 3.50 & 3.67 \\
\hline UCM 70315 & $\mathrm{~m} 2$ & 5.05 & - & 3.53 & 3.91 \\
\hline \multicolumn{6}{|l|}{ Omomys carteri } \\
\hline SDSNH 110357 & M3 & 2.35 & 3.55 & - & - \\
\hline UCM 68564 & $\mathrm{p} 4$ & 2.58 & 1.78 & - & - \\
\hline SDSNH 110355 & $\mathrm{~m} 2$ & $2.31 b$ & - & $1.60 \mathrm{~b}$ & $1.80 \mathrm{~b}$ \\
\hline DMNH 75326 & $\mathrm{~m} 3$ & 2.69 & - & 1.62 & 1.54 \\
\hline UCM 95772 & m3 & 2.90 & - & 1.80 & 1.75 \\
\hline \multicolumn{6}{|l|}{ Washakius insignis } \\
\hline UCM 68541 & M1 or 2 & 2.60 & 3.41 & - & - \\
\hline \multicolumn{6}{|l|}{ Trogolemur myodes } \\
\hline UCM 78097 & $\mathrm{~m} 2$ & 1.67 & - & 1.44 & 1.49 \\
\hline UCM 67883 & $\mathrm{~m} 3$ & 2.13 & - & 1.30 & 1.26 \\
\hline \multicolumn{6}{|l|}{ Notharctus robustior } \\
\hline DMNH 75300 & M1 & 7.06 & 8.57 & - & - \\
\hline UCM 78457 & p. M1 or 2 & - & $8.10 \mathrm{~b}$ & - & - \\
\hline UCM 69054 & M3 & 5.00 & $6.50 \mathrm{~b}$ & & \\
\hline UCM 72600 & p3 & 4.17 & 3.14 & - & - \\
\hline UCM 72600 & p. p4 & $5.15 b$ & 4.36 & - & - \\
\hline
\end{tabular}

Science. Detailed locality data are available at these institutions.

Subzones or biochrons of the Bridgerian and Uintan North American Land Mammal ages (e.g., $\mathrm{Br} 1 \mathrm{a}, \mathrm{Br} 1 \mathrm{~b}, \mathrm{Br} 2, \mathrm{Br} 3, \mathrm{Ui1a}, \mathrm{Ui1b}, \mathrm{Ui2}$, and Ui3) follow Gunnell et al. (2009).

Abbreviations are: ap, greatest anteroposterior length; $\mathrm{CV}$, coefficient of variation; $\mathrm{L}$, left; $\mathrm{m}$, meters; Ma, megannum (one million years in the radioisotopic time scale); $\mathrm{N}$, number of specimens; pch, protocone or protoconid height; R, right; SD, standard deviation; TBM, Turtle Bluff Member, Bridger Formation; tr, greatest transverse width; tra, anterior transverse width; trp, posterior transverse width. Abbreviations for institutions and specimens cited in text are: MPM, Milwaukee Public Museum; DMNH, Denver Museum of Nature and Science; SDNHM, San Diego Natural History Museum; SDSNH, San Diego Society of Natural
History; UCM, University of Colorado, Museum of Natural History.

\section{SYSTEMATIC PALEONTOLOGY}

Order PRIMATES Linnaeus, 1758

Infraorder PLESIADAPIFORMES Simons and

Tattersall, in Simons, 1972

Family MICROSYOPIDAE Osborn and Wortman, 1892

Subfamily UINTASORICINAE Szalay, 1969b

Genus UINTASOREX Matthew, 1909

Uintasorex parvulus Matthew, 1909

Figure 3.1-4, Table 1

Referred specimens. From SDSNH Locality 5841: partial M1 or 2, SDSNH 110359; dp4, SDSNH 110358. From DMNH Locality 4672: $\mathrm{m} 2$, DMNH 75287. From UCM Locality 92189: partial i1, UCM 95766. 
Description. The partial M1 or 2 has a broken anterolabial corner and is missing part of the paracone. Its paracone and metacone are conical, with the paracone slightly larger than the metacone. The protocone is the largest primary cusp and is positioned anterior of the transverse midline of the tooth. The preprotocrista and postprotocrista extend labially from the protocone as low crests in gentle arcs to join a distinct protoconule and metaconule, respectively. Although their labial termini are broken away, a distinct preparaconule crista extends labially from the paraconule and a precingulum (anterior cingulum) extends labially from the anterolingual base of the protocone. The posterior cingulum extends from the posterolingual base of the protocone to terminate at the posterior base of the metacone.

One partial lower incisor (UCM 95766) from UCM Locality 92189 has the extreme anterior end of the tip missing and a small wedge along the dorsal edge anterior to the crown base broken off. It is very small, with a dorsoventral width of $1.05 \mathrm{~mm}$ and a labiolingual width of $0.62 \mathrm{~mm}$ near the base of the crown. UCM 95766 is typical of the lower incisors of Uintasorex (Gazin, 1958; Szalay, 1969b), including a lanceolate shape with a sharp dorsal edge, a thin ridge or crest along the ventral lingual border that extends anteriorly from near the base of the crown to the tip, and a long, relatively straight root.

The dp4 is in very early wear. Its trigonid is open labially between the paraconid and metaconid, and significantly narrower than the talonid, but only moderately taller than the talonid. The protoconid is the largest trigonid cusp. The paracristid extends anterolingually in an arc from the protoconid apex to join a weak, shelf-like paraconid. The protocristid extends lingually from the protoconid apex to join a small metaconid. The cristid obliqua extends anterolingually from the hypoconid apex to join the posterior base of the protoconid. The hypoconid and entoconid are distinct cusps, widely separated, resulting in a wide talonid basin. A low postcingulid extends lingually from the hypoconid to terminate at a very small hypoconulid (only a slight expansion), which is separated from the entoconid by a very shallow notch. A small posterior cingulid extends lingually from the posterior base of the hypoconid to terminate near the middle of the postcingulid. The hypoflexid notch is shallow.

DMNH 75287 is identified as an $\mathrm{m} 2$ because it lacks a paraconid and the trigonid is closed labially (Szalay, 1969b; Krishtalka, 1978). Its trigonid is moderately taller than the talonid. The protoconid and metaconid are distinct cusps connected anteriorly by a relatively tall paracristid and posteriorly by a low protocristid. The entoconid and hypoconid are robust. The postcingulid extends lingually from the hypoconid to a small hypoconulid that is positioned close to the entoconid, but is separated from it by a distinct notch. The cristid obliqua extends anterolingually from the apex of the hypoconid to terminate at the posterior base of the protoconid. The ectocingulid (labial cingulid) is prominent, extending from the anterolabial base of the hypoconid to the anterior base of the protoconid. The hypoflexid notch is shallow.

Remarks. Uintasorex is relatively rare in Eocene faunas. Two species of Uintasorex are currently recognized: $U$. parvulus from the Bridgerian of Wyoming and U. montezumicus Lillegraven, 1976, from the Uintan of the San Diego area of southern California (Matthew, 1909; Szalay, 1969b; Golz and Lillegraven, 1977; Nelson, 1977; Rudman, 1981; Walsh, 1991, 1996; Silcox and Gunnell, 2008). Additional samples of Uintasorex have also been described, but their specific statuses have been left in open nomenclature. These include $U$. sp. from the early Bridgerian Green River Formation, Wyoming (Gazin, 1958; Szalay, 1969b), U. sp., cf. U. parvulus from Uintan Tepee Trail Formation at Badwater Creek, Wyoming (Robinson, 1968b; Krishtalka, 1978), U. sp., cf. U. parvulus from late Wasatchian Red Desert region, Wyoming (Gazin, 1962), U. sp., cf. U. montezumicus from the late Uintan Tapo Canyon Local Fauna of the Sespe Formation, California (Kelly and Whistler, 1994), and cf. Uintasorex sp. from the middle Duchesnean Simi Valley Landfill Local Fauna of the Sespe Formation, California (Kelly, 2010). In addition, two other uintasoricine genera are known from the Bridgerian of Wyoming, Alveojunctus minutus Bown, 1982, from the Aycross Formation and Bartelsia pentadactyla Gunnell, 2012, from the Wasatch Formation at South Pass.

The partial $\mathrm{i} 1$ and $\mathrm{m} 2$ can be confidently assigned to $U$. parvulus because they are indistinguishable in size and occlusal morphology to those described for the species (e.g., Matthew, 1909; Gazin, 1958; Szalay, 1969b; Rudman, 1981). The $\mathrm{m} 2$ differs from the lower molars of $U$. montezumicus by being slightly larger and by having a robust ectocingulid (labial cingulid). It can be easily distinguished from the lower molar of Alveojunctus by being significantly smaller and by having a relatively narrower talonid basin. It can also be easily distinguished from the lower molars of Bartelsia by being larger and by having the trigonid relatively 
narrower than the talonid, the trigonid height relatively taller than the talonid and a much more robust ectocingulid.

To the best of our knowledge, the dp4 of Uintasorex has not been previously described. SDSNH 110358 is molariform and very similar in size and occlusal morphology to the $\mathrm{m} 1$ of Uintasorex parvulus except for a narrower trigonid relative to the talonid width and a more anteriorly projecting trigonid that is more open labially, characters seen in other early primate dp4s (e.g., Godinot, 1983; Bloch et al., 2010; Rose et al., 2009). Thus, we tentatively assign it to $U$. parvulus.

The partial M1 or 2 (SDSNH 110359) is very similar in occlusal morphology to those of $U$. montezumicus (Lillegraven, 1976) and U. sp. from the early Bridgerian Green River Formation (Szalay, 1969b) and can be confidently assigned to the genus. SDSNH 110359 is larger relative to the referred $\mathrm{m} 2$ (DMNH 75287) than one might expect, so it could be argued that these teeth are not conspecific. Although the upper molars of $U$. parvulus have not been previously described, the M1-2s of $U$. montezumicus and $U$. sp. from the Green River Formation correlate well in their observed ranges in size to those of their m1-2s. The m2s of $U$. parvulus vary in size, with an ap observed range of 1.09-1.40 mm (Szalay, 1969b; Rudman, 1981; Silcox and Gunnell, 2008; Gunnell, 2012). Although SDSNH 110359 is broken, its ap is $1.18 \mathrm{~mm}$ and, even accounting for the missing anterolabial corner of the tooth, its complete ap would have been considerably less than $1.40 \mathrm{~mm}$, the largest reported $\mathrm{m} 2$ ap for $U$. parvulus. Therefore, the relative difference in size of SDSNH 110359 to that of the referred $\mathrm{m} 2$ is regarded as individual variation, and it is also assigned to $U$. parvulus.

\section{Subfamily MICROSYOPINAE Osborn and Wortman, 1892}

Genus MICROSYOPS Leidy, 1872

Microsyops annectans (Marsh, 1872)

Figure 3.5-7, Table 1

Referred specimens. From UCM Locality 92189: $\mathrm{m} 1$, UCM 67984; partial dentary with $\mathrm{m} 2$, UCM 70315.

Description. The partial dentary is missing the ascending ramus and the portion of the horizontal ramus anterior of the p2 alveolus. Its morphology is typical of that of Microsyops, being relatively deep (depth of ramus below $\mathrm{m} 2=5.50 \mathrm{~mm}$ ) and with the mental foramen positioned below the posterior root of $\mathrm{p} 3$. The $\mathrm{m} 1$ differs from the $\mathrm{m} 2$ by being narrower relative to its length and by having the paracristid slightly less robust. Otherwise the $\mathrm{m} 1$ and $\mathrm{m} 2$ are very similar. The metaconid, protoconid, and hypoconid are robust and bulbous, whereas the paraconid is reduced to a small, but distinct cusp. The trigonid is narrower than the talonid and compressed anteroposteriorly with the paraconid positioned relatively close to the metaconid. The talonid basin is relatively deep with the cristid obliqua extending anterolingually from the hypoconid to join the posterior wall of the trigonid, lingual of the protoconid apex. The hypoconulid is smaller than the entoconid and positioned relatively close to it, giving these cusps a somewhat twinned appearance.

Remarks. The TBM Microsyops specimens agree well in size and molar occlusal morphology to those of Microsyops annectans (e.g., Marsh, 1872; Wortman, 1903; Szalay, 1969a; Silcox and Gunnell, 2008) and are referred to the species.

Infraorder STREPSIRRHINI Geoffroy Saint-Hilaire, 1812

Family NOTHARCTIDAE Trouessart, 1879

Subfamily NOTHARCTINAE Trouessart, 1879

Genus NOTHARCTUS Leidy, 1870

Notharctus robustior Leidy, 1872

Figure 4.1-3, Table 1

Referred specimens. From UCM Locality 92189: partial M1 or 2, UCM 78457; partial M3, UCM 69054; partial dentary with p3 and partial p4, UCM 72600. From DMNH Locality 4672: M1, DMNH 75300.

Description. The M1 (DMNH 75300) is complete, but the other two upper molars are broken. UCM 78457 is missing the anterolabial portion, including most of the paracone and the parastyle, and UCM 69054 is missing the parastyle. The tooth position of UCM 78457 cannot be determined unequivocally from an isolated partial tooth, but it represents either M1 or 2. The M3 differs from the M1 or 2 by its smaller size, more lingually positioned metacone and by lacking a distinct, robust hypocone (= pseudohypocone, postprotocingula or protocone fold, see Gazin, 1958; Covert, 1990; Gunnell et al., 2008) that is separated from the protocone by a distinct notch. The upper molars exhibit the following additional characters: 1) large size; 2) a large, conical protocone; 3) a somewhat crescentic paracone and metacone, each with sharp, acute apices when unworn; 4) a V-shaped centrocrista with a prominent mesostyle; and 5) strong labial, lingual, anterior, and posterior cingula.

The p4 of UCM 72600 is well worn and broken with a small portion of the posterior wall missing, whereas the $p 3$ is complete. The p3 exhibits a sim- 


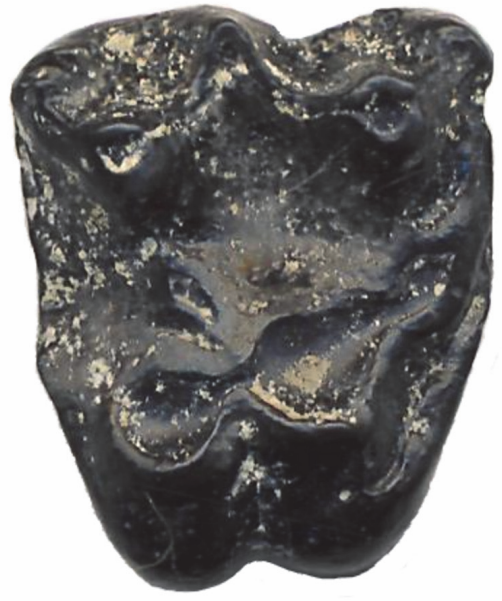

1

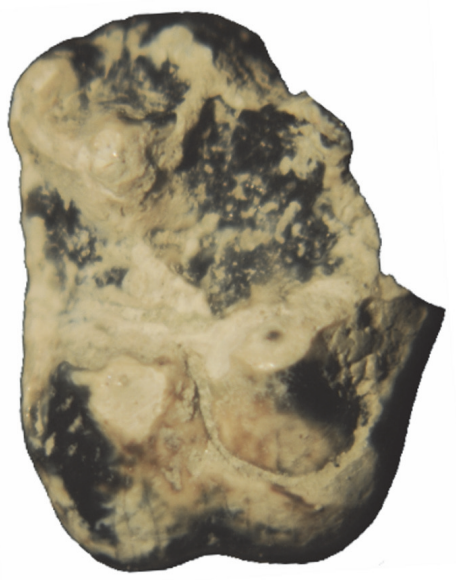

2

-

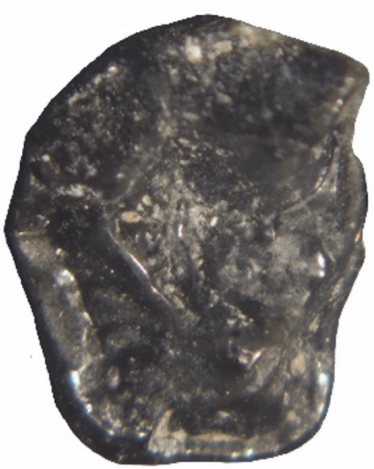

3

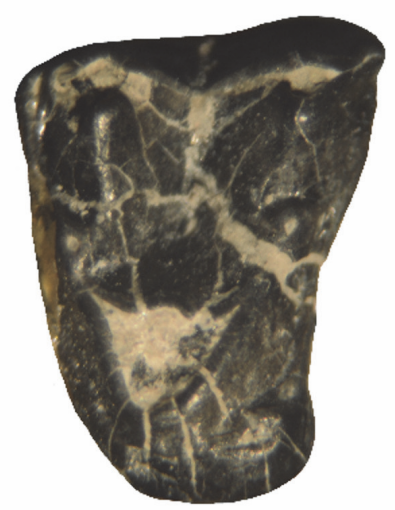

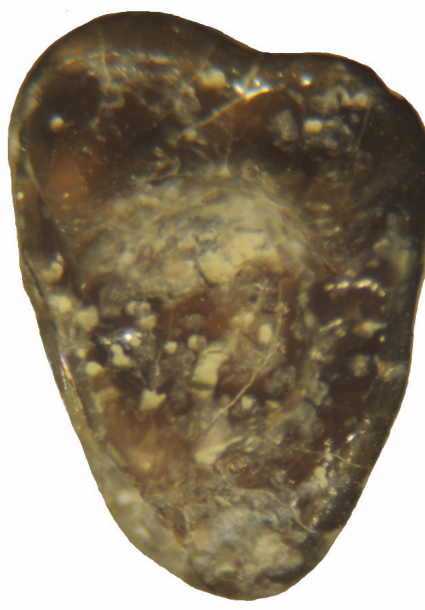

7

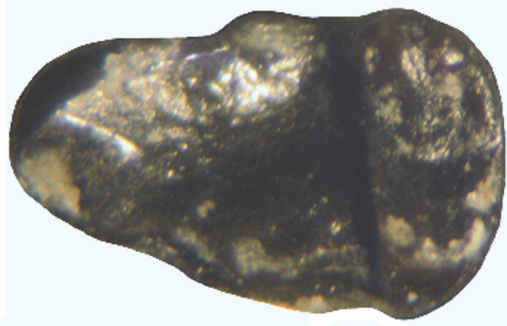

5
6

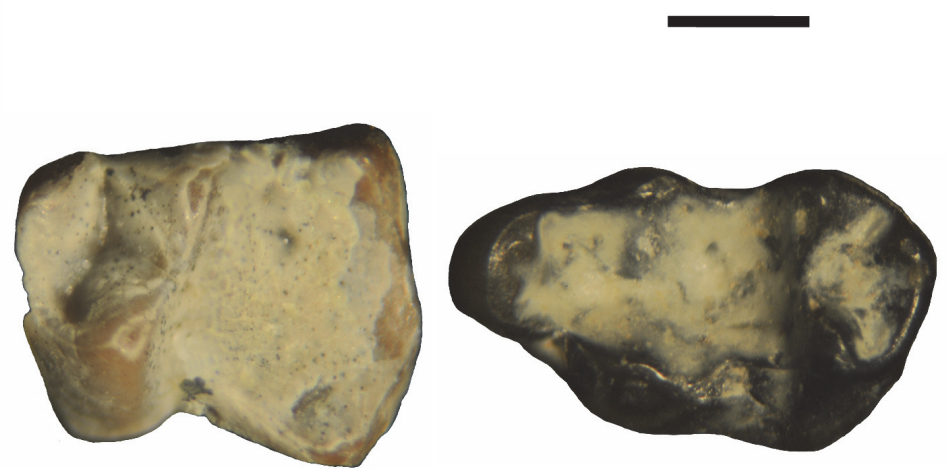

8

FIGURE 4. Primates from TBM. 1-3, Notharctus robustior: 1, RM1, DMNH 75300; partial RM1 or 2, UCM 78457; 3 , partial RM3, UCM 69054. 4-5, Trogolemur myodes: 4, Rm2, UCM 78097; 5, Rm3, UCM 67883. 6, Washakius insignis, LM1 or 2, UCM 68541. 7-9, Omomys carteri: 7, LM3, 110357; 8, Lm1, SDSNH 110355; 9, Rm3, DMNH 75326. All occlusal views. Scale bar equals $1 \mathrm{~mm}$. 
ple morphology with a moderately tall protoconid, a very small entoconid, weak lingual and anterolabial cingulids and is lacking a paraconid. Although worn, the following characters of the p4 can still be distinguished: 1) premolariform with a distinct, small paraconid and distinct metaconid; 2) an incipient entoconid; 3) an incipient hypoconid at the posterior termination of the cristid obliqua; and 4) weak labial and lingual cingulids.

Remarks. The TBM Notharctus specimens are indistinguishable in size and occlusal morphology to those of Notharctus robustior (e.g., Granger and Gregory, 1917; Robinson, 1957; Beard, 1988; Covert, 1990; Gunnell et al., 2008) and are referred to the species.

Infraorder TARSIIFORMES Gregory, 1915

Family OMOMYIDAE Trouessart, 1879

Subfamily ANAPTOMORPHINAE Cope, 1883

Genus TROGOLEMUR Matthew, 1909

Trogolemur myodes Matthew, 1909

Figure 4.4-5, Table 1

Referred specimens. From UCM Locality 92189: m2, UCM 78097; m3, UCM 67833.

Description. The $\mathrm{m} 3$ differs from the $\mathrm{m} 2$ by having a relatively narrower talonid, a slightly more anteroposteriorly compressed trigonid and in being much more elongate anteroposteriorly due the presence of a large hypoconulid. The m1-2 exhibit the following additional characters: 1 ) small size; 2 ) relatively low-crowned; 3) a paraconid positioned relatively close to the metaconid, resulting in the trigonid being almost closed off labially; 4) a relatively tall, distinct entoconid and hypoconid; 5) a cristid obliqua extending anterolingually from the hypocone to join the posterior wall of the trigonid below the protoconid apex; and 6) a weak labial cingulid.

Remarks. The TBM molars are indistinguishable in size and occlusal morphology from those of Trogolemur myodes (Matthew, 1909; Szalay, 1976; Gunnell et al., 2008) and are referred to the species.

\section{Subfamily OMOMYINAE Trouessart, 1879 Genus OMOMYS Leidy, 1869 \\ Omomys carteri Leidy, 1869 \\ Figure 4.7-9, Table 1}

Referred specimens. From SDSNH Locality 5841: M3, SDSNH 110357; partial m1, SDSNH 110355. From DMNH Locality 4672: m3, DMNH 75326. From UCM Locality 92189: p4, UCM 68564; m3, UCM 95722.

Description. The M3 is complete, but its enamel surface is somewhat abraded. Its occlusal outline is transversely elongate and triangular. The paracone is larger than the metacone and a meso- style is lacking between these cusps. The protocone is large and positioned anterior of the midline of the tooth. The preprotocrista and postprotocrista extend labially to join a small, but distinct protoconule and metaconule, respectively. The preprotoconule, postprotoconule, premetaconule, and postmetaconule cristae are very short and extend labially from the protoconule and metaconule to join the labial base of the paracone and metacone, respectively. The ectocingulid is moderately robust, extending from the posterolabial base of the metacone to join the base of the paracrista (preparacrista). The precingulum and postcingulum are moderately strong and joined labially, forming a distinct, continuous lingual cingulum. The pericone is a distinct cusp on the labial cingulum, but a hypocone is lacking on the lingual cingulum.

A single p4 was recovered from the TBM. Its protoconid is the largest and tallest cusp. The paracristid descends rapidly in a gentle arc from the protoconid apex to terminate at a small, shelf-like paraconid. The protocristid is short, extending posterolingually from the protoconid apex to join a small, but distinct metaconid. The cristid obliqua is narrow and descends posteriorly from the posterior wall of the trigonid, below the center of the protocristid, to terminate at a very small hypoconulid. The talonid is relatively shallow and transversely narrow with a slight swelling at its posterolingual corner (incipient entoconid). The lingual and anterolabial cingulids are distinct.

The partial $\mathrm{m} 1$ (SDSNH 110355) has the labial bases of the protoconid and hypoconid along with the anterolingual edge of the trigonid broken away. The two m3s are complete and differ from the $\mathrm{m} 1$ by having a more anteroposteriorly elongate occlusal outline due to the presence of a large hypoconulid that extends posteriorly from the talonid, a relatively smaller paraconid that is positioned less lingually (just lingual of the midline of the trigonid), and relatively narrower trigonid and talonid basins. Although the ectocingulid (labial cingulid) morphology for the $\mathrm{m} 1$ cannot be determined because the basal labial margin of the tooth is missing, the $\mathrm{m} 3$ ectocingulid extends from the anterolabial base of the protoconid to the anterolabial base of the hypoconid and then continues from the posterolabial base to the hypoconid to terminate at the labial base of the hypoconulid. The $\mathrm{m} 1$ and $\mathrm{m} 3$ exhibit the following additional characters: 1) a three cusped trigonid (protoconid, metaconid, paraconid) that is moderately taller than the talonid; 2 ) a widely basined talonid, especially on $\mathrm{m} 1$; 3) an anteroposteriorly wide hypoconid that is larger than the ento- 
conid; and 4) a cristid obliqua extending anterolingually from the hypoconid apex to terminate at the base of the protoconid, below and in line with its apex.

Remarks. Omomys carteri is common throughout the upper and lower Bridger Formation (e.g., Gazin, 1958; West, 1969, 1973; Szalay, 1976; Gunnell, 1998; Gunnell et al., 2009; Murphey, 2001; Tornow, 2005; Cuozzo, 2008). The TBM lower premolar and molars are indistinguishable in size and occlusal morphology from those of $O$. carteri (Gazin, 1958; Szalay, 1976; Cuozzo, 2008) and can be confidently assigned to the species.

SDSNH 110357 has a complete labial cingulum that continues across the labial base of the protocone, a distinct pericone on the lingual cingulum, and is lacking a protocone fold and mesostyle, characters typical of the upper molars of Omomys (Szalay, 1976). In all other occlusal characters, SDSNH 110357 agrees well with the M3 of Omomys. However, compared to the M3 of $O$. carteri, its length is at the largest recorded measurement, and its width is slightly larger than the largest recorded measurement for the species, whereas its length and width are well within the observed ranges for the M2 of O. carteri (Tornow, 2005; Cuozzo, 2008). So, the question arose when examining SDSNH 110357 , could it possibly represent M2? Tornow (2005) and Cuozzo (2008) recently documented a significant amount of individual variation in samples of upper molars of $O$. carteri from the Bridger Formation. In Omomys, certain characters can be used to distinguish the M3 from the M2 (Gazin, 1958; Szalay, 1976; Tornow, 2005; Cuozzo, 2008). The M3 metacone is smaller than the paracone, wherein the anterior portion of the labial margin is more expanded labially than the posterior portion of the labial margin resulting in posteriorly inclined plane along the labial occlusal outline, whereas on M2 the metacone is equal in size or larger than the paracone, resulting in a straighter labial occlusal margin. A hypocone is always lacking on M3, whereas on $\mathrm{M} 2$, a hypocone is usually present on the postcingulid (95\% in Tornow's [2005] sample, $67 \%$ in Cuozzo's [2008] sample). A pericone is variably present on the $M 3$ lingual cingulum, whereas it is always present on M2 (100\%). The M3 has little to no inflection along the posterior margin of the tooth from the posterior margin of the metacone to the level of the protocone, whereas on M2 there is a distinct inflection. SDSNH 110357 has a posteriorly inclined labial occlusal margin (metacone smaller than paracone) and a distinct pericone, but is lacking a hypocone and a distinct inflection along the posterior margin of the tooth. The variable presence of a pericone on $\mathrm{M} 3$ and $\mathrm{a}$ hypocone on M2 does not allow use of these characters for identification of tooth position. The presence of the other two characters on SDSNH 110357 plus the fact that a distinct anterior appression facet is present along the anterolabial border of the tooth where it contacted another molar, but a posterolabial appression facet is lacking, strongly supports its identification as M3. Therefore, SDSNH 110357 is identified as M3 and apparently represents the largest M3 recorded for $O$. carteri.

\section{Genus WASHAKIUS Leidy, 1873 \\ Washakius insignis Leidy, 1873}

Figure 4.6, Table 1

Referred Specimen. From UCM Locality 92189: M1 or 2, UCM 68541.

Description. UCM 68541 exhibits the following characters: 1) moderate size; 2) a large protocone; 3) a distinct hypocone; 4) a robust protoconule; 5) a two-cusped metaconule (doubled), with the larger of the two cusps positioned near the lingual base of the metacone; 6 ) paracone and metacone apices nearly in line with a relatively straight centrocrista extending between them; 7) a small mesostyle; and 8) strong labial, anterior, and posterior cingula.

Remarks. Based on a single, isolated tooth, the position of UCM 68541 cannot be unequivocally determined. It is lacking a pericone, a character that Tornow (2005) found to be variable on the M12 of Washakius insignis. In his study, a pericone was lacking on $43 \%$ of the M1s and $10 \%$ of the M2s. In size, UCM 68541 is within the observed ranges of both the $\mathrm{M} 1$ and $\mathrm{M} 2$ of $W$. insignis (Tornow, 2005). In all other occlusal characters, UCM 68541 agrees well with the M1-2 of $W$. insignis (Gazin, 1958; Szalay, 1976; Tornow, 2005; Gunnell et al., 2008) and is referred to the species.

Order RODENTIA Bowdich, 1821

Family ISCHYROMYIDAE Alston, 1876

Genus PARAMYS Leidy, 1871

Paramys sp., cf. P. delicatior Leidy, 1871

Remarks. West and Hutchinson (1981) described Paramys sp., cf. P. delicatior based on eight isolated teeth (MPM 5882-5887, 5892, 5893) recovered from MPM Locality 2970 in the TBM exposed on the southwest flank of Sage Creek Mountain. These teeth differ from those of $P$. delicatior by being slightly smaller and by having their enamel surfaces slightly less crenulated (West and Hutchison, 1981). No additional teeth of this taxon were recovered during this study. 


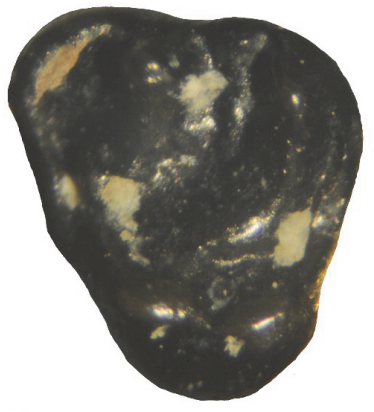

1

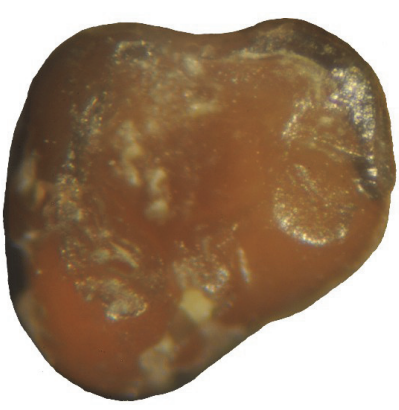

4

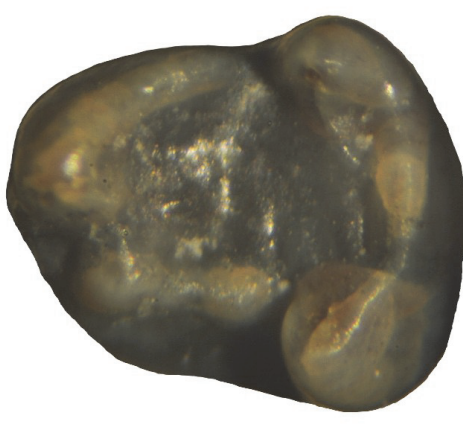

7

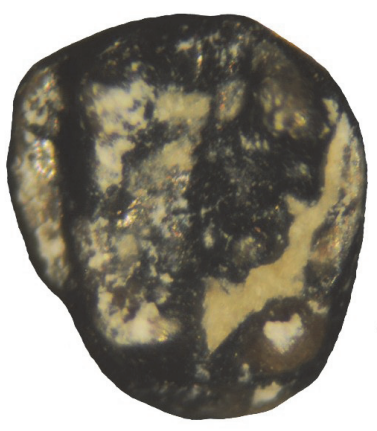

2

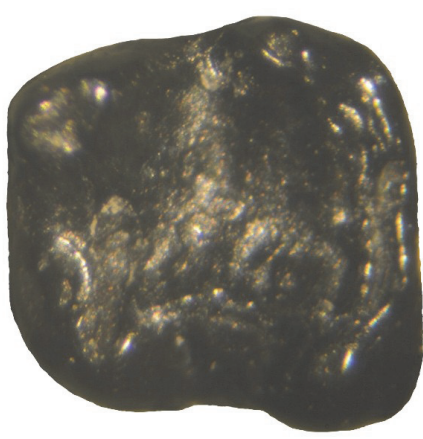

5

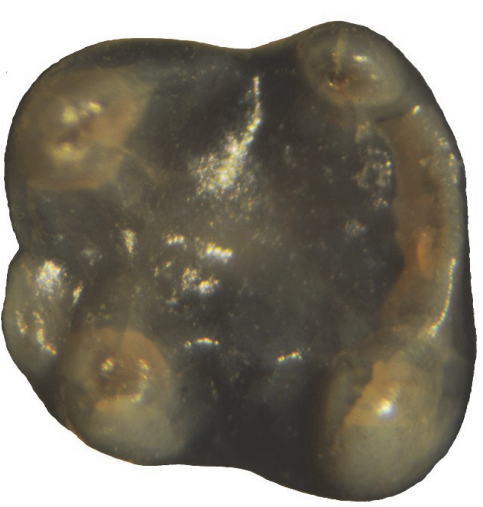

8

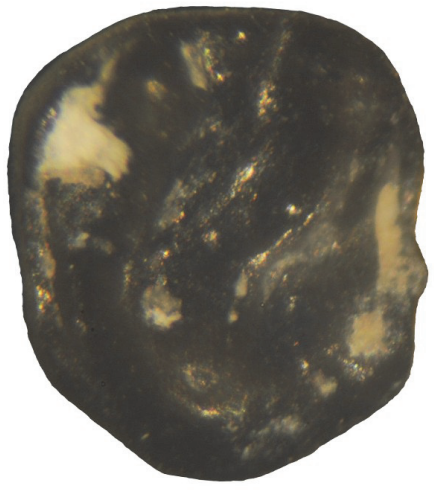

3

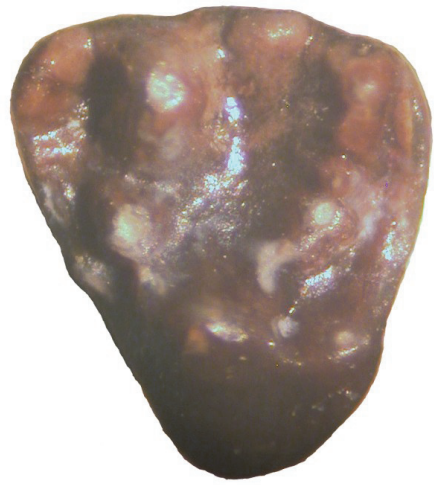

6

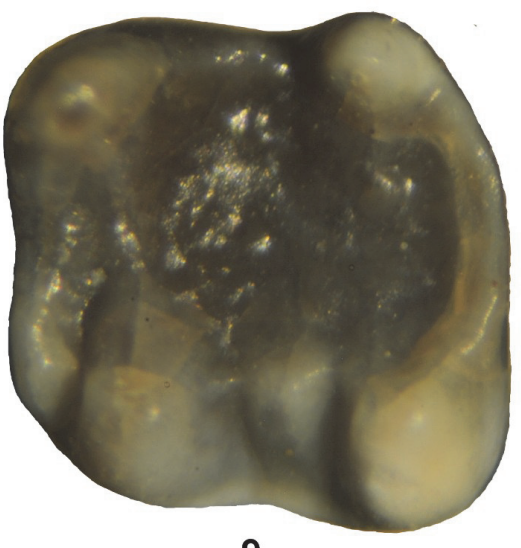

9

FIGURE 5. Microparamys from TBM. 1-5, Microparamys minutus: 1, LdP4, UCM 66310; 2, LP4, UCM 95695; 3, LM1 or 2, UCM 95697; 4, Rp4, SDSNH 110374; 5, Lm1 or 2, DMNH 74140. 6-9, Microparamys sp.: 6, LdP4, SDSNH 110395; 7, Lp4, SDSNH 110360; 8, Lm1, SDSNH 110361; 9, Lm2, SDSNH 110362. All occlusal views. Scale bar equals $1 \mathrm{~mm}$. 
TABLE 2. Measurements (in $\mathrm{mm}$ ) of Ischyromyidae and Rodentia, family undetermined from TBM $\left({ }^{*}=\right.$ probably associated teeth).

\begin{tabular}{|c|c|c|c|c|c|}
\hline Taxon/Specimen Number & Position & ap & $\operatorname{tr}$ & tra & $\operatorname{trp}$ \\
\hline \multicolumn{6}{|l|}{ Microparamys minutus } \\
\hline UCM 66310 & $\mathrm{dP} 4$ & 1.15 & 1.26 & - & - \\
\hline UCM 95696 & P4 & 1.16 & 1.28 & - & - \\
\hline SDSNH 110373 & $\mathrm{dp} 4$ & 1.23 & - & 0.75 & 0.90 \\
\hline SDSNH 110374 & $\mathrm{p} 4$ & 1.18 & - & 0.82 & 1.06 \\
\hline SDSNH 110375 & $\mathrm{~m} 1$ or 2 & 1.31 & - & 1.16 & 1.17 \\
\hline DMNH 74140 & $\mathrm{~m} 1$ or 2 & 1.35 & - & 1.18 & 1.36 \\
\hline \multicolumn{6}{|l|}{ Microparamys sp. } \\
\hline SDSNH 110395 & $\mathrm{dP} 4$ & 1.26 & 1.40 & - & - \\
\hline SDSNH 110360 & $\mathrm{p} 4^{*}$ & 1.36 & - & 0.93 & 1.16 \\
\hline SDSNH 110361 & $\mathrm{~m} 1^{*}$ & 1.41 & - & 1.23 & 1.41 \\
\hline SDSNH 110362 & $\mathrm{~m} 2^{*}$ & 1.49 & - & 1.44 & 1.50 \\
\hline \multicolumn{6}{|l|}{ Thisbemys corrugatus } \\
\hline UCM 70671 & $\mathrm{~m} 1$ & 4.04 & - & 3.76 & 3.90 \\
\hline \multicolumn{6}{|l|}{ Rodentia, family undet. } \\
\hline UCM 95700 & $\mathrm{~m} 1$ or 2 & 1.54 & - & 1.18 & 1.20 \\
\hline
\end{tabular}

Genus MICROPARAMYS Wood, 1959a

Microparamys minutus (Wilson, 1937)

Figure 5.1-5, Table 2

Referred specimens. From UCM Locality 92189: dP4, UCM 66310; P4, UCM 95695; M1 or 2, UCM 95696. From SDSNH Locality 5841: p4, SDSNH 110374; $\mathrm{m} 1$ or 2 , SDSNH 110375. From SDSNH Locality 5843: dp4, SDSNH 110373. From DMNH Locality 4672: $\mathrm{m} 1$ or 2, DMNH 74140.

Description. The dP4 is in very early wear. Its paracone and metacone are distinct, compressed slightly anteroposteriorly, and about equal in size. The protocone is similar in size to that of the paracone and metacone and positioned slightly labial of the hypocone. The hypocone is robust, slightly larger than the protocone, and separated from the protocone by a distinct valley that is continuous with the valley between the metaloph and posterior cingulum. The anterior cingulum extends labially in an anteriorly extended wide arc from about the middle of the anterior wall of the tooth to terminate at the anterior base of the paracone. The protoloph is complete, extending lingually from the paracone to join a small protoconule and then continuing as a very low loph to the lingual edge of the paracone. The metaloph is complete, extending anterolingually from the metacone to join the posterolabial corner of the protocone. The mesostyle is distinct with a short lophule extending lingually from it that has a small accessory cuspule present at about the middle of the lophule. The posterior cingulum is robust, extending labially from the posterolabial edge of the hypocone to terminate at the posterior base of the metacone. The enamel is crenulated.

The P4 occlusal morphology is nearly identical to that of the dP4, but differs in having the anterior cingulum not flared anteriorly, resulting in a much narrower valley between the anterior cingulum and protoloph, a small, but distinct metaconule, and the enamel is more crenulated.

Confident separation of M1 from M2 cannot be made for isolated teeth of Microparamys. On UCM 95696, the protocone is the largest primary cusp. The hypocone is prominent and slightly smaller than the protocone. The paracone and metacone are the smallest primary cusps, slightly compressed anteroposteriorly, and about equal in size. The anterior cingulum is long, extending from the anterior base of the protocone to terminate at the anterior base of the paracone. The protoloph is complete, extending labially from the protocone to join the lingual edge of the paracone. The metaloph is complete, extending from the posterolabial edge of the protocone to join the labial edge of the metacone. The posterior cingulum is robust, 
extending labially from the hypocone to terminate at the posterior base of the metacone. The enamel is crenulated.

One tooth (SDSNH 110373) is identified as a dp4 because it is elongate anteroposteriorly and very similar in size and occlusal morphologically to those tentatively referred by Dawson (1968) to Microparamys minutus. Its talonid is relatively narrow with the metaconid slightly larger than the protoconid. The entoconid is compressed anteroposteriorly, and the hypoconid is compressed obliquely. The anterior cingulid is short and separated from the metaconid and protoconid by a shallow valley. The metalophulid II is incomplete, extending lingually from the protoconid to terminate near the posterolabial base of the metaconid. The hypolophid is complete, extending lingually in a gentle arc from the hypoconid to join the entoconid. The ectolophid is incomplete, extending anteriorly from the hypoconid to connect with a transversely elongate mesoconid. A small metastylid is present between the posterior terminus of a distinct metastylid ridge and the anterior base of the entoconid. The posterior cingulid is short and low, extending from about the middle of the hypolophid to terminate at the posterior base of the entoconid.

The p4 is in moderate wear. Its trigonid is significantly narrower than the talonid. The metaconid is slightly larger than the protoconid and positioned close to the protoconid with a very short, but complete, metalophulid II extending between them. The metastylid crest extends posteriorly from the metaconid to a very small metastylid. The hypoconid is the largest primary cusp. The entoconid is robust, with its apex positioned slightly anterior of the hypoconid apex. The anterior cingulid is a short lophid extending from the anterior edge of the metaconid to terminate near the anterolingual base of the protoconid. The posterior cingulid is complete, extending lingually in a weak arc from the hypoconid to the entoconid. The ectolophid is low, connecting a small mesoconid anteriorly to the protoconid and posteriorly to the hypoconid. The enamel in the central basin is lightly crenulated.

Confident separation of the $\mathrm{m} 1$ from $\mathrm{m} 2$ cannot be made for isolated teeth of Microparamys. The $\mathrm{m} 1$ or $2 \mathrm{~s}$ have a subrectangular occlusal outline. The primary cusps are robust with the protocone, metacone and entoconid conical in shape, whereas the hypocone is slightly compressed obliquely. The anterior cingulid is strong, extending labially from the anterior edge of the metaconid to terminate near the anterior base of the protoconid, where it is weakly separated from the protoconid by a shallow valley that disappears with wear. The metalophulid II is incomplete, extending lingually from the protoconid to terminate near the posterolabial base of the metaconid. The hypolophid is short, either extending labially to terminate in the central basin or extending posterolabially to terminate near and at about the middle of the posterior cingulid. The posterior cingulid is relatively tall and complete, extending in an arc from the hypocone to join the posterior edge of the entoconid. A distinct metastylid is present at the posterior terminus of the metastylid ridge. The ectolophid is complete, connecting a small mesoconid anteriorly to the protoconid and posteriorly to the hypoconid. The enamel in the central basin is crenulated.

Remarks. In size and occlusal morphology, the premolars and molars are indistinguishable from those of Microparamys minutus (Wilson, 1937; Wood, 1962; Dawson, 1968) and are referred to the species.

\section{Microparamys sp.}

Figure 5.6-9, Table 2

Referred specimens. From SDSNH Locality 5841: p4, SDSNH 110360; m1, SDSNH 110361; m2, SDSNH 110362. From SDSNH Locality 5843: dP4, SDSNH 110395.

Description. The dP4 is in early wear. Its primary cusps are robust and conical with the protocone the largest, the paracone the second largest and the metacone and hypocone smaller and about equal in size. The hypocone is separated from the protocone by a shallow notch on the occlusal surface. The anterior cingulum is robust, extending lingually in a wide arc from the anterior base of the paracone to terminate along the anterior wall of the tooth, just labial of the level of the protoconule, resulting in a wide valley between it and the protoloph. The protoloph is nearly complete, with the lingual base of the paracone joining the labial base of a distinct protoconule and a short, low lophid extending from the protoconule to terminate on the anterolabial wall of the protocone. The metaloph is complete, extending lingually from the metacone to the posterolabial edge of the protocone and two cuspules are present at about the middle of the protoloph, the more lingual one being relatively large (= metaconule) and the more labial one being quite small (secondary metaconule or accessory cuspule). A relatively large, transversely elongate mesostyle is present between the paracone and metacone. The posterior cingulum is distinct, extending labially from the hypocone to the poste- 
rior edge of the metacone. The enamel in the central basin is lightly crenulated.

The p4 and two lower molars appear to represent a single individual because they were recovered from the same small batch of concentrate, exhibit nearly identical preservation in color and staining, are in the same stage of wear (unworn) and compatible in size. The larger lower molar is identified as $\mathrm{m} 2$, whereas the smaller molar, which has the trigonid slightly narrower relative to the talonid and a slightly more elongate anteroposterior occlusal outline, is identified as $\mathrm{m} 1$.

The p4 trigonid is significantly narrower than the talonid. The metaconid is robust and significantly larger than the protoconid. The hypoconid and entoconid are robust, with the entoconid subequal in size to the hypoconid. The anterior cingulid is short, extending lingually from the anterolingual base of the metaconid to terminate at the anterior base of the protoconid. The hypolophid is distinct and short, extending posteriorly from the entoconid to join the posterior cingulum near its labial terminus. The ectolophid is complete, connecting a distinct, oval mesoconid anteriorly to the protoconid and posteriorly to the hypoconid. The posterior cingulid is thick and relatively tall, extending labially in a gentle arc from the hypoconid to terminate near the lingual base of the entoconid, where it is separated from the entoconid by a shallow notch. The enamel in the central basin is lightly crenulated.

The $\mathrm{m} 1$ and $\mathrm{m} 2$ are very similar in occlusal morphology and have subrectangular occlusal outlines. The metaconid, protoconid, and entoconid are robust, with the metaconid slightly expanded anteroposteriorly. The hypoconid is large and slightly compressed obliquely. The anterior cingulum is prominent, extending lingually from the anterolingual corner of the metaconid to a distinct, lingual cuspule (= anteroconid) that is separated from the anterior base of the protoconid by a relatively deep valley. The metalophulid II is complete and low, extending labially from the protoconid to join the metaconid, resulting in a relatively deep trigonid basin that is isolated from the central basin. The hypolophid is incomplete, with two very low crests, one extending lingually from the entoconid and one labially from the hypoconid, that terminate in the central basin without connecting. The ectolophid is complete, connecting a distinct, oval mesoconid anteriorly to the protoconid and posteriorly to the hypoconid. The posterior cingulum is robust and relatively tall, extending in a gentle arc from the posterolabial edge of the hypoconid to termi- nate near the posterolingual base of the entoconid, where it is separated from the entoconid by a shallow notch. The enamel in the central basin is moderately crenulated.

Remarks. The presumably associated p4-m2 are similar in occlusal morphology to those of Microparamys minutus described above, but exhibit some notable differences. They are larger. In fact, their dimensions exceed the observed ranges of other samples of $M$. minutus from the Bridger Formation (Wood, 1962; West, 1973; Dawson, 1968) and those of $M$. sp., cf. M. minutus described by Lillegraven (1977) from southern California. They have a weak metastylid ridge and lack a metastylid on $\mathrm{m} 1-2$, whereas $M$. minutus is characterized by having a strong m1-2 metastylid ridge with a metastylid commonly positioned at its posterior terminus (Wood, 1962). The m1-2 further differ from those of $M$. minutus by the following: 1) a more cuspate labial terminus of the anterior cingulid (= anteroconid), resulting in a better separated and deeper valley between the anterior cingulid and metalophulid II; 2) a slightly more robust mesoconid; and 3) a slightly more distinct and complete metalophulid II. Similarly, the dP4 also exhibits some differences from the dP4 referred above to $M$. minutus by being larger and by having a relatively larger protocone and more distinct protoconule and metaconule. Emry and Korth (1989) described Microparamys sambucus from the early Bridgerian Elderberry Local Fauna of Nevada. The lower cheek teeth of the TBM Microparamys are very similar in occlusal morphology to those of $M$. sambucus, including a low, complete metalophulid II, a distinct labial cuspule on the anterior cingulid, and a reduced metastylid ridge. Their dimensions are also within the observed ranges for those of $M$. sambucus. All of the differences cited above could just represent individual variation, wherein these teeth represent extremes for $M$. minutus. However, we regard these differences as potentially significant and separate these teeth from those referred to $M$. minutus as an undetermined species of Microparamys.

\section{Genus THISBEMYS Wood, 1959a \\ Thisbemys corrugatus Wood, 1959a}

Figure 6.1, Table 2

Referred specimen. From UCM Locality 92189: m1, UCM 70671.

Description. Differentiation of $\mathrm{m} 1$ from $\mathrm{m} 2$ can be difficult when dealing with isolated ischyromyid teeth, but in Thisbemys the $\mathrm{m} 1$ differs from the $\mathrm{m} 2$ by being slightly smaller in size and having the trigonid narrower relative to the talonid. For example, 


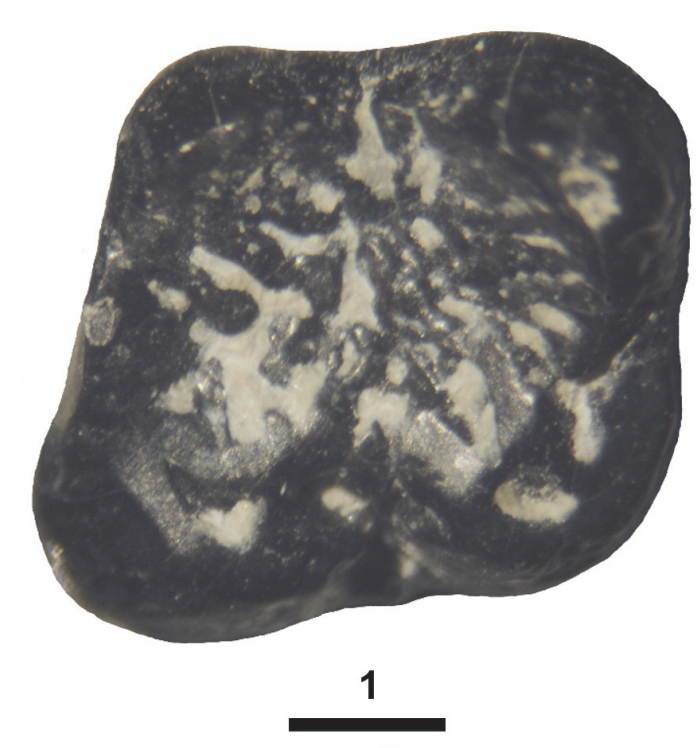

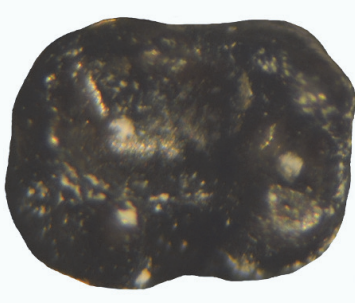

2

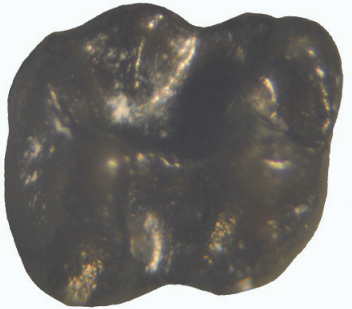

3
FIGURE 6. Thisbemys and Rodentia, family undetermined from TBM. 1, Thisbemys corrugatus, Rm1, UCM 70671. 2-3, Rodentia, family undetermined, Rm1 or 2, UCM 95700. 1-2, occlusal views. 3, oblique labial view. Scale bar equals $1 \mathrm{~mm}$.

in $T$. corrugatus the mean tra/mean ap ratio for $\mathrm{m} 1$ is 0.93 and that of $\mathrm{m} 2$ is 0.99 (Wood, 1962). UCM 70671 has a tra/ap ratio of 0.93 , indicating that it most likely represents $\mathrm{m} 1$. UCM 70671 is relatively large with robust primary cusps (protoconid, metaconid, hypoconid, and entoconid). The trigonid valley is moderately wide and open anterolingually. The metalophid is incomplete with a distinct valley bisecting it about one-third of the way from the protoconid to the metaconid. The ectolophid is incomplete between the protoconid and hypoconid, separated by a narrow transverse valley. The talonid is wide with a deep lingual gorge (valley) between the metaconid and entoconid that extends into the central basin. The hypoconulid is relatively robust and centrally positioned on the posterolophid (= posterior cingulid). The enamel is heavily corrugated (crenulated) throughout the talonid basin.

Remarks. Five species of Thisbemys are recognized from the Bridger Formation (Gunnell, 1998; Gunnell et al., 2009; Anderson, 2015): T. corrugatus Wood, 1959a; T. plicatus Wood, 1962; T. nini Wood, 1962; T. perditus Wood, 1962; and T. brevicrista (Ostrander, 1986). All five species coexisted during the middle Bridgerian (biochron $\mathrm{Br} 2$ ) in the Bridger Basin (Wood, 1962; Gazin, 1976; Anderson, 2015). Anderson's (2015) figure 2 showed $T$. plicatus occurring in the Twin Buttes Member (late Bridgerian, biochron $\mathrm{Br} 3$ ), but in her conclusions section (Anderson, 2015: p. 329) she stated that "only $T$. brevicrista and $T$. corrugatus continued into the latest Bridgerian (Br3)." Although apparently not recorded from the Twin Buttes Member of the Bridger Formation, T. plicatus has been recorded from the lower Bridgerian (biochron $\mathrm{Br} 1 \mathrm{~b}=$ Bridger A of Matthew [1909]) of Wyoming (Gunnell, 1998; Gunnell et al., 2009) and in early Uintan faunas (biochrons Ui1a and Ui1b) from the Devil's Graveyard Formation of Texas (Wood, 1962, 1973; Campisano et al., 2014).

Thisbemys nini and $T$. perditus can be easily distinguished from T. plicatus, T. corrugatus, and $T$. brevicrista by their significantly smaller size and by having the crenulations on the talonid enamel much less developed, along with certain other minor occlusal differences (Wood, 1962, 1973; Anderson, 2015). The lower molar occlusal morphology of $T$. plicatus is quite similar to that of $T$. corrugatus, but differs by having the talonid slightly less open with slightly weaker enamel crenulations and being slightly smaller (Wood, 1962, 1973; Campisano et al., 2014; Anderson, 2015). Thisbemys brevicrista is known from the middle through late Bridgerian ( $\mathrm{Br} 2-\mathrm{Br} 3)$ and is distinguished from $T$. corrugatus and $T$. plicatus by its slightly larger size and by having complete m1-3 metalophids and complete m1-2 ectolophids (Wood, 1962; Anderson, 2015). Thisbemys brevicrista further differs from $T$. corrugatus by having $\mathrm{m} 1$ with the trigonid narrower relative to its length (mean tra/mean $\mathrm{ap}=0.86$ ), $\mathrm{m} 1-2$ with a relatively narrower and less open trigonid, and $\mathrm{m} 2$ with more rhomboid occlusal outline (Anderson, 2015).

UCM 70671 is referred to Thisbemys corrugatus because it is well within the observed size range for the $\mathrm{m} 1$ of the species, and its occlusal morphology is indistinguishable from that of the species, including an incomplete metalophid, an anteriorly incomplete ectolophid, a relatively 
unconstricted and open trigonid, and an identical ratio of the trigonid width to tooth length.

Family SCIURAVIDAE Miller and Gidley, 1918

Remarks. The taxonomy of the sciuravids from the Bridger Formation has a complicated history, similar to that of the Cylindrodontidae (see below). The holotypes of many sciuravid species were originally based on fragmentary specimens, often only a partial dentition or known only from either an upper or lower partial dentition. To further complicate issues, the type localities for the holotypes of many species from the Bridger Formation are either very imprecise or unknown.

Marsh (1971) described the first sciuravid from the Bridger Formation, Sciuravus nitidus (= Sciuravus undans Marsh, 1871 and Colonomys celer Marsh, 1872; see Wilson, 1938a for synonymies). This is the most common and best represented sciuravid from the Bridger Formation, now known from numerous upper and lower dentitions plus cranial material (e.g., Matthew, 1910; Wilson, 1938a; Dawson, 1961). Marsh (1872) named three additional sciuravids from the Bridger Formation; Taxymys lucaris, based on a partial maxilla with P3-4 from Henry's Fork (presumably Br3), Tillomys senex based on a partial dentary with $\mathrm{m} 1$ from Henry's Fork (presumably Br3), and Sciuravus parvidens based on a partial dentary with $\mathrm{m} 2$ presumably from Grizzly Buttes (Br2). Sciuravus parvidens was later reassigned to Tillomys (Troxell, 1923b; Wilson, 1938b). Marsh (1872) also named a second species of Tillomys, T. parvus, but this taxon was later correctly recognized as belonging to Cylindrodontidae by Wilson (1938b) and transferred to Mysops (see also remarks below on cf. Pareumys sp.). Subsequent to Marsh (1871, 1872), investigators have questioned whether the upper dental specimens assigned to Taxymys and lower dentition assigned to Tillomys might be cogeneric because they are similar in size and compatible in occlusal morphology. Troxell (1923a) described Pauromys perditus based on a partial dentary with p4-m3 from an undetermined locality in the Dry Creek area (Dawson, 1968; Gazin, 1976), which includes strata of both the Bridger $B$ and $\mathrm{C}(\mathrm{Br} 2$ and $\mathrm{Br} 3)$. Wilson (1938a) described two additional sciuravids from the Bridger Formation; Sciuravus bridgeri based on a partial dentary with p4-m2 from Millersville (presumably $\mathrm{Br} 2$ ) along with referred specimens including a partial dentary with m1-3 and four isolated cheek teeth, and Sciuravus? rarus based on a partial dentary with p4$\mathrm{m} 1$ from an unknown locality in the Bridger Formation. Wilson (1938c) described Taxymys? progres- sus based on partial maxilla with $\mathrm{P} 3-4$ from an unknown locality in the Bridger Formation. Wood (1959b) described Pauromys schaubi based on a partial dentary with the alveolus for $\mathrm{p} 4$ and m1-2 from the "red stratum at Twin Buttes" ( $\mathrm{Br} 3$ or Ui1a?). Dawson (1962) described a partial maxilla with P3-M1 from Twin Buttes $(\mathrm{Br} 3)$ that she left without generic taxonomic assignment (sciuravid sp.) because it might represent a sciuravid genus already known only by lower dentitions from the Bridger Formation. To summarize, eight sciuravid species have been previously recognized from the Bridger Formation (Sciuravus nitidus, Sciuravus? rarus, Tillomys senex, Tillomys parvidens, Taxymys lucaris, Taxymys? progressus, Pauromys perditus, and Pauromys schaubi) along with one partial upper dentition left in open nomenclature. In addition to the above sciuravids from the Bridger Formation, Dawson (1968) described a large sample of isolated rodent teeth from the early Bridgerian Powder Wash Locality of the Green River Formation, Utah, wherein she divided the sciuravid teeth into two groups left in open nomenclature as Sciuravus sp. and Pauromys sp.

Additional sciuravid taxa have also been recognized from Wasatchian and Uintan strata including the following (Korth, 1984, 1994; Flanagan, 1986; Ivy, 1990; Walton and Porter, 2008): 1) Knightomys Gazin, 1961, primarily known from the Wasatchian and including seven species (the type species K. senior [Gazin, 1952, originally assigned to Tillomys], K. depressus [Loomis, 1907, originally assigned to Sciuravus, synonyms Microparamys lysitensis Wood, 1962, and Microparamys cathedralis Wood, 1962], K. cuspidatus [Bown, 1982, originally assigned to Taxymys], $K$. reginensis [Korth, 1984, originally assigned to Microparamys], K. huerfanensis [Wood, 1962], K. minor [Wood, 1965 , originally assigned to Dawsonomys], and possibly K. cremeneus Ivy, 1990); 2) four additional species of Sciuravus (S. eucristadens Burke, 1937, S. powayensis Wilson, 1940, S. popi Dawson, 1966, and probably S. altidens [Peterson, 1919]); 3 ) three additional species of Pauromys ( $P$. exallos Emry and Korth, 1989; P. texensis Walton, 1993, and P. simplex Walton, 1993) and 4) Prolapsus Wood, 1973, including two species (the type species $P$. sibilatorius Wood, 1973, and $P$. junctionis Wood, 1973).

The type species of Pauromys, $P$. perditus, is characterized by the following (Troxell, 1923a; Wood, 1959b; Dawson, 1968): 1) very small size; 2 ) an extremely reduced $p 4$ relative to the molars, where the p4 ap is only $56 \%$ of the $\mathrm{m} 1 \mathrm{ap}$; and 3 ) a 
transversely expanded mesoconid on m1-3 that is isolated from the protoconid. The lower molars of $P$. perditus also differ from those of Sciuravus and Tillomys by having the primary cusps less inflated and a more lophate occlusal pattern. Walsh (1997) described Pauromys lillegraveni based on a partial dentary with i-m3 along with a partial maxilla with P4-M1 and a number of isolated teeth from the early Uintan Stadium Conglomerate of southern California. Pauromys lillegraveni exhibits a very reduced $\mathrm{p} 4$ ( $\mathrm{p} 4 \mathrm{ap}=50 \%$ of $\mathrm{m} 1 \mathrm{ap}$ ), like that of $P$. perditus, and its $\mathrm{P} 4$ is similarly reduced $(\mathrm{P} 4$ ap $=$ $57 \%$ of $\mathrm{M} 1 \mathrm{ap}$ ). Although other investigators (e.g., Walton, 1993) have suggested that the very reduced $\mathrm{p} 4$ of $P$. perditus may be a character that rises to the level of generic distinction within Sciuravidae, Walsh (1997) went further and adopted a narrower interpretation for the diagnosis of Pauromys sensu stricto, including only $P$. perditus and $P$. lillegraveni, confidently in the genus.

Walsh (1997) questioned the previous generic assignment of certain other species referred to Pauromys. He noted that although Dawson's (1968) Pauromys sp. from Powder Wash, which is known only from isolated teeth, does exhibit similarity in size and lower molar occlusal morphology to $P$. perditus, its p4 and $\mathrm{P} 4$ are not quite as reduced as in those of $P$. perditus or $P$. lillegraveni. He further noted that Pauromys exallos is known only from isolated teeth and if the referred p4 was correctly assigned by Emry and Korth (1989) to the species, then the species does not have a reduced p4 and can be excluded from the genus; however, Walsh (1997) suggested that the referred p4 may actually represent Microparamys sambucus from the same locality, so that the other molars referred to $P$. exallos could still possibly represent Pauromys. Lastly, he noted that some of the teeth referred by Walton (1993) to Pauromys texensis and $P$. simplex more closely resemble those of the eomyid Metanoiamys than those of Pauromys, and if correctly assigned, then these species are not referable to Pauromys. Walton and Porter (2008) partially followed Walsh (1997) in their diagnosis of Pauromys along with additional characters used by Porter (2001) in his analysis of the Sciuravidae, which included the following: 1) p4 reduced (p4 ap $<60 \%$ of $\mathrm{m} 1 \mathrm{ap} ; 2) \mathrm{m} 1$ entoconid not connected to mesolophid; 3) m2 mesoconid does not contact hypolophid; and 4) m3 entoconid connects to posterolophid (= posterior cingulid). However, contrary to Walsh (1997), Walton and Porter (2008) tentatively included $P$. schaubi and $P$. exallos in the genus.
Based on the size of the p4 alveoli in the holotype of $P$. schaubi, its $\mathrm{p} 4$ is not greatly reduced with an alveolar ap that is about $80 \%$ of the $\mathrm{m} 1$ ap. Pauromys schaubi further differs from $P$. perditus by having a doubled $\mathrm{m} 2$ mesoconid and more robust lower molar primary cusps, and lacking a lingual extension of the posterior cingulid (Wood, 1959b). These differences suggest that $P$. schaubi is probably generically distinct from Pauromys.

The isolated molars that Emry and Korth (1989) referred to Pauromys exallos are significantly larger than those of $P$. perditus or $P$. lillegraveni, but exhibit occlusal morphologies very similar to these species, including a lophate occlusal pattern and a transversely expanded mesoconid that is isolated from the protoconid. Whether the single, isolated, heavily worn $\mathrm{p} 4$ referred to $P$. exallos by Emry and Korth (1989) is correctly assigned or represents another taxon (i.e., Microparamys), as proposed by Walsh (1997), cannot be determined without intact dentitions, but the occlusal patterns of the referred molars do suggest a close relationship with $P$. perditus and $P$. lillegraveni.

Walton and Porter (2008) supported Walsh's (1997) analysis of $P$. texensis and $P$. simplex and regarded most of the teeth previously assigned by Walton (1993) to these species to actually belong to Metanoiamys. Most recently in a geochronological and taxonomic revision of the early Uintan Whistler Squat Quarry, Campisano et al. (2014) retained $P$. texensis as valid, but did not mention Walsh's (1997) or Walton and Porter's (2008) referral of $P$. texensis, at least in part, to Metanoiamys. Walton (1993) was very careful in her analysis of $P$. texensis and $P$. simplex and only tentatively assigned premolars to these species. She recognized the difficulty of referring isolated teeth representing different positions to a single species, as have other investigators (e.g., Dawson, 1968).

Although Walton and Porter (2008) tentatively referred $P$. texensis and $P$. simplex to Metanoiamys, the assignment of all the referred teeth may be too inclusive. The lower molars of Pauromys, as typified by $P$. perditus and P. lillegraveni, exhibit a number of characters that differ from those of Metanoiamys. In Pauromys, the metalophid (= metalophulid II) extends lingually from the protoconid to terminate at and slightly posterior of the labial base of the metaconid, whereas in Metanoiamys, the metalophid is usually a continuous cristid with the metalophid forming a smooth arc between the protoconid and metaconid (more complete and joining the metaconid slightly more ante- 
riorly). The ectolophid is less complete with the mesoconid either isolated or nearly isolated (only connected posteriorly by a low cristid to the hypoconid), whereas in typical Metanoiamys, the ectolophid is more complete, usually connecting the mesoconid anteriorly to the protoconid and relatively taller. The hypolophid is incomplete, whereas in Metanoiamys, the hypolophid is stronger, usually forming a complete, continuous cristid joining the hypoconid to the entoconid. The separation of the entoconid from the lingual termination of the posterior cingulid is more distinct in Pauromys. Some of the lower molars that Walton (1993) assigned to $P$. texensis (e.g., Walton, 1993, figures 4J-O) and $P$. simplex (e.g., Walton, 1993, figures 8G-I) appear more similar to those of Pauromys than to those of typical Metanoiamys. Differentiating upper molars of Pauromys from those of primitive Metanoiamys is more difficult. The upper molars of Pauromys lillegraveni are characterized by the following (Walsh, 1997): 1) strong M1-2 anterior cingula; 2) M1-2 lacking an anterocone and protoconule; 3) a complete M1-2 protoloph that extends from the protocone to the anterolingual base of the paracone; 4) a complete M1-2 metaloph connecting the hypocone to the metacone; and 5) an incomplete M1 endoloph, only connecting the mesocone to the hypocone, but complete in M2 connecting the mesocone to the protocone and hypocone. The occlusal morphology of Pauromys sp. from Powder Wash (Dawson, 1968) is very similar to that of $P$. lillegraveni. The M1-2 of primitive Metanoiamys are also similar to those of $P$. lillegraveni and Pauromys sp. from Powder Wash, but have slightly stronger protolophs and metalophs, a greater tendency for the endolophs to be complete with small accessory lophules that extend from the endoloph or mesocone into the central basin. These subtle differences are not surprising because Metanoiamys, the earliest known eomyid, has been postulated to have been derived from a Pauromys-like sciuravid (Walsh, 1997; Walton and Porter, 2008). This may help explain why some of the upper molars assigned to $P$. texensis and $P$. simplex likely represent Metanoiamys instead of Pauromys. Since the lower molars of Pauromys and Metanoiamys appear to be more easily distinguished, and some of the lower molars assigned to the Texas samples of Pauromys do exhibit more similarity to Pauromys rather than primitive Metanoiamys, it is possible that the Texas samples include examples of both Pauromys (e.g., Walton, 1993, figures 6I, 6M, 7C and 8D-E) and Metanoiamys (e.g., Walton, 1993, figures 4A, 6J,
6K, and 7D). Thus, referral of all teeth from Texas assigned by Walton (1993) to P. texensis, P. simplex and Pauromys spp. (taxa left in open nomenclature) to Metanoiamys may not be justified. However, the holotype of $P$. texensis, a LM1 (TMM 41745-412), and the holotype of $P$. simplex, a LM1 (TMM 42486-515), appear more similar in occlusal morphology to those of primitive Metanoiamys than to those of $P$. lillegraveni and $P$. sp. from Powder Wash. Therefore, we accept Walton and Porter's (2008) reassignment of $P$. texensis and $P$. simplex to Metanoiamys, but question the referral of some of the lower molars in the hypodyms of these two species to Metanoiamys. Only with the discovery of intact upper and lower dentitions of both of these species will their taxonomic identities be fully clarified.

Other investigators have noted the similarity of other rodent taxa to Pauromys, which also exhibit a significantly reduced $\mathrm{p} 4$, including Wasatchian 'Microparamys' scopaiodon (Korth, 1984, 1994; Walton and Porter, 2008) and Bridgerian 'Sciuravus' rarus (Korth, 1994). 'Microparamys' scopaiodon is known only from a partial dentary with $\mathrm{p} 4$ and $\mathrm{m} 2$ plus the alveoli for $\mathrm{m} 1$, and its $\mathrm{p} 4$ and $\mathrm{m} 2$ occlusal morphologies are very similar to those of $P$. perditus and $P$. lillegraveni. However, the p4 of ' $M$.' scopaiodon is slightly less reduced than those of $P$. perditus and $P$. lillegraveni. A comparison of the relative reduction of $\mathrm{p} 4$ to $\mathrm{m} 1-2$ and P4 to M1 for Sciuravidae and 'Microparamys' scopaiodon is presented in Table 3. If one accepts the character state of the p4 ap $<60 \%$ of $\mathrm{m} 1$ ap (Walsh, 1997; Walton and Porter, 2008) as a diagnostic character of Pauromys, then only P. perditus, P. lillegraveni, P. sp. from Powder Wash, and possibly 'Sciuravus' rarus would be included in the genus. However, the $\mathrm{m} 1$ of ' $S$.' rarus is significantly larger than those of $P$. perditus and P. lillegraveni, but similar in size to those of Sciuravus. Moreover, the $\mathrm{m} 1$ of 'S.' rarus differs from those of $P$. perditus and $P$. lillegraveni by having more well-defined, inflated primary cusps (less lophate) and a less transversely expanded mesoconid, characters more typical of the lower molars of Sciuravus. Thus until additional, more complete specimens of 'S.' rarus are available, its phylogenetic relationships to Pauromys or Sciuravus cannot be determined with confidence.

Korth (1984) referred a sample of nine isolated teeth from the late Wasatchian (Wa7) Lost Cabin Member of the Wind River Formation to Pauromys sp. In the Lost Cabin sample, the p4 length is not greatly reduced relative to the $\mathrm{m} 1-2$ 
TABLE 3. Comparison of $\mathrm{P} 4 / \mathrm{p} 4$ ap reduction in size (in percent) relative to $M 1 / \mathrm{m} 1-2$ aps in sciuravids and 'Microparamys' scopaiodon ${ }^{*}$ = percentages for means of isolated teeth that can only be identified as M1 or 2 and $\mathrm{m} 1$ or 2 , ** = percentage based on alveolar ap of p4 or m1). References: ${ }^{1}$ Bown (1982); ${ }^{2}$ Burke (1937); ${ }^{3}$ Dawson (1962); ${ }^{4}$ Dawson (1966); ${ }^{5}$ Dawson (1968); ${ }^{6}$ Emry and Korth (1989); ${ }^{7}$ Flanagan (1986); ${ }^{8}$ Gazin (1952); ${ }^{9}$ Gazin (1961); 10 Guthrie (1971); ${ }^{11}$ Ivy (1990); ${ }^{12}$ Korth (1984); ${ }^{13}$ Korth (1994); ${ }^{14}$ Loomis (1907); 15 Marsh (1871); 16 Marsh (1872); 17Nelson (1974); 18Peterson (1919); ${ }^{19}$ Rasmussen et al. (1999); ${ }^{20}$ Troxell (1923a); ${ }^{21}$ Walsh (1997); 22Walton (1993); 23Walton and Porter (2008); 24West (1973); 25Wilson (1938a); 26Wilson (1938b); 27Wilson (1938c); 28Wilson (1940); 29Wood (1959b); 30Wood (1962); 31Wood (1965).

\begin{tabular}{|c|c|c|c|c|}
\hline Taxon & P4 ap/M1 ap & p4 ap/m1 ap & p4 ap/m2 ap & References \\
\hline Knightomys huerfanensis & $95 \% *$ & $80 \%$ & $81 \%$ & 12,30 \\
\hline Knightomys minor & $83 \%$ & $90 \% *$ & $85 \% *$ & 11,31 \\
\hline Knightomys senior & - & $93 \%$ & $90 \%$ & $8,9,11$ \\
\hline Knightomys reginensis & $85 \%$ & - & - & 7,12 \\
\hline Knightomys cuspidatus & $77 \%$ & $74 \%$ & $72 \%$ & 1,12 \\
\hline Knightomys depressus & $93 \%$ & $87 \%$ & $82 \%$ & $8,11,14,30,31$ \\
\hline Knightomys cremneus & - & $79 \%$ & $79-85 \%$ & 11,23 \\
\hline Sciuravus wilsoni & - & $95 \%$ & $90 \%$ & 9,30 \\
\hline Sciuravus nitidus & $85 \%$ & $84-93 \%$ & $74-87 \%$ & 15,24 \\
\hline 'Sciuravus' bridgeri & - & $93 \%$ & $88 \%$ & 26 \\
\hline Sciuravus eucristadens & $79 \%$ & $87.50 \%$ & $79 \%$ & 2,5 \\
\hline Sciuravus powayensis & $70 \%$ & $82 \%$ & $78-82 \%$ & 21,28 \\
\hline Sciuravus altidens & $87 \%$ & - & - & 18 \\
\hline Sciuravid sp. Powder Wash & $91 \% *$ & $88 \% *$ & - & 5 \\
\hline Sciuravid sp. Br3 & $79 \%$ & - & - & 3 \\
\hline Sciuravus popi & $79 \%$ & - & - & 5,19 \\
\hline 'Sciuravus' rarus & - & $59 \%$ & - & 25 \\
\hline 'Microparamys' scopaidon & - & $\sim 65 \%$ ** & $63 \%$ & $12,13,22$ \\
\hline 'Pauromys' schaubi & - & $\sim 75 \%$ & $\sim 80 \%$ ** & 21,29 \\
\hline Pauromys perditus & - & $56 \%$ & $56 \%$ & 5,20 \\
\hline Pauromys lillegraveni & $57 \%$ & $50 \%$ & $56 \%$ & 22 \\
\hline Pauromys exallos & - & $101 \%$ & $92 \%$ & 6,21 \\
\hline Pauromys sp. Powder Wash & - & $59 \%$ & - & 4,22 \\
\hline Pauromys sp. Lost Cabin & - & $85 \%$ & $76 \%$ & 12 \\
\hline Taxymys lucaris & $84 \%$ & - & - & 16,27 \\
\hline Tillomys senex & - & $\sim 75 \%$ ** & - & 16,27 \\
\hline Tillomys? sp. Fowkes & $74 \%$ & $97 \%$ & - & 17 \\
\hline
\end{tabular}

lengths, as in those of $P$. perditus and $P$. lillegraveni, but are within the observed ranges for species of Knightomys (Table 3). However, the referred teeth are very similar in size and occlusal morphology to those of $P$. perditus and $P$. lillegraveni, differing primarily in having lower lophs (Korth, 1984). Korth (1984) suggested that rela- tively larger p4 of the older Lost Cabin species would be predicted if there was a progressive reduction of the premolar in the genus through time. However, it could also be argued that the increased loph height and extreme reduction of the p4 seen in later species of Pauromys rises to the 
level of generic separation from the earlier Lost Cabin species.

The above discussion indicates that after more than 140 years of collecting fossils from the Bridger Formation, the phylogenetic relationships of many of the poorly characterized Bridgerian sciuravids is still controversial. Only with the discovery of much more complete specimens, including intact upper and lower dentitions, will their relationships be fully clarified. We follow the taxonomic scenario presented by Walton and Porter (2008) for the Sciuravidae, with the exception of 'P.' schaubi, which we regard as likely generically distinct from other species of Pauromys.

The larger sciuravid teeth (molars with ap observed range of $1.74-2.05 \mathrm{~mm}$ ) from the TBM can be assigned with reasonable confidence to previously recognized taxa from the Bridger Formation. However, several potential hurdles arose regarding the generic and specific identification of the small to medium-small sized sciuravid teeth (molars with ap $<1.47 \mathrm{~mm}$ ). First, the sample size of sciuravid teeth from each locality is small. Second, many of the previously recognized sciuravid species are poorly documented so the amount of individual variation in their occlusal morphology and size has not been adequately determined. Lastly, many of the previously recognized sciuravid taxa are known only from either upper or lower partial dentitions. As with any analysis of isolated rodent teeth, the assignment of teeth representing different positions to a single species is difficult, but accomplished best when a very large sample of upper and lower teeth that agree in size and occlusal morphology are available from a single locality. However, this is not the case for the small to medium-small sized sciuravid teeth from the TBM. The best sample came from UCM Locality 92189 , which yielded 20 medium-small sized sciuravid teeth (molars with ap observed range of 1.20-1.46 $\mathrm{mm}$ ) that agree in occlusal morphology and can be reasonably regarded as conspecific. UCM Locality 92189 also yielded one smaller $(a p=1.13 \mathrm{~mm}) \mathrm{sci}-$ uravid upper molar that appears to represent a second species at the locality. Only four other localities (SDSNH Localities 5841, 5842, 5787, and UCM Locality 92189) yielded small to mediumsmall sized sciuravid teeth, ranging from one to five isolated teeth from each locality. As noted above, the systematic relationships of most of the Bridgerian sciuravids are unclear, so the systematic accounts of the small to medium-small sized sciuravid teeth from the TBM presented below is very conservative, wherein the majority of these teeth are only placed into informal taxonomic groups left in open nomenclature. Hopefully, confident generic and specific assignments for these teeth can be accomplished in the future with the discovery of intact associated upper and lower dentitions from the TBM.

\section{Genus SCIURAVUS Marsh, 1871 \\ Sciuravus nitidus Marsh, 1871 \\ Figure 7.1, Table 4}

Referred specimen. From UCM Locality 92189: partial P4, UCM 68430.

Description. The partial P4 is moderately well worn with the enamel abraded away along the lingual aspect of the metacone. It has a transversely elongate oval occlusal outline. The anterior cingulum is strong, slightly lower in height than the metaloph, and extends labially from the protocone to join the anterolabial corner of the paracone. The protocone is moderately large and connected to the paracone by a complete protoloph. The metacone is nearly as large as the paracone. A hypocone is lacking. The metaloph extends lingually from the metacone to join an indistinct metaconule (slight swelling) and terminates just short of the posterior cingulum. The posterior cingulum is robust and extends from the protocone to the posterolabial corner of the metacone.

Remarks. Based on its occlusal outline and lack of a distinct hypocone, UCM 68430 can be confidently identified as a P4. In size and occlusal morphology, UCM 68430 is indistinguishable from the P4s of S. nitidus (Troxell, 1923b; Wilson, 1938b, Dawson, 1961) and is referred to the species.

$$
\begin{gathered}
\text { Genus TILLOMYS Marsh, } 1872 \\
\text { Tillomys senex Marsh, } 1872 \\
\text { Figure 7.5-7, Table } 4
\end{gathered}
$$

Referred specimens. From SDSNH Locality 5841: $\mathrm{m} 1$ or 2 , SDSNH 110363. From UCM Locality 92189: $\mathrm{m} 1$ or 2 , UCM 95753, 78451. From DMNH Locality 4672: $\mathrm{m} 1$ or 2, DMNH 75279 , 75328.

Description. The five $\mathrm{m} 1$ or $2 \mathrm{~s}$ from the TBM are very similar in size and occlusal morphology. They have a relatively short anterior cingulid that extends lingually from the anterior edge of the protoconid to the anterolabial base of the metaconid. The primary cusps are robust with the hypoconid being the largest, the protoconid the second largest, and the metaconid and entoconid being about subequal in size. The metalophulid II (posterior arm of the protoconid) is incomplete, extending lingually from the apex of the protoconid to terminate near and slightly posterior to the posterolabial base 


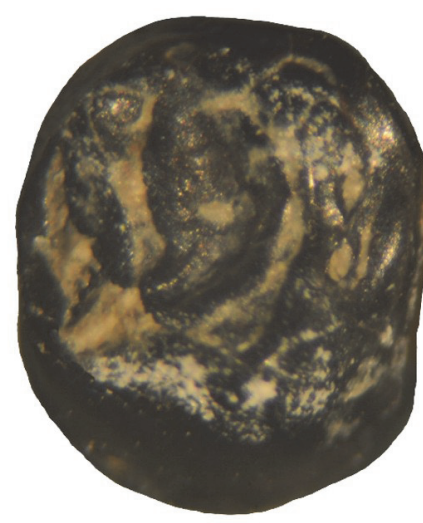

1

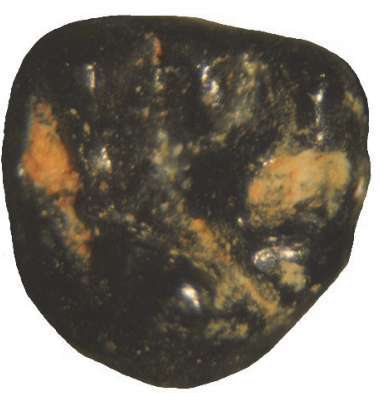

4

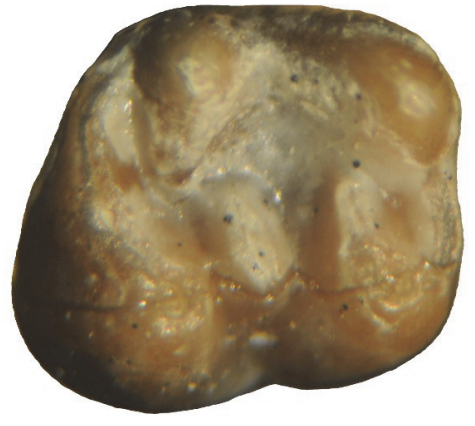

7

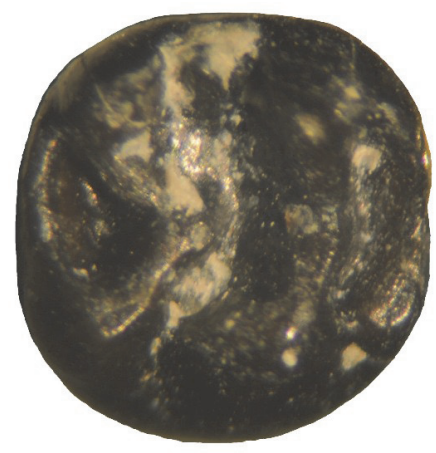

2

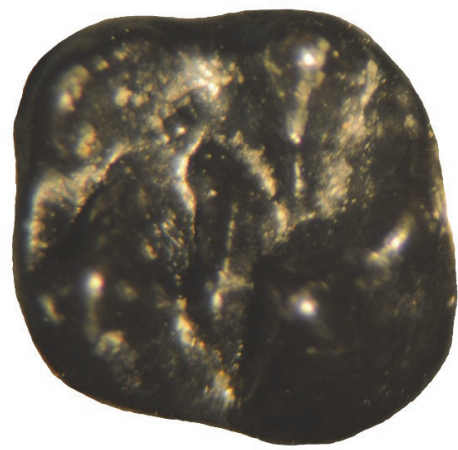

5

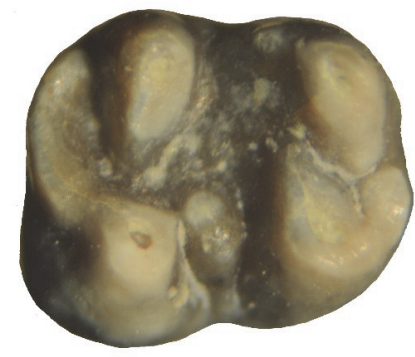

8

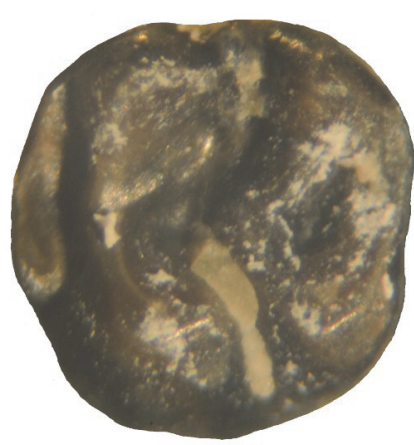

3

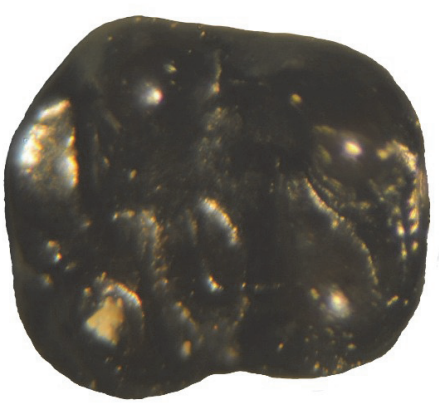

6

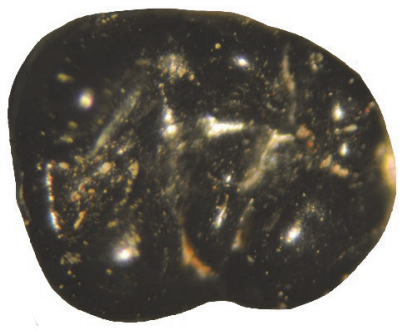

9

FIGURE 7. Larger Sciuravidae from TBM. 1, Sciuravus nitidus, RP4, UCM 68430. 2-4, Taxymys lucaris: 2, RM1 or 2, UCM 68307; 3, LM1 or 2, UCM 95762; 4, LM3, DMNH 75336. 5-7, Tillomys senex: 5, Lm1 or 2, DMNH 75328; 6, Rm1 or 2, DMNH 75279; 7, Rm1 or 2, SDSNH 110363. 8-9, Tillomys? parvidens: 8, Rm1 or 2, SDSNH 110379; 9, Lm3, DMNH 75288. All occlusal views. Scale bar equals $1 \mathrm{~mm}$. 
TABLE 4. Measurements (in mm) of specimens of Sciuravus, Taxymys, Tillomys, Pauromys sp., cf. $P$. perditus, sciuravid sp. B, sciuravid sp. C and Sciuravidae, genus and species undetermined from TBM $(a=$ approximate; $p$. = partial).

\begin{tabular}{|c|c|c|c|c|}
\hline Taxon/Specimen Number & Position & ap & tra & $\operatorname{trp}$ \\
\hline \multicolumn{5}{|l|}{ Sciuravus nitidus } \\
\hline UCM 68430 & p. P4 & 1.97 & 2.42 & $2.28 a$ \\
\hline \multicolumn{5}{|l|}{ Taxymys lucaris } \\
\hline UCM 68307 & M1 or 2 & 1.97 & 1.97 & 2.13 \\
\hline UCM 95759 & M1 or 2 & 1.87 & 1.87 & 1.70 \\
\hline UCM 95762 & M1 or 2 & 1.90 & 2.05 & 1.87 \\
\hline UCM 68924 & M1 or 2 & 1.82 & 1.82 & 1.92 \\
\hline UCM 68921 & p. M3 & 1.72 & 1.77 & - \\
\hline DMNH 75336 & M3 & 1.77 & 1.80 & 1.41 \\
\hline \multicolumn{5}{|l|}{ Tillomys senex } \\
\hline SDSNH 110363 & $\mathrm{~m} 1$ or 2 & 1.96 & 1.82 & 1.92 \\
\hline DMNH 75279 & $\mathrm{~m} 1$ or 2 & 1.96 & 1.67 & 1.88 \\
\hline DMNH 75328 & $\mathrm{~m} 1$ or 2 & 2.05 & 1.80 & 1.97 \\
\hline UCM 78451 & $\mathrm{~m} 1$ or 2 & 1.92 & 1.57 & 1.72 \\
\hline UCM 95753 & $\mathrm{~m} 1$ or 2 & 1.95 & 1.54 & 1.69 \\
\hline \multicolumn{5}{|l|}{ Tillomys? parvidens } \\
\hline SDSNH 110379 & $\mathrm{~m} 1$ or 2 & 1.87 & 1.50 & 1.64 \\
\hline DMNH 75329 & $\mathrm{~m} 1$ or 2 & 1.82 & 1.30 & 1.51 \\
\hline UCM 68533 & p. $\mathrm{m} 1$ or 2 & 1.74 & - & - \\
\hline DMNH 75288 & $\mathrm{~m} 3$ & 1.81 & 1.51 & 1.46 \\
\hline \multicolumn{5}{|l|}{ Pauromys sp., cf. P. perditus } \\
\hline SDSNH 110414 & $\mathrm{~m} 1$ & 1.00 & 0.72 & 0.82 \\
\hline \multicolumn{5}{|l|}{ Sciuravid sp. B } \\
\hline SDSNH 110412 & M1 or 2 & 1.06 & 1.05 & 1.08 \\
\hline \multicolumn{5}{|l|}{ Sciuravid sp. C } \\
\hline UCM 68672 & M1 or 2 & 1.13 & 1.23 & 1.18 \\
\hline SDSNH 110447 & M1 or 2 & 1.12 & 1.23 & 1.13 \\
\hline SDSNH 110443 & M1 or 2 & 1.13 & 1.26 & 1.10 \\
\hline SDSNH 110439 & m3 & 1.16 & 0.95 & 0.87 \\
\hline SDSNH 110441 & $\mathrm{~m} 3$ & 1.16 & 1.02 & 0.93 \\
\hline \multicolumn{5}{|l|}{$\begin{array}{l}\text { Sciuravidae, gen. and sp. } \\
\text { undet. }\end{array}$} \\
\hline SDSNH 110462 & P4 & 0.77 & 1.00 & 0.95 \\
\hline SDSNH 140176 & p. p4 & 0.67 & - & 0.55 \\
\hline SDSNH 110454 & p. p4 & - & - & 0.80 \\
\hline
\end{tabular}


of the metaconid. The entoconid is anteroposteriorly compressed with an incomplete hypolophid that extends posterolabially (obliquely) from the entoconid apex to terminate near the junction of the hypoconid and posterior cingulid. The mesoconid is transversely elongate and isolated from the protoconid and hypoconid. The posterior cingulid is robust, extending lingually from the hypoconid to terminate near the posterior base of the entoconid, where it is separated from the entoconid by a weak valley.

Remarks. Two species of Tillomys are recognized from the Bridger Formation, T. senex and T.? parvidens (Troxell, 1923b; Wilson, 1938a, b; Walton and Porter, 2008). Both species are known only from lower dentitions. The five TBM lower molars are compatible in size and occlusal morphology to those of $T$. senex, including robust tall trigonids, moderately strong metastylid crests, and obliquely orientated hypolophids.

\section{T.? parvidens (Marsh, 1872)}

Figure 7.8-9, Table 4

Referred specimens. From SDSNH Locality 5841: $\mathrm{m} 1$ or 2, SDSNH 110379. From DMNH Locality 4672: $\mathrm{m} 1$ or 2, DMNH 75329; m3, DMNH 75288. From UCM Locality 92189: partial $\mathrm{m} 1$ or 2 , UCM 68533.

Description. The three $\mathrm{m} 1$ or $2 \mathrm{~s}$ are very similar in occlusal morphology to those referred above to Tillomys senex including the following: 1) a robust, tall trigonid; 2) an incomplete metalophulid II; 3) an isolated mesoconid; 4) an incomplete hypolophid that is orientated obliquely posteriorly; and 5) a robust posterior cingulid. They differ from those referred to $T$. senex in being slightly smaller and by having a double-cusped mesoconid that is slightly less elongate transversely and a slightly shorter hypolophid.

The $\mathrm{m} 3$ is unworn and has a rectangular, elongate occlusal outline. The primary cusps (protoconid, metaconid, hypoconid, and entoconid) are robust. The anterior cingulid is a thick, short cristid extending from the anterior edge of the protoconid to the labial base of the metaconid. A moderate metastylid crest extends posteriorly from the metaconid. The metalophulid II (posterior arm of the protoconid) is incomplete, extending lingually from the protoconid to terminate near the posterolabial base of the metaconid. The mesoconid is isolated from the protoconid and hypoconid and is doubled (two swellings or incipient cusps). The entoconid is prominent with a very short hypolophid extending posteriorly and at an oblique angle from it. The posterior cingulid is robust extending lingually in an arc from the hypoconid and terminating at the posterolingual corner of the tooth, where it is separated from the entoconid by a shallow, but distinct, valley.

Remarks. Tillomys? parvidens was originally assigned to Sciuravus by Marsh (1872), but Troxell (1923b) and Wilson (1938b) noted that the $\mathrm{m} 2$ of the holotype is more similar in occlusal morphology to those of $T$. senex than to those of Sciuravus and questionably referred it to Tillomys (see also Walton and Porter, 2008). The lower molars of Tillomys? parvidens are very similar to those of $T$. senex, but differ primarily by the following: 1) slightly smaller; 2) a tendency for a doubled mesoconid (two-cusped) that is less transversely elongate; and 3) a shorter hypolophid. Whether these differences rise to the level of specific separation is debatable, but the four lower molars from the TBM exhibit the putative diagnostic characters of $T$.? parvidens and are tentatively assigned to the species.

\section{Genus TAXYMYS Marsh, 1872 \\ Taxymys lucaris Marsh, 1872 \\ Figure 7.2-4, Table 4}

Referred specimens. From DMNH Locality 4672 : M3, SDSNH 75336. From UCM Locality 92189: M1 or 2, UCM 68307, 68924, 95759, 95762; partial M3, UCM 68921.

Description. The M1 or 2s have a robust, but relatively short anterior cingulum that extends lingually from the paracone to the level of the origination of the protoloph from the protocone, where it is separated from the protoloph by a shallow valley. The protoloph is a complete, relatively tall crest extending from a robust, conical protocone to an anteroposteriorly compressed paracone. On one molar there is a slight swelling along the protoloph that appears to be an incipient protoconule, whereas the other three molars lack a protoconule. The protocone is separated from the hypocone by a distinct, relatively deep valley that extends labially into the central portion of the tooth. A small mesostyle is present between the paracone and metacone. The metaloph is a complete crest extending anterolabially from the hypocone to about the center of the tooth and then turns posterolabially to connect with the metacone. The posterior cingulum is robust, slightly lower in height than the metaloph, and extends labially from the hypocone to terminate at the posterior base of the metacone.

The M3 is in very early wear, with a rounded, triangular occlusal outline. The anterior cingulum is robust, but relatively short, extending labially from near the origin of the protoloph from the protocone 
to terminate at the anterior base of the paracone. The protocone is large and separated from the hypocone by a distinct valley that extends labially into the central portion of the tooth. The protoloph is complete, relatively tall, and extends in an arc from the protocone to the paracone. The metaloph is complete, extending anterolabially from the hypocone and then bifurcates, with a low crest extending to the mesostyle and a taller crest that turns posterolabially to connect with the metacone. The posterior cingulum is short, extending from the hypocone to the posterolingual base of the metacone.

Remarks. Taxymys lucaris is known only from upper dentitions, and Troxell (1923b) proposed that specimens assigned to the genus may actually represent the upper dentition of Tillomys, which is known only from lower dentitions. Although this scenario may be reasonable because their respective dentitions are compatible in size and occlusal morphology, we follow most previous investigators (e.g., Wilson, 1938b; Walton and Porter, 2008) and retain these two genera as distinct pending the discovery of associated upper and lower dentitions that would unambiguously clarify their taxonomic relationship. In size and occlusal morphology, the six TBM upper molars are indistinguishable from those of Taxymys lucaris and are assigned to the species.

Genus PAUROMYS Troxell, 1923a

Pauromys sp., cf. P. perditus Troxell, 1923a

Figure 8.1, Table 4

Referred specimen. From SDSNH Locality 5842: m1, SDSNH 110414.

Description. The trigonid of SDSNH 110414 is considerably narrower than the talonid, a character that is often observed in the p4 and $\mathrm{m} 1$ of rodents. It has a distinct, small anterior appression facet, which confirms its identity as an $\mathrm{m} 1$ and not a p4. SDSNH 110414 exhibits the following additional characters: 1) an elongate occlusal outline; 2) an anterior cingulid that extends from the anterior base of the protoconid to the anterior base of the metaconid; 3) a low, but complete, metalophulid that extends lingually from the posterolingual corner of the protoconid to the posterolabial corner of the metaconid; 4) a relatively large hypoconid and entoconid; 5) a short hypolophid that extends labially and slightly posteriorly from the entoconid to terminate near the origin of the posterior cingulid from the hypoconid; 6) a distinct, isolated, ovalshaped mesoconid; 7) a distinct posterior cingulid that extends lingually from the hypoconid to termi- nate near the posterolabial base of the entoconid; and 8) very small size.

Remarks. Pauromys perditus is known only from the holotype, a partial dentary with p3-m3. SDSNH 110414 is the only lower molar from the TBM that is equal in size and agrees well in occlusal morphology to the $\mathrm{m} 1$ in the holotype of $P$. perditus (Troxell, 1923a; Dawson, 1968). An unambiguous assignment of a single, isolated tooth to $P$. perditus would not be prudent without additional representative teeth, especially $p 4$, to confirm its identity. Therefore, we only compare SDSNH 110414 to the species, as $P$. sp., cf. $P$. perditus.

Sciuravid sp. A

Figure 9.1-9, Table 5

Referred specimens. From UCM Locality 92189 : M1 or 2, UCM 68425, 68903, 70910, 71413, 95763, 95696; m1, UCM 95694, 95812, 71414; m2, UCM 68969, 71415, 77428, 95754, 95755, 95757, 95698, 95699; m3, UCM 71516, 95752, 95756. Tentatively referred specimens from SDSNH Locality 5844: m1, SDSNH 110398; m2, SDSNH 10458, 110459, 110460; m3, SDSNH 110440.

Description. Six upper molars from UCM Locality 92189, either M1 or M2s, are compatible in size and occlusal morphology. They have a strong anterior cingulum that extends lingually from the anterior base of the paracone to about three-quarters of width of the tooth where it is separated from the protocone by a shallow valley. The protocone and paracone are robust and slightly compressed transversely, with the paracone just slightly smaller than the protocone. The hypocone and metacone are distinct, about equal in size and smaller than the protocone and paracone. The protocone and hypocone are separated by a moderately deep valley that continues into the central basin. The protoloph is a complete, relatively tall crest extending from the protocone to the paracone. The protoconule is represented as a slight swelling on the protoloph. The metaloph extends anterolabially from the hypocone and then bifurcates with one crest turning posteriorly to join the metacone and one crest continuing into the central basin of the tooth, terminating short of the protoloph as an incomplete endoloph. A small metastylid is present in three teeth. A small cuspule (anterocone) is present on the lingual terminus of the anterior cingulum in five teeth. The posterior cingulum is robust, extending from the hypocone to the posterior base of the metacone.

UCM Locality 92189 yielded 14 lower molars that are compatible in size and occlusal morphol- 


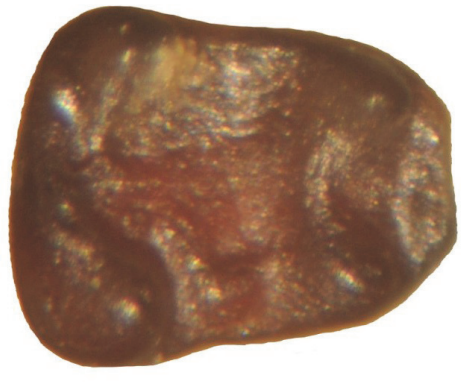

1

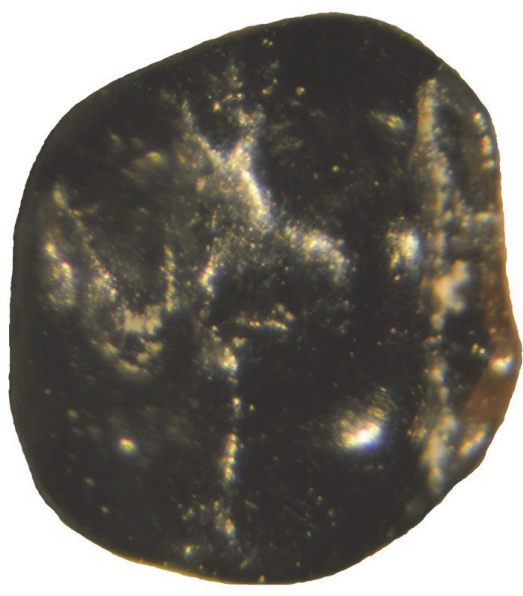

3

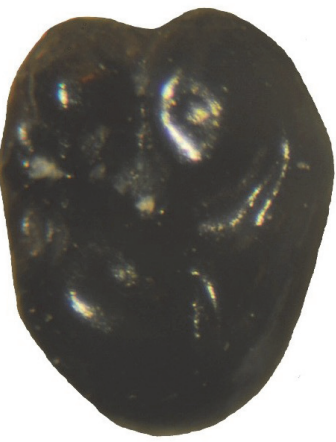

5

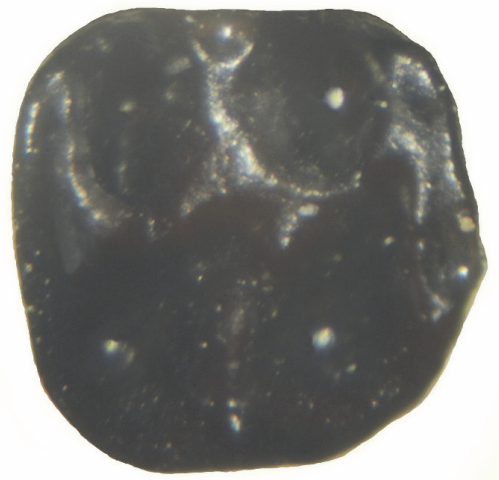

2

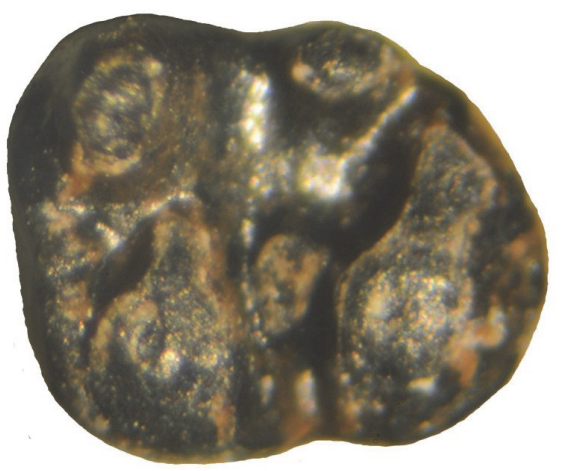

4
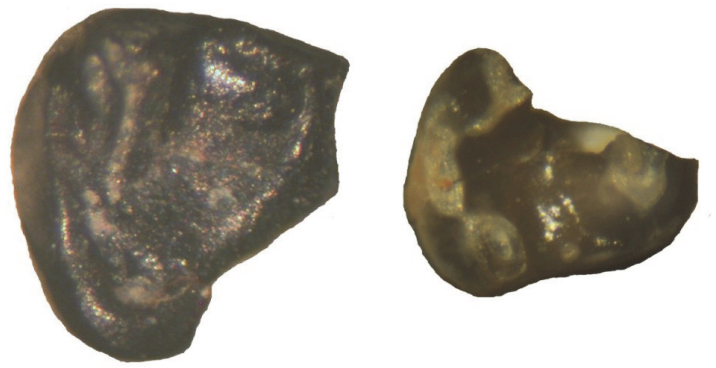

7

FIGURE 8. Smaller Sciuravidae from TBM. 1, Pauromys sp., cf. P. perditus, Lm1, SDSNH 110414. 2, sciuravid sp. B, RM1 or 2, SDSNH 110412. 3-4, Sciuravid sp. C: 3, RM1 or 2, SDSNH 110443; 4, Lm3, SDSNH 110441. 5-7, Sciuravid premolars: 5, LP4, SDSNH 110462; 6, partial Rp4, SDSNH 110454; 7, partial Rp4, SDSNH 140176. All occlusal views. Scale bar equals $1 \mathrm{~mm}$. 


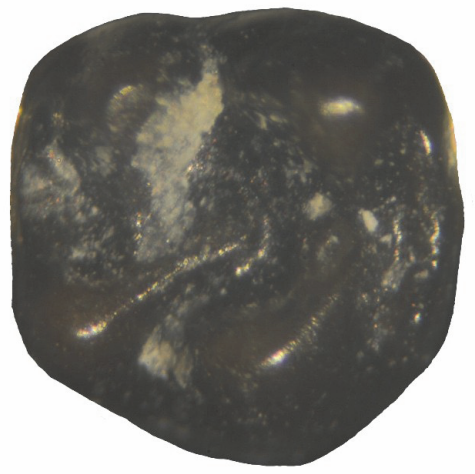

1

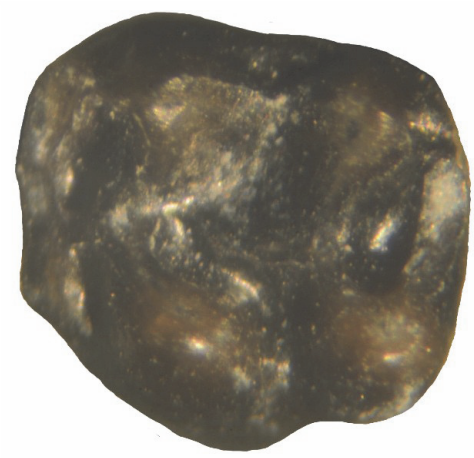

4

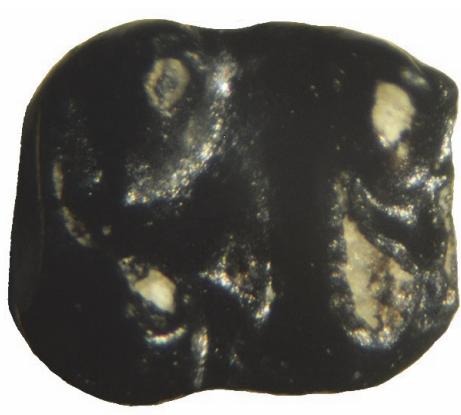

7

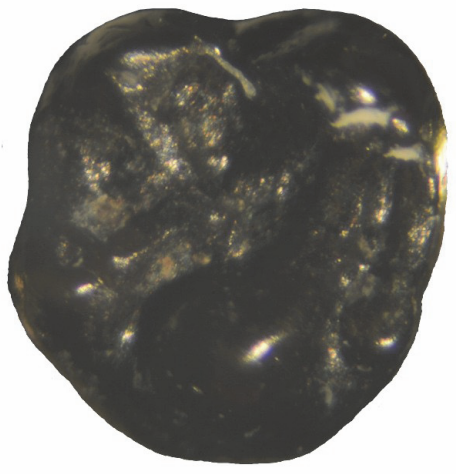

2

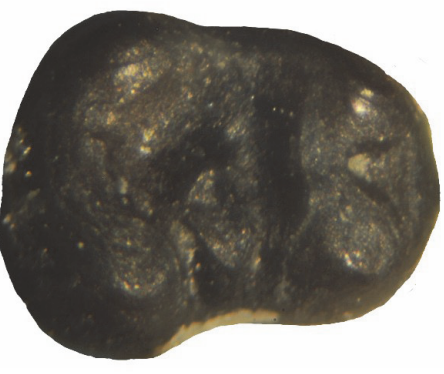

5

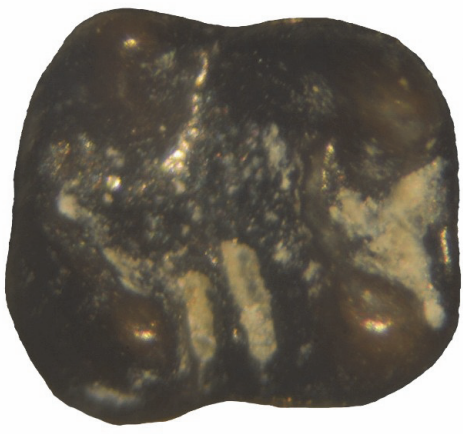

8

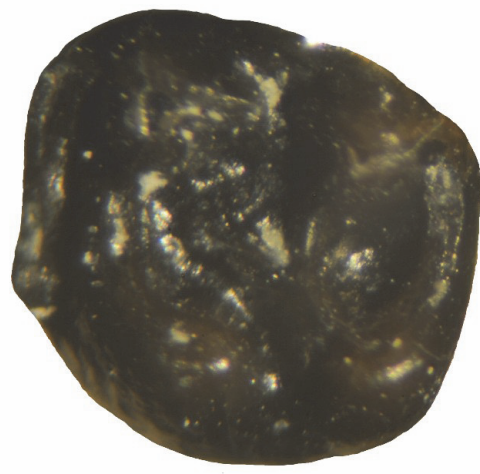

3

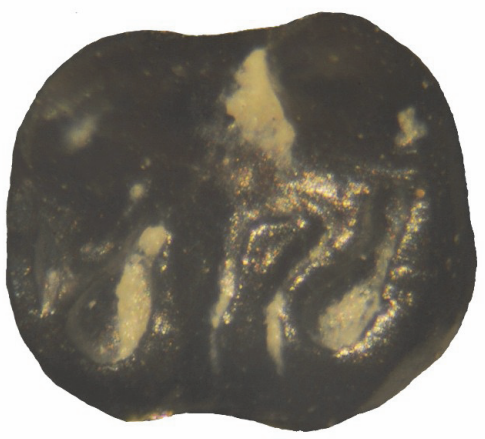

6

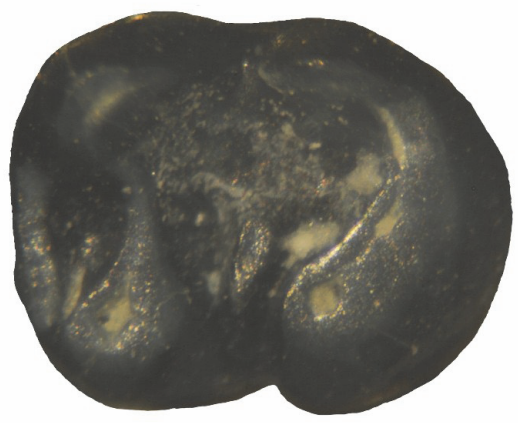

9

FIGURE 9. Sciuravid sp. A from TBM: 1, RM1 or 2, UCM 709102; 2, RM1 or 2, UCM 68903; 3, LM1 or 2, UCM 71413; 4, LM1 or 2, UCM 95763; 5, Rm1, UCM 95694; 6, Lm1 or 2, UCM 95757; 7, Rm1 or 2, SDSNH 110459; 8 , Rm1 or 2, UCM 95699; 9, Lm3, UCM 95756. All occlusal views. Scale bar equals $1 \mathrm{~mm}$. 
TABLE 5. Measurements (in mm) of sciuravid sp. A from TBM (p. = partial).

\begin{tabular}{lcccc}
\hline Specimen Number & Position & ap & tra & trp \\
\hline UCM 68425 & M1 or 2 & 1.25 & - & 1.13 \\
UCM 70910 & M1 or 2 & 1.28 & 1.35 & 1.23 \\
UCM 71413 & M1 or 2 & 1.33 & 1.26 & 1.13 \\
UCM 95763 & M1 or 2 & 1.29 & 1.23 & 1.10 \\
UCM 95692 & M1 or 2 & 1.28 & 1.33 & 1.25 \\
UCM 95696 & M1 or 2 & 1.28 & 1.34 & 1.28 \\
UCM 95694 & $\mathrm{m} 1$ & 1.23 & 0.90 & 1.00 \\
UCM 95812 & $\mathrm{p} . \mathrm{m} 1$ & 1.21 & - & 1.00 \\
SDSNH 110398 & $\mathrm{p} . \mathrm{m} 1$ & 1.18 & - & - \\
UCM 71414 & $\mathrm{m} 1$ & 1.26 & 1.00 & 1.05 \\
UCM 68969 & $\mathrm{m} 2$ & 1.36 & 1.06 & 1.13 \\
UCM 71415 & $\mathrm{m} 2$ & 1.28 & 1.03 & 1.10 \\
UCM 77428 & $\mathrm{m} 2$ & 1.28 & 1.03 & 1.21 \\
UCM 95754 & $\mathrm{m} 2$ & 1.34 & 1.05 & 1.19 \\
UCM 95755 & $\mathrm{m} 3$ & 1.28 & 1.00 & 0.95 \\
UCM 95757 & $\mathrm{m} 2$ & 1.36 & 1.18 & 1.26 \\
UCM 95698 & $\mathrm{m} 2$ & 1.30 & 1.10 & 1.13 \\
UCM 95699 & $\mathrm{m} 2$ & 1.31 & 1.18 & 1.26 \\
SDSNH 110458 & $\mathrm{m} 2$ & 1.26 & 1.08 & 1.17 \\
SDSNH 110459 & $\mathrm{m} 2$ & 1.22 & 1.08 & 1.08 \\
SDSNH 110460 & 1.21 & 1.07 & 1.10 \\
UCM 71516 & 1.23 & 1.04 & 1.10 \\
UCM 95752 & $\mathrm{m} 3$ & 1.39 & 1.08 & 1.06 \\
UCM 95756 & m & 1.43 & 1.01 & 1.04 \\
SDSNH 110440 & $\mathrm{m}$ & 1.46 & 1.14 & 1.11 \\
\hline
\end{tabular}

ogy. Although similar in occlusal morphology, first lower molars were tentatively differentiated from second lower molars because they exhibit distinctly narrower trigonids relative to their talonids, which is typical of the m1s of most Sciuravidae. They have a distinct anterior cingulid that extends lingually from the anterior base of the metaconid to near the anterior base of the protoconid, where it is separated from the protoconid by a shallow valley. The primary cusps (protoconid, hypoconid, metaconid, and entoconid) are robust. The metalophulid II (posterior arm of the protoconid) is incomplete, wherein it extends posterolingually from the protocone to terminate near the posterolabial base of the metaconid. A distinct hypolophid is lacking (i.e., the entoconid has only a very slight labial extension towards the hypoconid). The mesoconid is moderately elongate transversely and isolated from the protoconid and hypoconid, and in five teeth there are two small, cuspulids present on the mesoconid. A small mesostylid is present on six teeth. The posterior cingulid is robust, extending posterolingually from the hypoconid to terminate near the posterior base of the entoconid, where it is separated from the entoconid by a shallow valley. The third lower molars are very similar in occlusal morphology to the $\mathrm{m} 1-2$, but can be easily distinguished by having a more elongate occlusal outline, a more complete posterior cingulid (posteroloph) that extends in a larger arc from the hypoconid to the entoconid, and they lack posterior appression facets.

SDSNH Locality 5844 yielded five lower molars that are indistinguishable in occlusal mor- 
phology from the above sample from UCM Locality 92189, but differ by being, on average, slightly smaller in size.

Remarks. The molars from UCM Locality 92189 represent the largest sample of sciuravid teeth from a single locality in the TBM that are compatible in size and occlusal morphology. The lower molars exhibit dental characters typical of those of Sciuravidae, including an incomplete metalophulid Il that terminates near the posterolabial base of the metaconid, and an isolated mesoconid. In addition, the lower molars basically lack a hypolophid, a character seen in certain sciuravid taxa, such as Pauromys perditus, P. lillegraveni, Pauromys sp. from Power Wash, and 'Pauromys' schaubi. UCM Locality 92189 yielded only one other sciuravid tooth, an upper molar (UCM 68672) that differs from the other sciuravid upper molars by being significantly smaller in size (see remarks below of sciuravid $\mathrm{sp}$. C). Thus, it is reasonable to assume that the upper and lower molars from UCM Locality 92189 that agree in size and occlusal morphology are conspecific. Five sciuravid lower molars from higher in the section at SDSNH Locality 5844 cannot be distinguished morphologically from the sample of molars from UCM Locality 92189, but are on average slightly smaller in size (4-8\% smaller). This size difference is not regarded as being significant enough to separate these molars specifically from the sample from UCM Locality 92189 and they are tentatively regarded as conspecific with that sample. Unfortunately, no sciuravid premolars have been recovered from UCM Locality 92189, which would help clarify the generic status of this sciuravid. However, two relatively small sciuravid premolars, a P4 and partial p4, were recovered from SDSNH Locality 5844 (see remarks below on Sciuravidae, genus and species undetermined). Whether these premolars are conspecific with the medium-small sciuravid teeth from UCM Locality 92189 and SDSNH Locality 5844 cannot be determined because a second smaller sciuravid species is also recorded from these two localities. Thus, without intact dentitions, the premolars could belong to either sciuravid species.

A few additional distinctions can be noted regarding sciuravid $\mathrm{sp}$. A. It is similar in size to Pauromys exallos, slightly larger than Pauromys lillegraveni, significantly smaller than species of Sciuravus, Tillomys, and Taxymys, and significantly larger than Pauromys perditus, Pauromys sp. from Powder Wash, and 'Pauromys' schaubi. It further differs from Sciuravus and Tillomys by lacking a distinct hypolophid and from 'P.' schaubi by having the m1-2 mesoconid isolated from the hypoconid. Thus, sciuravid sp. A probably represents a distinct species that was previously unknown from the Bridger Formation. However, we refrained from giving it a formal specific name because its generic assignment cannot be determined with confidence.

Sciuravid sp. B

Figure 8.2, Table 4

Referred specimens. From SDSNH Locality 5787: M1 or 2, SDSNH 110412.

Description. SDSNH 110412 is very small with a square occlusal outline. The anterior cingulum is distinct, extending lingually from the anterolabial base of the paracone to the anterior base of the protocone, where it is separated from the protocone by a shallow valley. The primary cusps (protocone, paracone, metacone, and hypocone) are moderately robust, rounded, and nearly equal in size. The protoloph is incomplete, extending anterolabially from the protocone to terminate anterior to the anterolingual base of the paracone. The protocone and hypocone are separated by a deep valley that continues labially into the central basin. The endoloph is incomplete, extending anterolabially from the hypoconid into the central basin. The metaloph is a low crest connecting the hypocone to the metacone. A small mesostyle is present between the paracone and metacone. The posterior cingulum is moderately robust, but low, extending labially from the hypocone to the posterior base of the metacone.

Remarks. One small, isolated upper molar was recovered from SDSNH Locality 5787 that exhibits an occlusal morphology that is compatible with those of Sciuravidae, including an incomplete protoloph and incomplete endoloph, characters which also differentiate it from the upper molars of the eomyid Metanoiamys. In size, the ap of SDSNH 110412 is slightly larger than that of the m1-2 of Pauromys perditus and slightly smaller than that of the m1-2 of 'Pauromys' schaubi. However, assignment to either of these two species cannot be made because they are known only from lower dentitions. SDSNH 110412 is significantly smaller than the upper molars referred above to sciuravid sp. A. Thus, all that can be said is that SDSNH 110412 appears to represent a small sciuravid species and is informally assigned to sciuravid sp. B.

sciuravid sp. C

Figure 8.3-4, Table 4

Referred specimens. From UCM Locality 92189: M1 or 2, UCM 68672. From SDSNH Locality 5844: 
M1 or 2, SDSNH 110443, 110447; m3, SDSNH 110439, 110441.

Description. The two upper molars from SDSNH Locality 5844 and one upper molar from UCM Locality 92189 are indistinguishable in size and occlusal morphology. They have a trigon that is wider than the talon. The anterior cingulum is robust, extending lingually from the anterolabial corner of the paracone for about three-quarters the width of the tooth, terminating just labial of the level of the protocone apex where it is separated from the protocone by a shallow valley. A small anterocone is present at the lingual terminus of the anterior cingulum. The primary cusps (protocone, paracone, hypocone, and metacone) are rounded and relatively robust. The protoloph is a complete low crest extending from the protocone to the paracone. The endoloph is a low crest that is nearly complete, extending anterolabially from the hypocone and terminating very close to the protoloph. The metaloph is a low, complete crest extending from the hypocone to the metacone. A small mesostyle is present on two of the molars. The posterior cingulum is moderately robust, extending from the hypocone to the posterior base of the metacone.

Two m3s from SDSNH Locality 5844 are compatible in size to the upper molars. They have a thick, low anterior cingulid that extends labially from the labial base of the metaconid to terminate near the anterolabial corner of the tooth, where it is separated from the protoconid by a shallow valley. The primary cusps (protoconid, metaconid, entoconid, and hypoconid) are rounded and relatively robust. The metalophulid II (posterior arm of the protoconid) is incomplete, extending lingually from the protoconid to terminate near the posterolabial base of the metaconid. The mesoconid is isolated from the protoconid and hypoconid. On one tooth, a short, low hypolophid extends labially, nearly joining the mesoconid, whereas a hypolophid is lacking on the other tooth. The posterior cingulid is thick, extending lingually in an arc from the hypoconid to terminate at the posterolingual corner of the tooth, where it is separated from the entoconid by a distinct valley.

Remarks. The upper molars and lower molars are compatible in size, suggesting that they may be conspecific and are referred to the informal taxon sciuravid $\mathrm{sp}$. C. The upper molars differ from the $\mathrm{M} 1$ or 2 assigned above to sciuravid $\mathrm{sp}$. B by being slightly smaller and by having a complete protoloph and nearly complete endoloph. The lower molars are typical of those of Sciuravidae by having an incomplete metalophulid II and an isolated mesoconid. In size and occlusal morphology, the molars of sciuravid sp. C are very similar to those of $P a u-$ romys sp. from Powder Wash (Dawson, 1968), including upper molars (M1 or 2) that have the trigons noticeably wider than the talons, complete protolophs and nearly complete endolophs. In size, the molars are also compatible with those of 'Pauromys' schaubi, but this species is known only from a single partial dentary with well worn $\mathrm{m} 1-2$, so comparison of its occlusal morphology to that of sciuravid sp. C cannot be made. In summary, sciuravid sp. $C$ appears to represent a third species of Sciuravidae from the TBM, but its relationships to the previously recognized smaller Bridgerian sciuravids cannot be determined.

Sciuravidae, genus and species undetermined Figure 8.5-7, Table 4

Referred specimens. From SDSNH Locality 5841: partial p4, SDSNH 140176. From SDSNH Locality 5844: P4, SDSNH 110462; partial p4, SDSNH 110454.

Description. Two small, partial lower premolars and one complete upper premolar were recovered from the TBM. The P4 (SDSNH 110462) from SDSNH Locality 5844 is small with a transversely oval occlusal outline. The primary cusps are rounded and relatively robust with the protocone being the largest cusp, the paracone and metacone about equal in size, and the hypocone being the smallest primary cusp, but still very distinct. A relatively deep valley separates the protocone from the hypocone. The anterior cingulum is short, extending lingually from the anterior base of the paracone to near the anterolabial base of the protocone. The protoloph is low, but complete, extending from the protocone to the paracone, with a short spur originating from about the middle of the protoloph that extends anteriorly almost connecting with the anterior cingulum. The metaloph is low and incomplete, extending anterolingually from the metacone towards the protocone, but terminates before reaching the labial base of the protocone. The posterior cingulum is prominent, extending from the hypocone to the posterior base of the metacone.

The well worn partial p4 (SDSNH 110454) from SDSNH Locality 5844 is small. It is missing the protoconid and the anterior half of the metaconid, but even in its broken state, certain characters can still be discerned. Although the enamel wall is broken away from the anterolabial edge of the tooth, the overall occlusal outline appears to have been relatively short anteroposteriorly, with the tri- 
gonid much narrower than the talonid. Based on the posterior half of the metaconid, it is relatively large. The hypoconid is large. The entoconid is distinct, anteroposteriorly compressed and smaller than the hypoconid. The hypolophid extends posterolabially from the entoconid to terminate near the origin of the posterior cingulid from the hypoconid. The posterior cingulid is distinct, relatively thick, and extends lingually from the hypoconid to terminate at the posterior base of the entoconid.

The partial p4 from SDSNH Locality 5841 is in very early wear and is missing the anterolingual corner of the tooth, including the metaconid. Even in its broken state, certain characters can still be discerned. It is very small, with the anteroposterior length relatively short and, based on the labial inclination along the labial border, the trigonid was significantly narrower than the talonid. The protoconid is robust. The hypoconid is rounded and slightly smaller than the protoconid. The entoconid is distinct, anteroposteriorly compressed, and slightly smaller than the hypoconid. A very small, isolated mesoconid is present between the protoconid and hypoconid. A short cristid is present that extends posterolabially from the entoconid to terminate close to the posterior cingulid. The posterior cingulid is robust, extending lingually from the hypoconid to terminate near the posterior base of the entoconid.

Remarks. The P4 was listed in the SDSNH catalog as Pauromys sp. In size and occlusal morphology, the P4 from SDSNH Locality 5844 is indistinguishable from those of Pauromys sp. from Powder Wash (Dawson, 1968). SDSNH Locality 5844 yielded two sciuravid species (sp. A and sp. C). If the P4 is conspecific with sciuravid sp. A, then this species would have a greatly reduced $P 4$ indicating that it probably belongs in Pauromys. However, if the P4 is conspecific with the smaller sciuravid $\mathrm{sp}$. C, then this species would not have a greatly reduced P4 and would probably not represent Pauromys. Thus, to which of these two species the P4 belongs cannot be determined and it adds little to the generic assignment of either sciuravid sp. A. or sp. B. A similar situation exists for the partial p4 from SDSNH Locality 5844.

The partial p4 from SDSNH Locality 5841 is extremely small, with its length within the observed ranges of those of Pauromys lillegraveni and Pauromys sp. from Powder Wash (Dawson, 1968; Walsh, 1997), but longer than that of Pauromys perditus (Dawson, 1968). Unfortunately, there are no small to medium-small sciuravid teeth known from SDSNH Locality 5844.
In summary, three small premolars have been recovered from the TBM that are similar morphologically to those of Pauromys. However, their generic status cannot be determined due to the lack of adequate samples and intact dentitions and the fact that several different small to mediumsmall sized sciuravids occur in the TBM. Therefore, these premolars are assigned to Sciuravidae without generic or specific allocation.

\section{Family CYLINDRODONTIDAE Miller and Gidley, 1918 \\ Genus PAREUMYS Peterson, 1919 cf. Pareumys sp.}

Figure 10.1-12, Table 6

Referred specimens. From UCM Locality 92189: P4, UCM 95760; M1, UCM 95758, 92942; M3, UCM 67987, 70905; m1, UCM 69974. From SDSNH Locality 5841: m2, SDSNH 110365, 110366; m3, SDSNH 110367; partial m3, SDSNH 110368. From DMNH Locality 4672: P4, DMNH 75335, 75337; M1 or 2, DMNH 75334. From SDSNH Locality 5843: M1 or 2, SDSNH 110396, 110397. From SDSNH Locality 5844: partial P4, SDSNH 110435; m3, SDSNH 110434.

Description. Four teeth are identified as $\mathrm{P} 4 \mathrm{~s}$ because they are lacking a hypocone. Their occlusal outline is oval. The protocone is robust and the largest primary cusp. The paracone is slightly larger than the metacone, and both cusps are slightly anteroposteriorly compressed. The protoloph is a complete, relatively tall loph, extending labially from the protocone to connect with the paracone. On one P4, a small swelling occurs on the protoloph (incipient protoconule), near its connection with the paracone. The metaloph is a relatively tall loph that extends lingually from the metacone to terminate in the central valley, near the protocone. The anterior cingulum is moderately strong, extending labially from the anterior base of the protocone to terminate at the anterior base of the paracone. The posterior cingulum is robust and extends in an arc from the protocone to terminate at the posterior base of the metacone.

Confident separation of the first two upper molars in samples of isolated cylindrodontid teeth cannot be made. The protocone is the largest primary cusp. The hypocone is distinct, and separated from the protocone by an indentation along the lingual wall of the tooth. The paracone is robust and compressed anteroposteriorly. The metacone is smaller than the paracone and somewhat compressed anteroposteriorly. The crown is unilaterally hypsodont with the protocone and hypocone significantly taller than the paracone and metacone. 


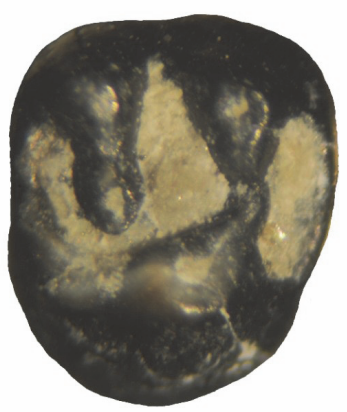

1

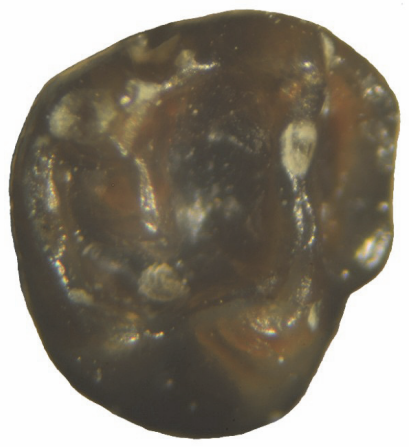

4

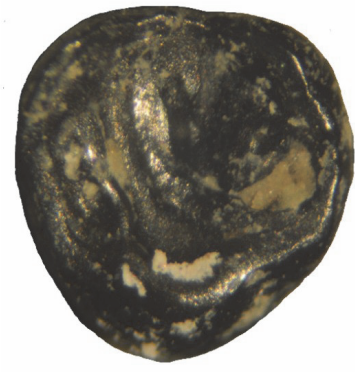

7

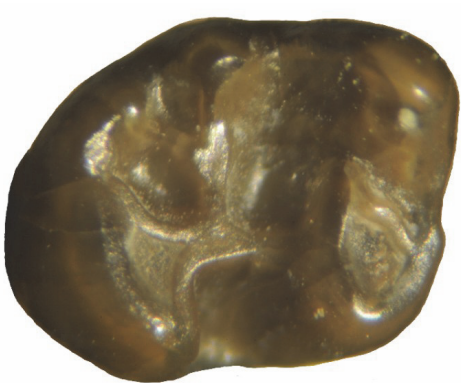

10

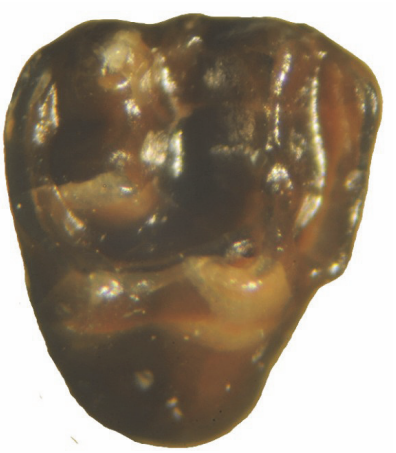

2

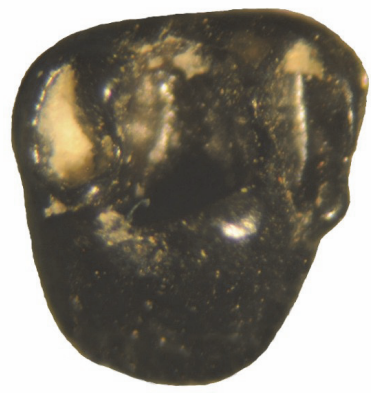

5

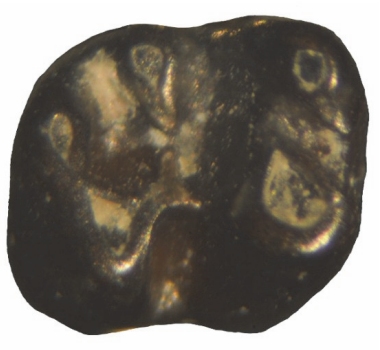

8

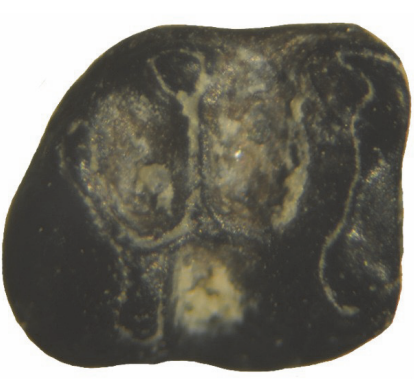

11

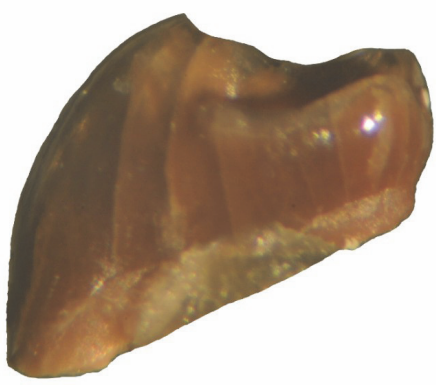

3

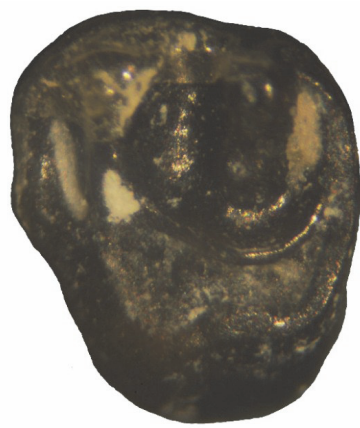

6

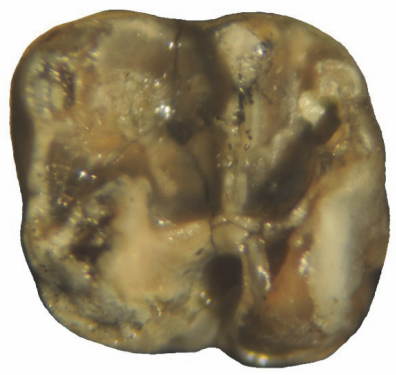

9

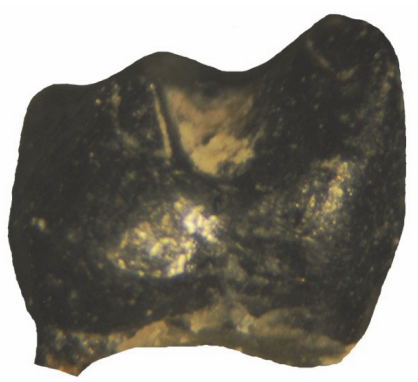

12

FIGURE 10. cf. Pareumys sp. from TBM: 1, RP4, UCM 95760; 2-3, RM1 or 2, SDSNH 110396; 4, RM1 or 2, SDSNH 110397; 5, RM1 or 2, DMNH 75334; 6, LM1 or 2, UCM 95758; 7, LM3, UCM 67987; 8, Rm1, UCM 69974; 9, Lm2, SDSNH 110366; 10, Rm3, SDSNH 110367; 11-12, Rm3, SDSNH 110434. 1-2, 4-11 occlusal views. 3, anterior view. 12, labial view. Scale bar equals $1 \mathrm{~mm}$. 
TABLE 6. Dental measurements (in $\mathrm{mm}$ ) and dental ratios of unworn to early wear teeth of cf. Pareumys sp. from the TBM $\left(\mathrm{a}=\right.$ approximate, $\mathrm{pch}=$ protocone or protoconid height of unworn teeth ${ }^{1}$ or teeth in early wear stage ${ }^{2} ; \mathrm{p} .=p$ partial).

\begin{tabular}{|c|c|c|c|c|c|c|c|}
\hline Specimen Number & Position & ap & tra & $\operatorname{trp}$ & pch & pch/ap & pch/tra \\
\hline UCM 95760 & $\mathrm{P} 4$ & 1.48 & 1.69 & 1.64 & $1.14^{2}$ & 0.86 & 0.85 \\
\hline DMNH 75335 & $\mathrm{P} 4$ & 1.36 & 1.76 & 1.72 & - & - & - \\
\hline DMNH 75337 & $\mathrm{P} 4$ & 1.35 & 1.77 & 1.69 & - & - & - \\
\hline SDSNH 110435 & p. P4 & 1.49 & - & - & - & - & - \\
\hline UCM 68942 & M1 or 2 & 1.67 & 1.82 & 1.74 & 1.511 & 0.90 & 0.83 \\
\hline UCM 95758 & M1 or 2 & 1.51 & 1.79 & 1.67 & - & - & - \\
\hline DMNH 75334 & M1 or 2 & 1.51 & 1.53 & 1.43 & $1.30^{1}$ & 0.86 & 0.85 \\
\hline SDSNH 110396 & M1 or 2 & 1.69 & 1.86 & 1.79 & 1.641 & 0.97 & 0.88 \\
\hline SDSNH 110397 & M1 or 2 & 1.71 & $1.85 a$ & 1.67 & - & - & - \\
\hline UCM 67987 & M3 & 1.51 & 1.67 & 1.31 & - & - & - \\
\hline UCM 70905 & M3 & 1.57 & 1.56 & 1.46 & $1.26^{1}$ & 0.80 & 0.81 \\
\hline UCM 69974 & $\mathrm{~m} 1$ & 1.56 & 1.39 & 1.36 & - & - & - \\
\hline UCM 67885 & $\mathrm{~m} 2$ & 1.61 & 1.39 & 1.44 & - & - & - \\
\hline SDSNH 110366 & $\mathrm{~m} 2$ & 1.64 & 1.54 & 1.58 & - & - & - \\
\hline SDSNH 110365 & $\mathrm{~m} 2$ & $1.57 a$ & - & 1.49 & - & - & - \\
\hline SDSNH 110367 & m3 & 1.97 & 1.46 & 1.51 & - & - & - \\
\hline SDSNH 110368 & p. m3 & $1.77 a$ & - & - & - & - & - \\
\hline SDSNH 110434 & $\mathrm{~m} 3$ & 1.77 & 1.54 & 1.57 & $1.47^{2}$ & 0.83 & 0.96 \\
\hline
\end{tabular}

The anterior cingulum is robust, extending from the anterior edge of the protocone to terminate at the anterior edge of the paracone. The protoloph is a complete, tall loph connecting the protocone to the paracone. The metaloph is incomplete, extending labially from the metacone to an indistinct metaconule (usually a slight swelling) to terminate either in the central basin (three teeth) or turn posteriorly to connect with the posterior cingulum (two teeth). The posterior cingulum is relatively tall, extending labially from the posterior edge of the hypocone to terminate at the posterior edge of the metacone. The central basin, and the valleys between anterior cingulum and protoloph and between the metaloph and posterior cingulum, are relatively deep.

Two teeth are identified as M3. They have a subcircular occlusal outline and are a little reduced in size relative to M1-2 (mean M3 ap $=95 \%$ of mean M1-2 ap). The protocone and paracone are the largest primary cusps. The metacone is distinct and compressed slightly transversely. The hypocone is weak and separated from the protocone by a notch or indentation along the lingual wall of the tooth. The anterior cingulum is strong, extending labially from the anterior edge of the protocone to join the anterior edge of the paracone. The protoloph is complete, relatively tall, extending labially from the protocone to connect with lingual edge of the paracone. The metaloph is tall, and in one M3 it is incomplete, extending lingually from the metacone to terminate in the central basin near the protocone, whereas in the other M3, it is complete, extending lingually from the metacone to join the posterolabial edge of the protocone. The posterior cingulum is robust, extending labially from the hypocone to terminate at the posterolingual edge of the metacone.

Confident separation of the first two lower molars in samples of isolated cylindrodontid teeth is difficult, but the $\mathrm{m} 1$ is usually more elongate anteroposteriorly, whereas the $\mathrm{m} 2$ has a more squared occlusal outline with the width greater relative to the length. Only one tooth (UCM 69974) meets the above criteria for $\mathrm{m} 1$. In length and all other dental characters, it is nearly identical to the 
teeth identified as $\mathrm{m} 2$, but differs by having a small gap at about the middle of the hypolophid. The sections of the hypolophid that are lingual and labial to this small gap are relatively robust and tall, similar in height to that of the m2-3 hypolophid. This gap is regarded as most likely representing individual variation or an aberrant developmental defect. All of the teeth identified as $\mathrm{m} 2$ have a tall, complete hypolophid, extending lingually from the ectolophid, just anterior to its origination from the hypoconid, to join the labial edge of the entoconid. The occlusal morphology of the $\mathrm{m} 3$ is very similar to that of the $\mathrm{m} 2$, but differs by being more elongated anteroposteriorly and by having the hypoconid and posterior cingulid more robust, forming a more convex posterior occlusal margin. The lower molars exhibit a number of shared characters. In early wear, the talonid is nearly as tall as the trigonid. The anterior cingulid is short, extending lingually from the protoconid to join the labial edge of the metaconid. The metalophulid II (posterior arm of the protoconid) extends from the posterolingual corner of the protoconid to terminate near the posterolingual base of the metaconid. The ectolophid is tall and complete, extending from the protoconid to the hypoconid. The central basin and the valley between the hypolophid and posterior cingulid are deep.

Remarks. The taxonomy of Bridgerian cylindrodontids has a complicated history. Leidy (1871) named Mysops minimus, the type species, based on a partial right dentary with moderately well-worn m2-3 from the lower Bridger Formation at Grizzly Buttes. The diagnostic characters of the species are as follows (Leidy, 1871; Matthew, 1910; Troxell, 1923b; Wilson, 1938b): 1) an incomplete m2 hypolophid; 2) a quadrate $\mathrm{m} 2$ occlusal outline (tra and trp subequal); 3) a complete m3 hypolophid; and 4) a narrow valley between the $\mathrm{m} 2$ entoconid and posterior cingulid. Wilson (1938b) referred one additional specimen to the species, which also exhibits an incomplete $\mathrm{m} 2$ hypolophid. Wilson (1938b) stated that the referred specimen is "presumably from the Bridger Formation, but its exact locality is unknown."

In 1872, Marsh named three new taxa from the Bridger Formation; Tillomys parvus based on a partial dentary with a well-worn $\mathrm{m} 1$, Tillomys senex based on a partial dentary with $\mathrm{m} 2$, and Taxymys lucaris based on a partial maxilla with P3-4. Leidy (1873) named Mysops fraternus based on a partial right dentary with m1-3 from an unknown locality within the Bridger Formation. Matthew (1910) first suggested that the holotype of T. parvus may actu- ally be cogeneric with Mysops minimus. However, Troxell (1923b) followed Marsh (1872) and retained T. parvus. Troxell (1923b) questionably considered Mysops fraternus as a junior synonym of $T$. parvus. Although Troxell (1923b) recognized Mysops minimus as valid, he considered Taxymys lucaris to be cogeneric with Tillomys, which made Taxymys a junior synonym of Tillomys. Troxell (1923b) further recognized two subspecies of Tillomys parvus; T. parvus parvus, represented by the holotype of $T$. parvus, and Tillomys parvus plicatus, based on a partial dentary with p4-m3, both of which are from Grizzly Buttes (Troxell, 1923b; Wilson, 1938c). Troxell (1923b) distinguished T. p. plicatus from T. p. parvus by it smaller size and a more complicated occlusal pattern. In a series of papers revising certain Bridgerian rodents, Wilson (1938a, 1938b, 1938c) provided convincing evidence that Taxymys and Tillomys are representatives of Sciuravidae, whereas T. parvus is actually cogeneric with Mysops minimus as Mysops parvus, and both of the latter taxa belong in Cylindrodontidae. Wilson (1938b) listed the following characters in the diagnosis of $M$. parvus: "hypolophid of $\mathrm{m} 2$ generally strongly developed; [lower molar] entoconids usually not especially robust, more or less crested; posterior valleys of [lower] molars well-developed; $\mathrm{m} 2$ more elongate than in M. minimus." Wilson (1938b) further noted that the occlusal pattern of the type specimen of M. p. plicatus is no more complicated than additional specimens that he referred to $M$. p. parvus. Wilson (1938b) stated that because the holotype of M. $p$. parvus is so incomplete, with only $\mathrm{m} 1$ present, the characters used by Troxell (1923b) to distinguish it from $M$. p. plicatus may very well represent individual variation instead and not rise to a subspecific level. Wilson (1938b) noted the following additional differences between the holotype of $M$. $p$. parvus and that of M. p. plicatus: 1) the anterior termination of the masseteric fossa slightly farther forward; and 2) the mental foramen relatively more superior and anteriorly positioned. Wilson (1938b) also regarded the differences between $M$. $p$. plicatus and $M$. fraternus as possibly just examples of individual variation, but noted that "because of the uncertain relation of $M$. $p$. parvus to $M$. p. plicatus and $M$. fraternus," he tentatively retained all three taxa. Wilson (1938b) acknowledged that the then known sample of Mysops from the Bridger Formation is highly variable in occlusal morphology and stated "there are probably at least two valid species present, one form represented by the holotype of $M$. minimus and the other best represented by 
the holotypes of both M. p. plicatus and M. fraternus." However, M. p. parvus has priority over $M$. parvus plicatus and $M$. fraternus, but unfortunately it is represented by the poorest holotype (Wilson, $1938 b)$. In summary, Wilson (1938b) recognized $M$. mimimus as represented by the holotype and one referred specimen, $M$. fraternus as represented by the holotype only, and the subspecies M. p. plicatus by the holotype only, whereas all other specimens were assigned to $M$. p. parvus. Wilson (1938b) discussed in detail the wide degree of variation seen in the specimens he referred to $M$. $p$. parvus, but he was unable to correlate these differences into consistent groupings. His analysis was also hampered by a general lack of stratigraphic information for many of the specimens.

Wood (1973) named a new species of Mysops, M. boskeyi, based on isolated teeth from the early Uintan Whistler Squat Quarry in the lower member of the Devil's Graveyard Formation, Texas, which Campisano et al. (2014) have recently re-dated as between 45.04 - $44.88 \mathrm{Ma}$. Wood (1973) also provided a more complete summary of the dental measurements of the sample of M. parvus from the Bridger Formation and noted that the high coefficients of variation suggest that more than one species may be represented in the sample. Campisano et al. (2014) state "Wood (1973) described M. boskeyi as a high crowned species of Mysops with clear difference in height between the trigonid and talonid that is not characteristic of later cylindrodontids." Korth (1994) suggested that $M$. boskeyi should be referred to Pareumys (also see Black and Sutton, 1984), which was followed by Walsh and Storer (2008). However, although Campisano et al. (2014) acknowledged Korth's (1994) proposal they did not mention Walsh and Storer's (2008) referral of the species to Pareumys and chose to retain it in Mysops in the absence of a more formal argument for transferral. Although a reanalysis of the hypodym of $M$. boskeyi is beyond the scope of this study, judging from the illustrations and descriptions of $M$. boskeyi (Wood, 1973), the molars are distinctly higher crowned than the previously recognized species of Mysops from the Bridger Formation. The ratio of the m1-2 unworn protoconid height to m1-2 ap of Mysops specimens from the Bridger B$\mathrm{D}(\mathrm{Br} 2-3)$ ranges from 0.63 to 0.65 . In the holotype M1 of M. boskeyi, the protocone length (measured from the apex of the protocone to the lingual base of the enamel in anterior view) relative to its greatest transverse width (tra) equals 0.87 , whereas that of M1-2 of Mysops from the Bridger B-D ranges from 0.65 to 0.70 . Another character seen in M1-2s of $M$. boskeyi that is similar to those of Pareumys is that the metaloph is commonly directed toward and connected to the posterior cingulum (= posteroloph), whereas in the Mysops specimens from the Bridger B-D, the metaloph is directed towards the protocone and does not connect with the posterior cingulum. Mysops is very similar to Pareumys and most investigators believe that Pareumys was derived from Mysops (e.g., Wilson, 1938b; Wood, 1973), so where one draws the line between the two genera becomes somewhat arbitrary. However, we believe that Korth's (1994) and Walsh and Storer's (2008) assignment of the species to Pareumys is reasonable based on its greater hypsodonty, increased size, and the common occurrence of a connection between the M1-2 metaloph and posterior cingulum.

To summarize, the three species of the cylindrodont Mysops are currently recognized from the Bridger B-D (M. minimus, M. parvus and M. fraternus). Mysops parvus is further provisionally divided into two subspecies (M. p. parvus and M. p. plicatus). The validity of these species and the subspecies is unclear because the holotypes of the type species $M$. minimus and $M$. parvus are poorly preserved so adequate comparisons to the other species or subspecies is difficult. Moreover, many specimens of Mysops collected during early explorations of the Bridger Formation lack stratigraphic control, which also makes comparisons difficult. However, the degree of occlusal variation and wide observed ranges in the dental measurements (Wilson, 1938b; Wood, 1973), strongly suggests that when additional stratigraphically controlled samples become available, it may be possible to better define the actual species diversity of Mysops from the Bridger Formation. Until then, we follow Wilson's (1938b) taxonomic hierarchy. Contrary to Campisano et al. (2014) and following Korth (1994) and Walsh and Storer (2008), we consider the Texas cylindrodont from the early Uintan (Ui1b) Whistler Squat Quarry to represent a primitive member of Pareumys, $P$. boskeyi.

The cylindrodont teeth from the TBM (Ui1a) are interesting because they appear to be intermediate in morphology between Mysops species from lower in the Bridger Formation (Br2-3) and P. boskeyi. They exhibit significantly higher molar crown height than Bridgerian specimens of Mysops, wherein the observed range of their unworn M1-2 protocone height/tra equals $0.83-0.88$, similar to that of the holotype M1 of $P$. boskeyi. As noted above, a Rm1 (UCM 69974) from the lowest local- 
ity in the TBM (UCM Locality 92189) has the hypolophid almost complete, but with a small gap present at about the middle of the hypolophid. Considering the degree of variation of the hypolophid seen in the larger samples of Bridgerian (Br23) Mysops, the significance of this character is debatable, and it likely represents either individual variation or a developmental defect. Even though the protoconid is moderately worn on UCM 69974, it has a protoconid height/ap ratio of 0.64 , which is similar to those of unworn m1-2s of Mysops specimens from lower in the section. In unworn m1-2s of Bridgerian Mysops, the protoconid is equal to or only slightly lower than the metaconid height (unworn height of metaconid/protoconid height = $0.98-1.00$ ), but by moderate wear its height is significantly reduced relative to that of the metaconid, so presumably, this ratio would be greater if UCM 69974 was unworn. The m3 (SDSNH 110434) from SDSNH Locality 5843 is abraded, but in early wear, and has a protoconid crown height/ap ratio of 0.83 , which is significantly higher than those of unworn m3s of Bridgerian specimens of Mysops (observed range of unworn m1-3 protoconid height/ap $=0.63$ $0.65)$. Of the five M1 or $2 \mathrm{~s}$ from the TBM, two have the metaloph directed towards and connecting with the posterior cingulum, whereas in the other three, the metaloph is directed towards the hypocone, but well separated from it. The TBM sample of teeth are smaller than those of $P$. boskeyi, but within the observed size ranges of Mysops species from lower in the Bridger Formation.

Previously, two upper molars (SDSNH 110396 and 110397) from SDSNH Locality 5844 were referred in the SDSNH catalog to Pareumys, whereas all of the isolated teeth from SDSNH Locality 5841, which is $104 \mathrm{~m}$ lower in the TBM near its base, were referred to Mysops. In the UCM catalog, a number of isolated lower molars from UCM Locality 92189 , which is also near the base of the TBM at $103 \mathrm{~m}$ below SDSNH Locality 5844, were referred to Mysops. The occurrences of both genera in the TBM were also listed in Gunnell et al. (2009) and Murphey et al. (2011), but no explanations for their generic assignments were included. These investigators then included the last occurrence of Mysops and the first occurrence of Pareumys as part of their characterization of the earliest Uintan biochron Ui1a. In addition to the above three samples, three more cylindrodontid teeth from SDSNH Locality 6242 are now known. The fact that the small sample of cylindrodontid teeth from the TBM are significantly higher crowned than Mysops specimens from lower in the Bridger For- mation $(\mathrm{Br} 2-3)$ and they exhibit a tendency of the M1-2 metaloph to connect to the posterior cingulum $(40 \%$ of the teeth), indicates that they exhibit slightly more similarity to $P$. boskeyi than to Bridgerian Mysops. To reflect this putative relationship, the TBM specimens are only compared to the genus as cf. Pareumys sp. This phylogenetic scenario implies that the TBM specimens may represent a transitional form between Bridgerian Mysops and early Uintan P. boskeyi, which is not unreasonable, considering that the TBM is older $(\sim 2.0 \mathrm{Ma})$ than the Whistler Squat Quarry.

Family EOMYIDAE Winge, 1887

Genus METANOIAMYS Chiment and Korth, 1996 Metanoiamys sp.

Figure 11.1-12, Table 7

Referred specimens. From UCM Locality 92189 : M1 or 2, UCM 66311, 95693, 98815, 98816; M3, UCM 98813, 98814; p4, UCM 95751. From SDSNH Locality 5841: M3, SDSNH 110372; dp4, SDSNH 110369; p4, SDSNH 110437; m1, SDSNH 110370. From locality 5844: M1 or 2, SDSNH 110442; p4, SDSNH 110436; m3, SDSNH 110438. From SDSNH Locality 5787: dP4, SDSNH 110371; m3, SDSNH 110411. From DMNH Locality 4672: dP4, DMNH 74131, 74135; P4, DMNH 74130, 74149, 75331; M1 or 2, DMNH 74133, 74136, 74139, 74141, 75251, 75278, 75332, 75333; p4, DMNH $74143,75276,75277$; 1 or 2 , DMNH 74132, 74137, 74146, 74147, 75250, 75252, 75254, 75255; m3, DMNH 74144, 74145. From DMNH Locality 4673: M1 or 2, DMNH 75316; m1 or 2, DMNH 75318.

Description. Three teeth are identified as dP4. The anterior cingulum extends anterolabially from the anterior base of the protocone to a parastyle and then continues in a wide arc to join the anterior base of the paracone, forming an expanded (wide) cingular shelf. A small accessory lophule is present that extends from the parastyle to the protoloph (= adlophule of Chiment an Korth [1996]). The primary cusps (protocone, paracone, hypocone, and metacone) are about equal in size, with the protocone and hypocone being round and the paracone and metacone being slightly compressed anteroposteriorly. The protoloph is a complete, low crest connecting the protocone to the lingual base of the paracone. The endoloph is complete, connecting the protocone to the hypocone. On one $\mathrm{dP} 4$, a small mesocone is present at about the center of the endoloph, and there is also a small, posterolabially directed accessory lophule coming off the mesocone (mesoloph), whereas in the other dP4s the mesocone is vestigial (only a small swelling on 


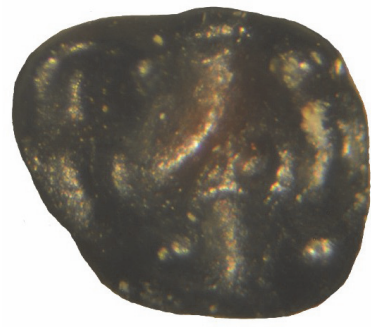

1

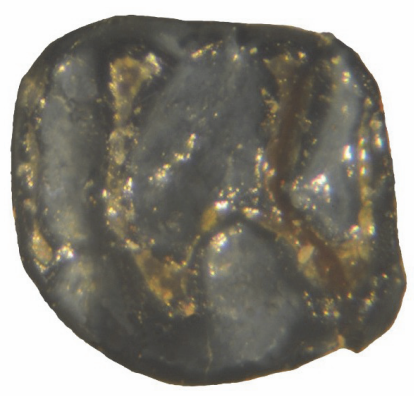

4

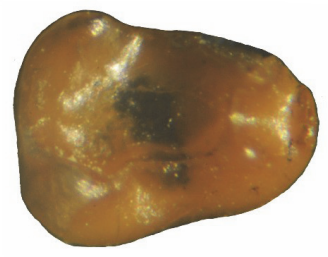

7

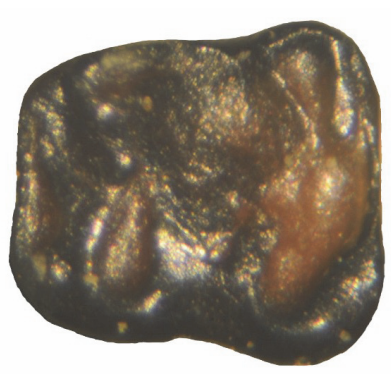

10

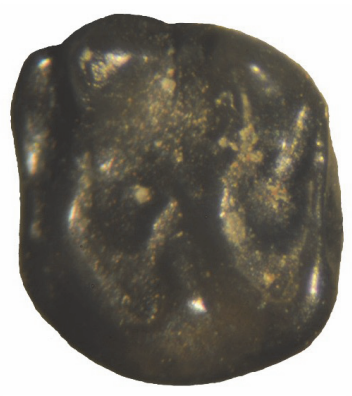

2

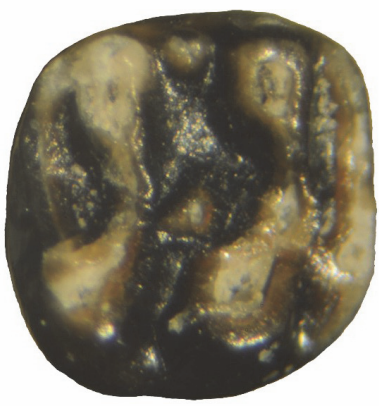

5

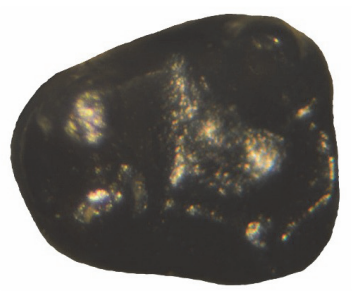

8

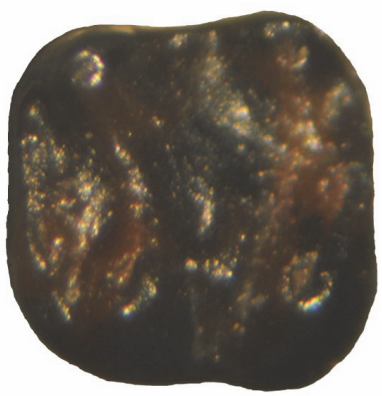

11

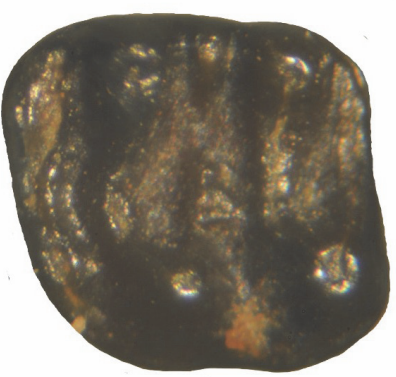

3

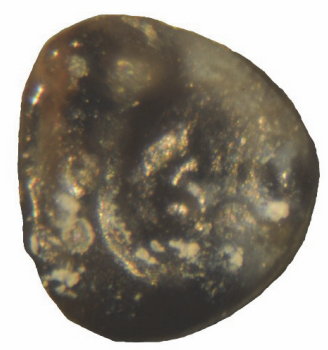

6

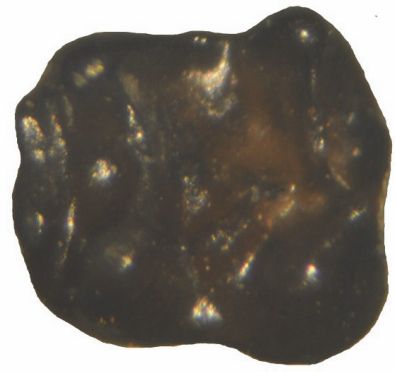

9

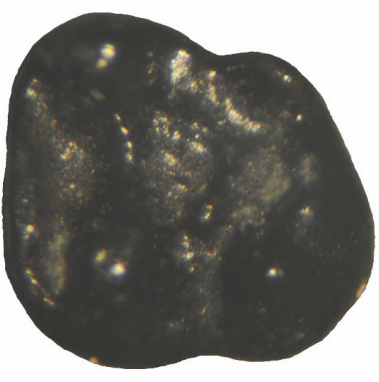

12

FIGURE 11. Metanoiamys sp. from TBM: 1, LdP4, DMNH 74135; 2, LP4, DMNH 75331; 3, LM1 or 2, DMNH 74136; 4, LM1 or 2, DMNH 75251; 5, RM1 or 2, SDSNH 110442; 6, LM3, UCM 98813; 7, Rdp4, SDSNH 110369; 8, Lp4, DMNH 74143; 9, Lm1 or 2, DMNH 75252; 10, Lm1 or 2, DMNH 75250; 11, Lm1 or 2, DMNH 75254; 12, Lm3, DMNH 74144. All occlusal views. Scale bar equals $1 \mathrm{~mm}$. 
TABLE 7. Dental measurements (in $\mathrm{mm}$ ) and statistics for Metanoiamys sp. from TBM.

\begin{tabular}{|c|c|c|c|c|c|c|}
\hline Position & & $\mathbf{N}$ & Mean & Observed range & SD & CV \\
\hline \multirow[t]{3}{*}{$\mathrm{dP} 4$} & ap & 3 & 0.97 & $0.93-1.00$ & 0.04 & - \\
\hline & tra & 3 & 0.81 & $0.79-0.82$ & 0.02 & - \\
\hline & $\operatorname{trp}$ & 3 & 0.81 & $0.77-0.85$ & 0.04 & - \\
\hline \multirow[t]{3}{*}{ P4 } & ap & 3 & 0.83 & $0.77-0.89$ & 0.06 & - \\
\hline & tra & 3 & 0.88 & $0.80-1.00$ & 0.09 & - \\
\hline & $\operatorname{trp}$ & 3 & 0.84 & $0.77-0.93$ & 0.07 & - \\
\hline \multirow[t]{3}{*}{ M1 or 2} & ap & 14 & 1.02 & $0.90-1.09$ & 0.05 & 4.9 \\
\hline & tra & 13 & 1.03 & $0.95-1.10$ & 0.05 & 4.8 \\
\hline & $\operatorname{trp}$ & 13 & 1.01 & $0.89-1.09$ & 0.06 & 5.9 \\
\hline \multirow[t]{3}{*}{ M3 } & ap & 6 & 0.89 & $0.83-0.93$ & 0.05 & 5.6 \\
\hline & tra & 6 & 0.94 & $0.83-1.00$ & 0.06 & 6.3 \\
\hline & $\operatorname{trp}$ & 6 & 0.79 & $0.77-0.82$ & 0.03 & 3.7 \\
\hline \multirow[t]{3}{*}{ dp4 } & ap & 1 & 0.80 & - & - & - \\
\hline & tra & 1 & 0.49 & - & - & - \\
\hline & $\operatorname{trp}$ & 1 & 0.70 & - & - & - \\
\hline \multirow[t]{3}{*}{ p4 } & ap & 6 & 0.86 & $0.79-0.93$ & 0.06 & 6.5 \\
\hline & tra & 6 & 0.67 & $0.58-0.70$ & 0.03 & 4.6 \\
\hline & $\operatorname{trp}$ & 6 & 0.79 & $0.70-0.84$ & 0.04 & 5.1 \\
\hline \multirow[t]{3}{*}{$\mathrm{m} 1$ or 2} & ap & 10 & 1.00 & $0.89-1.07$ & 0.06 & 6.0 \\
\hline & tra & 10 & 0.88 & $0.80-1.00$ & 0.07 & 7.9 \\
\hline & $\operatorname{trp}$ & 10 & 0.94 & $0.82-1.04$ & 0.08 & 8.5 \\
\hline \multirow[t]{3}{*}{$\mathrm{m} 3$} & ap & 4 & 1.05 & $1.00-1.08$ & 0.04 & - \\
\hline & tra & 4 & 0.92 & $0.85-0.98$ & 0.06 & - \\
\hline & $\operatorname{trp}$ & 4 & 0.85 & $0.79-0.93$ & 0.06 & - \\
\hline
\end{tabular}

the endoloph). The mesostyle is small, but distinct. The metaloph is complete connecting the hypocone to the metacone. The posterior cingulum extends labially from the hypocone to terminate at the posterior base of the metacone.

Three teeth are identified as P4. Their occlusal outlines are roughly square. The anterior cingulum extends labially from the anterior base of the protocone to the anterior base of the paracone and, in two specimens, there is a slight posterior indentation at about the middle of the cingulum. The protoloph is a complete crest, connecting the protocone to the paracone. The endoloph is a complete crest in two teeth and nearly complete in one tooth. A small mesocone is present on the endoloph in two teeth. The metaloph is complete, connecting the hypocone to the metacone. A very weak adlophule is present on two teeth. The poste- rior cingulum extends labially from the hypocone to terminate near the posterior base of the metacone. Confident differentiation of M1 from M2 cannot be made for Metanoiamys. Fourteen teeth are identified as either M1 or M2. The occlusal outline is nearly square. The anterior cingulum is robust, extending lingually from near the anterior base of the metacone to terminate at a level just labial to the protocone apex, where it is separated from the protocone by a shallow valley. A small, but distinct, anterocone is usually present on the anterior cingulum (10 teeth), near its lingual terminus. An adlophule is commonly present (eight teeth) connecting the anterocone or anterior cingulum to the protoloph. A small mesostyle is usually present (11 teeth). The protoloph is complete, extending from the anterolabial edge of the protocone in a gentle arc to connect with lingual edge of the paracone. 
The endoloph is usually a complete crest connecting the protocone to the hypocone, but in three teeth it is incomplete extending anterolabially from the hypocone to terminate near the posterolabial base of the protocone. The mesocone varies from a slight swelling (incipient) to a small, but distinct, cuspule on the endoloph and from one to two additional, small accessory lophules (mesolophs) extend from the mesocone into the central basin. The metaloph is complete, connecting the hypocone to the metacone. The posterior cingulum is robust, extending labially from the hypocone to terminate at the posterior base of the metacone.

Six teeth are identified as M3. They have a rounded occlusal outline and are smaller than the M1-2. The paracone is the largest primary cusp, slightly larger than the protocone. The hypocone is smaller than the protocone and separated from the protocone by a distinct notch along the posterolingual border of the tooth. The metacone is weak, varying from a slight bulge to a small cusp. The anterior cingulum is strong, extending labially from the anterior base of the protocone to the anterior base of the paracone. The protoloph is a complete crest, extending labially from the protocone to the paracone. The posterior arm of the protocone extends posterolabially into the central basin with from one to two small accessory lophs extending labially or posterolabially from it terminus. The posterior cingulum extends in a continuous arc from the hypocone to the posterior base of the paracone.

One tooth is identified as dp4 because it exhibits a significantly narrower trigonid and a distinct anteroconid. Its protoconid and metaconid are about equal in size and are connected by a short, low metalophulid II. The entoconid and hypoconid are robust and larger than the protoconid and metaconid. A moderate metastylid crest is present that extends posteriorly from the metaconid to terminate near the anterior base of the entoconid. The ectolophid is low, complete, and connects the protoconid to the hypoconid. The hypolophid is low and complete, extending from the lingual base of the hypoconid to terminate at the labial base of the entoconid. The posterior cingulum is very short, originating from the posterior cingulum and extending to near the posterolabial base of the entoconid.

Six teeth are identified as p4. The trigonid is narrower than the talonid, with the metaconid slightly larger than the protoconid. The hypoconid and entoconid are the largest primary cusps and are subequal in size. The anterior cingulid is distinct, extending labially from the metaconid to ter- minate near the anterior base of the protoconid. The mesoconid varies from a small, round cuspulid (two teeth) to a slightly transversely expanded cuspulid (three teeth), and one tooth has a short spur extending from the mesoconid into the central basin (incipient mesolophid). The ectolophid varies from being complete (three teeth), connecting the mesoconid anteriorly to the protoconid and posteriorly to the hypoconid, to incomplete, connecting the mesoconid anteriorly to the protoconid. The hypolophid is complete, extending lingually from the hypoconid to join the entoconid. The posterior cingulid is distinct, originating from about the center of the hypolophid to terminate at the posterior base of the entoconid.

Confident separation of $\mathrm{m} 1$ from $\mathrm{m} 2$ cannot be made for Metanoiamys. Ten teeth are identified as $\mathrm{m} 1$ or 2 . The occlusal outline is subrectangular. The primary cusps (protoconid, metaconid, hypoconid, and entoconid) are somewhat lophate, being slightly anteroposteriorly compressed. The anterior cingulid is robust, extending labially from the anterior base of the metaconid to terminate near the anterior base of the protoconid, where it is separated from the protoconid by a shallow valley. An anteroconid is usually present on the anterior cingulid (seven teeth), and on three teeth an accessory cristid is present that extends posteriorly from the anteroconid towards the metalophulid II (= adlophulid of Chiment and Korth [1996]). The metalophulid II is complete, extending lingually in a gentle arc from the protoconid to join the labial edge of the metaconid. The ectolophid is usually complete (nine teeth), extending from the protoconid to the hypoconid, but in one tooth it is incomplete, only connecting the mesoconid posteriorly to the hypoconid. The mesoconid varies from a distinct, small round cuspulid (eight teeth) to a slightly transversely elongated cuspulid (two teeth). A small mesostylid is present between the metaconid and entoconid on five teeth. A short mesolophid is present that extends lingually or posterolingually from the mesoconid into the central basin. The hypolophid is complete, extending lingually from the hypoconid to join the labial edge of the entoconid. The posterior cingulid extends from the hypolophid, near its origination from the hypoconid, to the posterolabial base of the entoconid.

Four teeth are identified as $\mathrm{m} 3$ and are very similar in occlusal morphology to the m1-2, but differ by having the talonid narrower than the trigonid, a more robust hypolophid and a much weaker posterior cingulid. In addition, the m3 ectolophid exhibits variation. It is complete on two teeth, connecting 
the mesoconid anteriorly to the protoconid and posteriorly to the hypoconid and incomplete on two teeth, wherein on one tooth it is a low cristid that only connects the mesoconid anteriorly to the protoconid, and on the other it is a low cristid that only connects the mesoconid posteriorly to the hypoconid.

Remarks. In the sample of rodent teeth from SDSNH Locality 6242, no teeth representing Sciuravidae are present. All 26 small rodent teeth from the locality agree well with those of Metanoiamys and are compatible in size and occlusal morphology, supporting their referral to a single species. Additional teeth from four other localities within the TBM are morphologically indistinguishable from the sample from SDSNH Locality 6242 and are included in the species. Metanoiamys sp. is the most abundant rodent from the TBM.

Previous investigators have noted a similarity in the occlusal morphology of the basal eomyid Metanoiamys to that of certain Sciuravidae (e.g., Pauromys) and have considered Metanoiamys and thus Eomyidae to have been derived from a sciuravid ancestor (Lindsay, 1968; Walsh, 1997; Walton and Porter, 2008). In addition, Walsh (1997) discovered that the early Uintan Metanoiamys agorus Chiment and Korth, 1996, from southern California retains a very small P3 based on an intact upper dentition preserving a small, single rooted $\mathrm{P} 4$ alveolus along with the common occurrence of small anterior appression facets on isolated $\mathrm{dP} 4 \mathrm{~s}$ and $\mathrm{P} 4 \mathrm{~s}$ assigned to the species. Where known, all Sciuravidae also retain a greatly reduced $\mathrm{P} 3$, thus this character is a pleisomorphy for $M$. agorus and Sciuravidae. Although similar in occlusal morphology, the lower molars of Metanoiamys sp. can be distinguished from those of Sciuravidae (see also remarks of Sciuravidae above). In Metanoiamys, the metalophulid II (= metalophid) is complete, forming a smooth arc between the protoconid and metaconid, and its junction with the metaconid is positioned more anteriorly, whereas in sciuravids the metalophulid II usually terminates slightly more posteriorly, near the posterolabial base of the metaconid. The ectolophid of Metanoiamys is relatively taller, and has a much greater tendency to be complete, usually connecting the mesoconid anteriorly to the protoconid and posteriorly to the hypoconid. The hypolophid of Metanoiamys is better developed, usually a continuous lophid joining the hypoconid to the entoconid and the entoconid is not separated from the lingual terminus of the posterior cingulid by a distinct valley. Metanoiamys sp. further differs from
Pauromys by having the $\mathrm{p} 4$ much less reduced relative to the $\mathrm{m} 1$, with the mean $\mathrm{p} 4$ ap equal to $87 \%$ of the mean $\mathrm{m} 1 \mathrm{ap}$.

As noted above in the remarks on the Sciuravidae, the upper molars of Metanoiamys are more difficult to distinguish from those of Sciuravidae than are the lower molars. However, the upper molars of Metanoiamys differ from those of Sciuravidae by having the protolophs and metalophs slightly taller and with a greater tendency to be complete, a greater tendency for the endolophs to be complete (connecting the mesocone to the protocone anteriorly and to the hypocone posteriorly), and small accessory lophules (mesolophs) that extend from the mesocone or endoloph into the central basin.

Based on isolated teeth from the early Bridgerian Powder Wash locality of Utah, Dawson (1968) described a sciuravid species that she left in open nomenclature as sciuravid sp. Dawson (1968) noted that the m1-2 of the Powder Wash sciuravid $\mathrm{sp}$. exhibit some occlusal similarity to those of Sciuravus bridgeri, but differs from this species and other species of Sciuravus by having the p4 metaconid very reduced resulting in the p4 trigonid being significantly narrower than the talonid. In Metanoiamys, the p4 talonid is also significantly narrower than the talonid. The lower molars of the Powder Wash sciuravid sp. are characterized by the following (Dawson, 1968): 1) an incomplete metalophulid II, extending lingually from the protoconid to terminate either a short distance into the central basin or near the posterolabial base of the metaconid; 2) a hypolophid that varies from incomplete (only a short lophid extending from the entoconid into the central basin) to nearly complete, extending from the entoconid to near the lingual base of the hypoconid; 3) a commonly complete ectolophid, connecting the protoconid to the hypoconid; and 4) a small mesoconid on the ectolophid. The M1-2 of the Powder Wash sciuravid sp. are characterized by the following (Dawson, 1968): 1) a protoloph that extends labially to terminate at a small protoconule near the anterolingual base of the paracone; 2) a relatively complete metaloph connecting the hypocone to the metacone; and 3) a complete endoloph connecting the protocone to the hypocone. Although the lower molars of the Powder Wash sciuravid sp. exhibit the typical sciuravid configuration of an incomplete metalophulid II and hypolophid, the complete ectolophid is very similar to that of Metanoiamys. Similarly, although the M1-2 of the Powder Wash sciuravid sp. have the typical sciuravid configuration of an incomplete 
protoloph, the endoloph is complete, a character that is lacking in all other Bridgerian and Uintan sciuravid genera in which the upper molars are known (Sciuravus and Taxymys), but present in Metanoiamys. It is unlikely that Metanoiamys was derived from Pauromys because the p4 of Metanoiamys is not as greatly reduced. However, the fact that the Powder Wash sciuravid sp. shares certain dental characters with Metanoiamys that are generally lacking in other sciuravid taxa, suggests that a morphotype similar to the Powder Wash sciuravid sp. could have given rise to Metanoiamys.

As detailed above in the remarks on the Sciuravidae, most of the isolated teeth, including the holotypes, from the Uintan of Texas assigned by Walton (1993) to two species of Pauromys (P. texensis and $P$. simplex) are now regarded as belonging to Metanoiamys (Walsh, 1997; Walton and Porter, 2008). However, a reanalysis and formal revision of the Texas species and their hypodyms is still needed. Metanoiamys sp. is similar in size to Metanoiamys agorus and M. marinus Chiment and Korth, 1996, larger the M. lacus (Storer, 1987) and smaller than M. fugitivus (Storer, 1984), M. korthi Kelly and Whistler, 1998, M. fantasma (Lindsay, 1968), M. texensis (Walton, 1993), and M. simplex (Walton, 1993) (see also Walton and Porter, 2008; Kelly et al., 2012). Metanoiamys sp. is the oldest recorded species of the genus and appears to represent a new species that is not far removed from its sciuravid ancestor. However, until the systematic relationships of the Texas species of Metanoiamys are clarified so that adequate comparisons can be made, the TBM species is left in open nomenclature as Metanoiamys sp.

Family DIPODIDAE? Fisher Von Waldheim, 1817

Genus ELYMYS Emry and Korth, 1989

Elymys? emryi new species

Figure 12.1-16, Table 8

zoobank.org/92BA7EA2-3D41-4D82-91A2-BB2B56AC29FF

Holotype. RM1, SDSNH 110466.

Referred specimens. From SDSNH Locality 5844: M1, SDSNH 110463, 110464, 110465; M2, SDSNH 100444; M3, SDSNH 110448; m1, SDSNH 110455, 110456; m2, SDSNH 110457; m3, SDSNH 110461. From SDSNH Locality 5843: $\mathrm{m} 2$, SDSNH 110405.

Type Locality. SDSNH Locality 5844, $105 \mathrm{~m}$ above the base of the Turtle Bluff Member, Bridger Formation, Wyoming.

Distribution and Age. Type locality and SDSNH Locality 5843 , which is at the same stratigraphic level on strike and just west of SDSNH Locality
5844, Turtle Bluff Member, Bridger Formation, Uinta County, Wyoming. Earliest Uintan (Ui1a).

Diagnosis. Differs from Elymys complexus Emry and Korth, 1989, by the following: 1) significantly larger size; 2) molars slightly higher crowned and slightly more lophate; 3) M1-2 usually with short to moderate mesoloph; 4) m1-2 commonly with short mesolophid; 5) m2-3 with metalophulid I; and 5) m1-2 usually with distinct hypoconulid.

Etymology. Patronym for Robert J. Emry of the Smithsonian Institution in honor of his many contributions to vertebrate paleontology, including his detailed analysis of the myomorph rodent Elymys.

Description. The M1-2 and all lower molars are longer than wide and low crowned. Four teeth are identified as $\mathrm{M} 1$, three of which are complete and one has the anterolabial portion of paracone broken away. The M1 talon and trigon vary from being equal in width to slightly narrower anteriorly. Two of the M1s have very small, but distinct, anterior appression facets, indicating that a small P4 was presumably present in the species. The M1 anterior cingulum is strong, extending lingually from a distinct parastyle to terminate near the anterolingual base of the protocone. Two cuspules are present along the anterior cingulum, the more lingually positioned one being the larger. The primary cusps (paracone, metacone, protocone, and hypocone) are robust and about equal in height. The preprotocrista (anterior arm of the protocone) extends anterolabially from the anterolabial corner of the protocone to a distinct protoconule and then continues to connect with a cuspate parastyle (= anterocone of cricetids) at the anterolabial corner of the tooth. A short paralophule (or protolophule I) is present that extends from the protoconule to connect with the anterolingual edge of the paracone. The endoloph is complete, connecting a small mesoconid anteriorly to the protocone and posteriorly to the hypocone. A distinct mesostyle is present between the paracone and metacone. Two M1s have a mesoloph that extends labially from the mesocone to about half the way to the mesostyle, whereas the other two have a shorter mesoloph that only extends about one third or one quarter of the way. The metaloph is complete and moderate height, connecting the metacone and hypocone. The posterior cingulum (or posteroloph) is robust, extending from the posterolabial corner of the hypocone to a distinct hypoconule and then continues to the posterolabial base of the metacone.

The one tooth identified as M2 has the enamel somewhat abraded. It is very similar in size and 


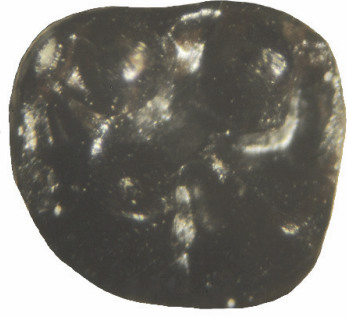

1

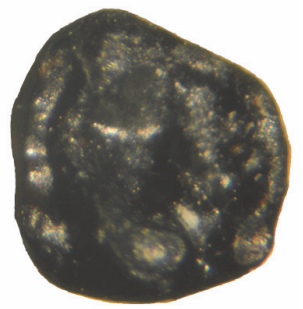

5

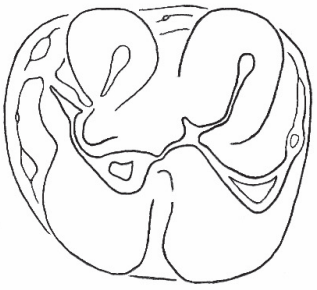

9

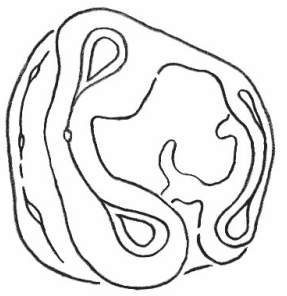

13

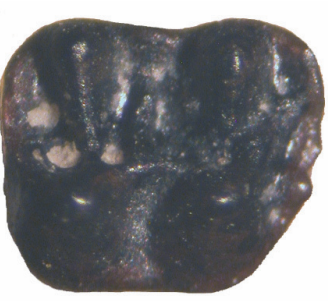

2

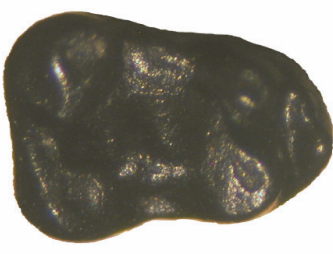

6

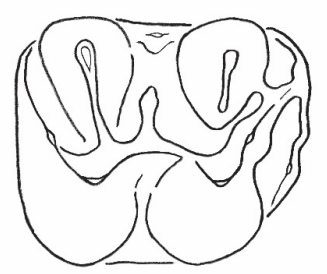

10

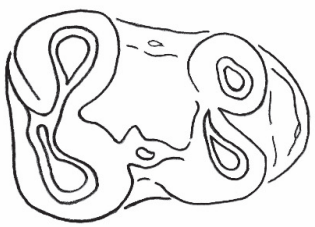

14

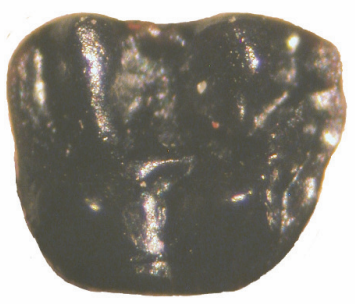

3

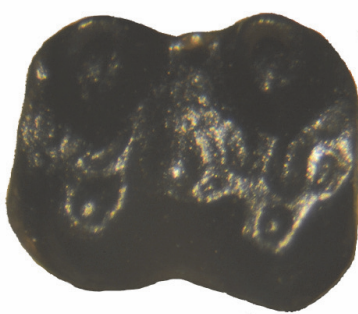

7

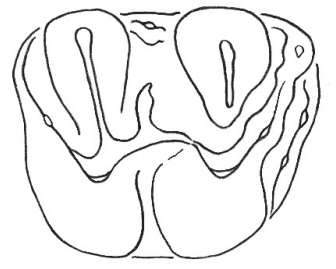

11

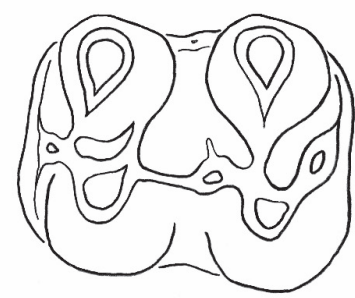

15

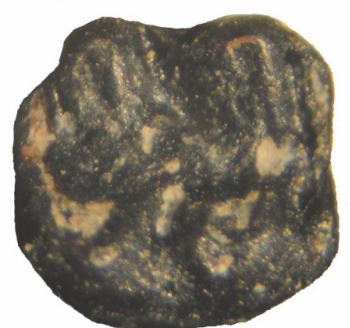

4

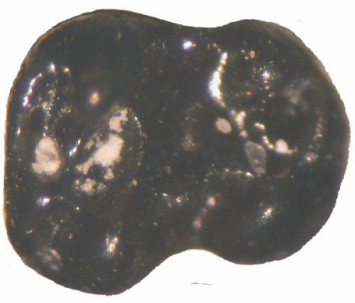

8

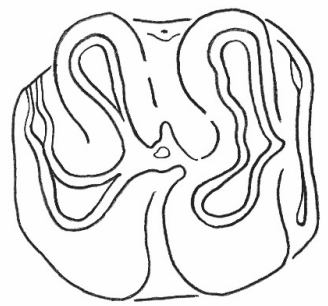

12

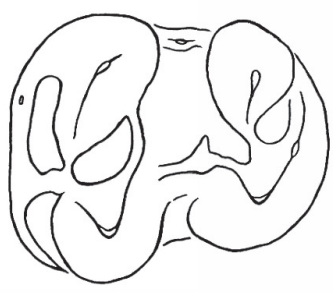

16

FIGURE 12. Elymys? emryi new species from TBM, macrophotographs with corresponding line drawings of specimens: 1 and 9, LM1, SDSNH 110463; 2 and 10, RM1, SDSNH 110465; 3 and 11, RM1 (holotype), SDSNH 110466; 4 and 12, RM2, SDSNH 110444; 5 and 13, LM3, SDSNH 110448; 6 and 14, Rm1, SDSNH 110456; 7 and 15, Lm2, SDSNH 110457; 8 and 16, Lm3, SDSNH 110461. All occlusal views. Scale bar equals $1 \mathrm{~mm}$.

occlusal morphology to the referred M1s, but exhibits certain differences. The preprotocrista extends similarly from the paracone to a distinct protoconule, but then continues more anteriorly than in the M1 to connect with the anterior cingulum rather than with the parastyle. The anterocone is a distinct cuspule positioned slightly nearer the lingual terminus of the anterior cingulum and the accessory cingulum cuspule seen in the M1s is lacking. The anterior cingulum is slightly wider and oriented more vertically, whereas in the M1s it obliquely inclined. The mesocone is slightly larger. 
TABLE 8. Measurements (in $\mathrm{mm}$ ) of SDSNH specimens of Elymys? emryi new species from TBM (a = approximate, enamel abraded; p. = partial).

\begin{tabular}{lcccc}
\hline \multicolumn{1}{c}{ Specimen Number } & Position & ap & tra & trp \\
\hline 110466 (holotype) & $\mathrm{M} 1$ & 1.17 & 0.95 & 0.95 \\
110465 & $\mathrm{M} 1$ & 1.18 & 0.96 & 0.96 \\
110463 & $\mathrm{M} 1$ & 1.20 & 1.07 & 1.15 \\
110464 & $\mathrm{p} . \mathrm{M} 1$ & 1.18 & - & 1.13 \\
110444 & $\mathrm{M} 2$ & 1.21 & 1.10 & 1.10 \\
110448 & $\mathrm{M} 3$ & 0.98 & 1.00 & 0.82 \\
110455 & $\mathrm{~m} 1$ & 1.23 & 0.54 & 0.89 \\
110456 & $\mathrm{~m} 1$ & 1.16 & 0.52 & 0.81 \\
110405 & $\mathrm{~m} 2$ & $1.18 \mathrm{a}$ & $0.92 \mathrm{a}$ & $0.90 \mathrm{a}$ \\
110457 & $\mathrm{~m} 2$ & 1.28 & 0.98 & 1.05 \\
110461 & $\mathrm{~m} 3$ & 1.21 & 1.00 & 0.82 \\
\hline
\end{tabular}

The M3 has the talonid expanded transversely, resulting in a trapezoidal occlusal outline. The anterior cingulum is robust, extending from the anterolabial corner of the paracone to the anterolingual corner of the tooth, where it is separated from the protocone by valley. A robust anterocone is present on the anterior cingulum near its lingual terminus. The protocone and paracone are the largest primary cusps and about equal in size. The preprotocrista (anterior arm of the protocone) extends anterolabially to a weak protoconule and then continues labially connecting to the anterolingual corner of the paracone, resulting in a complete protoloph. The hypocone is distinct and connected to the posterior cingulum (posteroloph), which extends labially in a gentle arc to an incipient entoconid. A short accessory crest extends anterolingually from the entoconid into the central valley towards the mesocone. The mesocone is distinct and connected by a very short, anterolingually directed crest to the anterolabial base of the protocone and a short, posterolingually directed crest to the anterolabial base of the hypocone, resulting in a complete, but low, endoloph. A short mesoloph extends from the mesocone into the central valley. The protocone and hypocone are separated by a deep valley lingual to the endoloph.

The $\mathrm{m} 1$ is distinctly narrower anteriorly than posteriorly. It has a distinct anteroconid that is separated from the protoconid and metaconid by a valley. The protoconid is large with a metalophulid II (= posterior arm of the protoconid) that extends lingually in an arc from the protoconid to the posterolabial base of the metaconid. The metaconid is conical and slightly smaller than the protoconid. The entoconid and hypoconid are robust, about equal in size and larger than the metaconid and protoconid. The mesoconid is distinct, connected to the protoconid anteriorly by a relatively tall cristid and posteriorly to the hypoconid by an equally tall cristid, resulting in a complete ectolophid. A short mesolophid is present in one $\mathrm{m} 1$, whereas the other has no mesolophid. A strong mesostylid is present between the metaconid and entoconid. The hypolophid (entolophulid) is low, but complete, extending from the entoconid to either the lingual base of the hypoconid or the hypoconulid. The posterior cingulid is robust, extending from the posterolingual edge of the hypoconid to a strong hypoconulid and then continues lingually to terminate at the posterior base of the entoconid.

The $\mathrm{m} 2$ has a rectangular occlusal outline. The anterior cingulid extends lingually from a small parastyle positioned near the anterolabial edge of the metaconid to a distinct anteroconid and then continues to the anterolabial corner of the tooth, where it is separated from the protoconid by a valley. The primary cusps (metaconid, entoconid, protoconid, and hypoconid) are robust and about equal in size. The preprotocristid (anterior arm of the protoconid) extends from the anterolingual corner of the protoconid to the anteroconid, and a short cristid extends from the anteroconid to the anterolabial base of the metaconid, resulting in a complete metalophulid I. The metalophulid II is complete, extending lingually from the posterolingual corner of the protoconid to the posterolabial base of the metaconid. The mesoconid is con- 
nected anteriorly to the protoconid by a relatively tall cristid and posteriorly by a relatively tall cristid, resulting in a complete ectolophid. A short mesolophid extends lingually from the mesoconid into the central valley. The hypolophid is relatively tall and complete, connecting the entoconid to the hypoconid. A distinct mesostylid is present between the metaconid and entoconid. The posterior cingulid extends posterolingually from the hypoconid to a distinct hypoconulid and then continues to join the posterolabial base of the entoconid.

The $\mathrm{m} 3$ has an elongate talonid that is considerably narrower than the trigonid. The anterior cingulid is robust, extending labially from an incipient parastylid (slight swelling) at the anterolingual corner of the tooth to a distinct anteroconid, and then continues to the anterolabial corner of the tooth, where it is separated from the protoconid by a valley. The primary cusps (metaconid, entoconid, protoconid, and hypoconid) are conical and robust. The preprotocristid (anterior arm of the protoconid) extends lingually from the anterolingual corner of the protoconid to the anterolabial edge of the metaconid, resulting in a complete metalophulid I. A distinct cristid extends anteriorly from the metalophulid I to the anteroconid. The postprotocristid (posterior arm of the protoconid) extends lingually in an arc to join with the posterolabial base of the metaconid, resulting in a complete metalophulid II. The mesoconid is distinct, connected anteriorly to the protoconid, and posteriorly to the hypoconid by relatively tall cristids, resulting in a complete ectolophid. A short mesolophid extends lingually from the mesoconid. A distinct mesostylid is present between the metaconid and entoconid. The entolophulid extends labially from the entoconid to either the labial base of the hypoconid or to the posterior cingulid near its origin from the hypoconid, resulting in a complete metalophid. The posterior cingulid extends lingually from the posterolingual corner of the hypoconid to the posterior base of the entoconid.

Remarks. Emry and Korth (1989) described Elymys complexus from the early Bridgerian Elderberry Canyon Local Fauna, Sheep Pass Formation, Nevada, and questionably assigned it to the Zapodidae Coues, 1875, based on the presence of a small, peg-like P4. Subsequently, Emry (2007) provided a detailed account of the species based on a much larger sample, wherein he considered Elymys to be a definitive basal myomorph possibly representing the ancestral morphotype that lead to both cricetids and dipodoids.
Rodrigues et al. (2010) also recognized Elymys as the earliest known myomorph and regarded it as a basal dipodoid, but noted that it shares a suite of characters with the first cricetids. For example, in early representatives of the basal cricetid Pappocricetodon Tong, 1992, of Asia (e.g., $P$. antiquus Wang and Dawson, 1994; P. kazakstanicus Emry et al., 1998, and $P$. neimongolensis Qian, 2012) a small P4 is present, the anterior arm of the M1 protocone extends anterolabially to join the protoconule and then commonly continues as an anterolophule to terminate at a small cuspate anterocone (= parastyle), the $\mathrm{M} 2$ has a squared occlusal outline, the $\mathrm{m} 1$ trigonid is significantly narrower than the talonid, and the m2-3 have a small, but distinct, transversely elongate anteroconid. Although compared to more derived cricetids, the M1 anterocone of these early members of Pappocricetodon is significantly smaller and does not extend nearly as far forward. The TBM teeth share the above characters of these basal cricetids, but differ by having a shorter, weaker M1 mure that extends less anterolabially, a slightly more distinct (more cuspate) M1 anterocone (= parastyle), a taller, better developed M1 anterolophule, more weakly developed upper molar mesolophs (not mesostylar), a stronger $\mathrm{m} 1$ posterior arm of the protoconid, a stronger metalophulid I and II on m23 , distinct molar hypoconules and hypoconulids, and lower molars lacking ectomesolophids. Although difficult to distinguish basal cricetids from basal dipodoids (Rodrigues et al. 2010), the above differences appear to eliminate the TBM teeth as representing a basal cricetid immigrant from Asia.

Based on a small sample of specimens from the late Uintan through early Duchesnean portions of the Sespe Formation of southern California, Wilson (1935a, 1935b) described three species of Simimys (S. simplex, S. vetus, and S. murinus). Lillegraven and Wilson (1975) provided an analysis of a large sample of Simimys from California and concluded that Wilson's (1935a) three species actually represent a single normally variable species, making $S$. vetus and $S$. murinus junior synonyms of $S$. simplex. One additional species of Simimys, S. landeri from the late Duchesnean portion of the Sespe Formation, was described by Kelly (1992), and is significantly larger than S. simplex.

When examining the TBM teeth, it was clear they represent a new species, but their generic allocation was questionable because they appear to be intermediate morphologically between Elymys and Simimys. It could be argued that they rep- 
resent a transitional morphotype that rises to the level of generic separation, but erecting a new genus based on a small sample of isolated teeth cannot be justified. Because the new species exhibits more similarity to Elymys than Simimys, we questionably referred them to the former genus.

Elymys? emryi shares the following characters with E. complexus: 1) brachydont; 2) presumably a small P4, based on small anterior appression facets on half of the M1s; 3) M1-2 Ionger than wide; 4) M1 anterior arm of the protocone (preprotocrista) extending anterolabially from the protocone to a protoconule and continuing as an anterolophule to connect with a cuspate parastyle (= anterocone of cricetids) on the anterolabial terminus of the anterior cingulum; 5) M3 talonid notably wide transversely and long posteriorly; 6) M3 protoloph low, but complete; 7 ) m1 trigonid notably narrower than talonid; 8) $\mathrm{m} 2$ protoconid connected to anteroconid by a short cristid; 9) m3 trigonid distinctly wider than talonid; and 10) endolophs and ectolophids complete on the upper and lower molars, respectively. Elymys? emryi also shares the following characters with Simimys simplex and $S$. landeri, some of which are also shared with $E$. complexus (see above): 1) M1-2 longer than wide; 2) the M1 anterior arm of the protocone extends anterolabially to the protoconule and then continues as an anterolophule to connect with a distinct parastyle on the labial terminus of the anterior cingulid; 3) m2-3 with a metalophulid I; and 4) M1-2 and m1-2 with mesolophs and mesolophids, respectively. Elymys? emryi differs from Simimys simplex and $S$. landeri by the following: 1) cheek teeth significantly more brachydont and less lophodont; 2) mesolophs and mesolophids much weaker and shorter; 3) M2 anterolophule lacking (no connecting lophule between protoconule and parastyle); 4) M3 lacking any connections with anterior cingulum; and 5) molar accessory lophs and lophids lacking.

Wilson (1935a) regarded Simimys as a possible cricetid based on similarities in occlusal morphology to later cricetids. Since then, numerous investigators have debated the phylogenetic relationship of Simimys to other myomorph rodents (e.g., Wood, 1937, 1974; Stehlin and Schaub, 1951; Lindsay, 1968, 1977; Wilson, 1975; Emry, 1981; Vianey-Liaud, 1985; Wang and Meng, 1986; Kelly, 1992; Korth, 1994; Emry and Korth, 1989; Walsh, 1997; Emry, 2007; Rodrigues et al., 2010). Vianey-Liaud (1985) suggested that dipodoids first immigrated to North America from Asia in the middle Eocene (Uintan), as represented by Simimys.
Dawson et al. (1990) described Armintomys from the earliest Bridgerian and questionably assigned it to Dipodoidea Fisher de Waldheim, 1817, but Wang and Dawson (1994) later noted that it lacks the derived condition of the neurovascular canal seen in Dipodoidea (including Simimys). Walsh (1997) described additional material of Simimys from southern California and amended the diagnosis of the genus. Based on the presence of a single-rooted, peg-like $\mathrm{P} 4$ in some early representative specimens, a generalized myodont occlusal morphology and a hystricomorphous zygomasseteric structure, Walsh (1997) regarded Simimys along with Elymys and Nonomys Emry and Dawson, 1973, as possible basal dipodoids and the closest sister taxa to the Zapodidae. Walsh (1997) further regarded Myomorpha Brandt, 1855, to be derived from Sciuravidae with Eomyidae, Armintomys, and Pauromys as the closest successive sister taxa, respectively, to Dipodoidea (including Elymys and Simimys) and Muroidea Illiger, 1811. Emry (2007) provided the following scenario in his reinterpretation for the origin of Myomorpha: 1) myomorphs originated in North America from Sciuravidae at least as early as the beginning of the middle Eocene (earliest Bridgerian) with subsequent immigration of an Elymys-like myomorph to Asia during the early middle Eocene, from which dipodoids (Zapodidae) and muroids (Cricetidae Fisher von Waldheim, 1817) evolved in Asia; 2) an immigration of eumyines derived from something close to Asian Eucricetodon Thaler, 1966, back from Asia to North America near the end of the Eocene (Chadronian); and 3) followed by an immigration from Asia to North America of zapodid dipodoids in the Miocene. Emry (2007) also considered Simimys as more likely to have a North American origin, where it was derived from an Elymys-like ancestor.

The increased size, slightly higher crowns, slightly more lophate occlusal pattern, development of short mesolophs and mesolophids, and presence of a metalophulid I on m2-3 of E.? emryi indicate that it is slightly more derived than E. complexus. These characters also suggest that Simimys could have been easily derived from E.? emryi or a very similar ancestral morphotype, further supporting Emry's (2007) proposal of a North American origin for Simimys.

Rodentia, family undetermined
Figure $6.2-3$, Tables 2,9

Referred specimen. From UCM Locality 92189, Lm1 or 2, UCM 95700. 
TABLE 9. Comparison of lower molar characters of UCM 95700, Ailuravus michauxi, Eohaplomys, Haplomys and Spurimus scotti (presumed shared characters in bold; character states after Rensberger [1975] and Korth [1988]).

\begin{tabular}{|c|c|c|c|c|c|}
\hline Character & UCM 95700 & Ailuravus & Eohaplomys & Haplomys & Spurimus \\
\hline $\begin{array}{l}\text { 1. angle between } \\
\text { labial and posterior } \\
\text { margins }\end{array}$ & $\begin{array}{l}\text { nearly square - } \\
79^{0}-85^{\circ}\end{array}$ & $\begin{array}{l}\text { more acute }-60^{0} \\
73^{0} \text { on } \mathrm{m} 1-2 \\
\text { nearly square on } \\
\mathrm{m} 3\end{array}$ & $\begin{array}{l}\text { nearly square - } \\
79^{0}-85^{0}\end{array}$ & $\begin{array}{l}\text { more acute }-60^{0} \\
73^{0}\end{array}$ & $\begin{array}{l}\text { more acute }-60^{0} \\
73^{0}\end{array}$ \\
\hline $\begin{array}{l}\text { 2. trigonids } \\
\text { proportions }\end{array}$ & $\begin{array}{l}\text { Relatively wide } \\
\text { trigonid basin } \\
\text { with longer } \\
\text { metalophulids I } \\
\text { and II }\end{array}$ & $\begin{array}{l}\text { Relatively wide } \\
\text { trigonid basin } \\
\text { with longer } \\
\text { metalophulids I } \\
\text { and II }\end{array}$ & $\begin{array}{l}\text { Relatively wide } \\
\text { trigonid basin } \\
\text { with longer } \\
\text { metalophulids I } \\
\text { and II, especially } \\
\text { in } \mathrm{m} 3\end{array}$ & $\begin{array}{l}\text { trigonid basins } \\
\text { narrower with } \\
\text { shorter } \\
\text { metalophulid I and } \\
\text { II, especially m3 }\end{array}$ & $\begin{array}{l}\text { trigonid basins } \\
\text { narrower with } \\
\text { shorter } \\
\text { metalophulid I and } \\
\text { II, especially m3 }\end{array}$ \\
\hline 3. metastylid crest & $\begin{array}{l}\text { Strongly } \\
\text { developed }\end{array}$ & $\begin{array}{l}\text { Strongly } \\
\text { developed }\end{array}$ & $\begin{array}{l}\text { Strongly } \\
\text { developed }\end{array}$ & $\begin{array}{l}\text { More weakly } \\
\text { developed }\end{array}$ & $\begin{array}{l}\text { More weakly } \\
\text { developed }\end{array}$ \\
\hline 4. metastylid & Absent & Absent & $\begin{array}{l}\text { Absent or } \\
\text { sometimes } \\
\text { incipient on } \\
\text { posterior edge of } \\
\text { metastylid crest }\end{array}$ & $\begin{array}{l}\text { Present - well } \\
\text { developed }\end{array}$ & Absent \\
\hline 5. entoconid & Bulbous & Bulbous & Bulbous & $\begin{array}{l}\text { Not bulbous, more } \\
\text { anteroposteriorly } \\
\text { compressed }\end{array}$ & $\begin{array}{l}\text { Not bulbous, more } \\
\text { anteroposteriorly } \\
\text { compressed }\end{array}$ \\
\hline $\begin{array}{l}\text { 6. hypolophid and } \\
\text { hypolophid } \\
\text { connection }\end{array}$ & $\begin{array}{l}\text { Incomplete, } \\
\text { extending into } \\
\text { central basin with } \\
\text { no connection }\end{array}$ & $\begin{array}{l}\text { Usually } \\
\text { incomplete, } \\
\text { extending into } \\
\text { central basin, } \\
\text { especially m3, or } \\
\text { sometimes } \\
\text { connecting to } \\
\text { posterior cingulid }\end{array}$ & $\begin{array}{l}\text { Commonly } \\
\text { complete, but low } \\
\text { labially, connects } \\
\text { to mesoconid }\end{array}$ & $\begin{array}{l}\text { Complete, tall and } \\
\text { usually connects to } \\
\text { posterior corner of } \\
\text { ectolophid }\end{array}$ & $\begin{array}{l}\text { Complete, tall and } \\
\text { usually connects to } \\
\text { posterior corner of } \\
\text { ectolophid }\end{array}$ \\
\hline 7. mesoconid & $\begin{array}{l}\text { small - oval } \\
\text { shaped }\end{array}$ & $\begin{array}{l}\text { Commonly } \\
\text { present - usually } \\
\text { oval shaped }\end{array}$ & $\begin{array}{l}\text { Present - oval } \\
\text { shaped }\end{array}$ & $\begin{array}{l}\text { More triangularly } \\
\text { shaped with labial } \\
\text { crest }\end{array}$ & Absent \\
\hline 8. ectolophid & straight & $\begin{array}{l}\text { Relatively } \\
\text { straight }\end{array}$ & $\begin{array}{l}\text { Relatively } \\
\text { straight }\end{array}$ & Inflected & Inflected \\
\hline $\begin{array}{l}\text { 9. space (or valley) } \\
\text { between entoconid, } \\
\text { hypolophid and } \\
\text { posterior cingulid }\end{array}$ & Wide & Wide & Wide & Narrow & Narrow \\
\hline $\begin{array}{l}\text { 10. crenulated } \\
\text { enamel }\end{array}$ & Yes & Yes & Yes & No & No \\
\hline
\end{tabular}

Description. UCM 95700 is unworn with an anteroposteriorly elongate occlusal outline, wherein its length is significantly longer than its width $(a p / t r a=1.305$ and ap/trp =1.283). The trigonid and talonid widths are nearly equal. The anterior cingulid is complete and relatively tall, extending from the anterolingual corner of the protoconid to the anterolabial corner of the metaconid. The metalophulid II is tall and complete, extending posterolingually from the posterolingual corner of the protoconid and, at about its center, bends back anterolingually to join the anterolabial corner of the metaconid, resulting in a distinct inflection and rela- tively wide trigonid basin. The metastylid crest is a relatively strong ridge positioned along the posterolingual border of the metaconid and separated from the metaconid apex by a distinct notch. The primary cusps (protoconid, metaconid, entoconid, and hypoconid) are robust and nearly equal in size. The trigonid and talonid basins are deep. A ridge is present on the center of the labial surface of the entoconid that extends labially from its apex to its base (incipient hypolophid). The ectolophid is tall, straight, and complete, connecting a small, but distinct, oval shaped mesoconid anteriorly to the protoconid and posteriorly to the hypoconid. The 
posterior cingulid (posterolophid) is tall, robust and extends from the posterolingual edge of the hypoconid to a strong, centrally positioned hypoconulid and then continues lingually to terminate near the posterolingual corner of the tooth, where it is separated from the entoconid by a relatively wide, deep valley. The enamel is moderately crenulated.

Remarks. UCM 95700 was identified in the UCM catalog as Aplodontidae, genus and species undetermined. When first examining UCM 95700, the question arose; could this tooth possibly represent a cylindrodontid that lacks the typical complete hypolophid as seen in some examples of Bridgerian Mysops (e.g., $\mathrm{m} 1$ of M. parvus plicatus or $\mathrm{m} 2$ of M. minimus; see also Wilson, 1938b: p. 216)? Moreover, it is similar in length to that of m1-2 of Bridgerian Mysops. UCM 95700 differs from the m1-2s of Bridgerian Mysops and cf. Pareumys sp. from the TBM in a number of characters. Its occlusal outline is significantly more elongate, with the tra and trp narrower relative to the ap (ap/tra ratio = $16-17 \%$ narrower and ap/trp ratio $=16-18 \%$ narrower), and the trigonid and talonid are nearly equal in width. The entoconid is very robust, relatively larger and wider, and not anteroposteriorly compressed. The anterior cingulid is taller and more complete. The metalophulid II (posterior arm of the protoconid) is relatively taller, more completely connected to the posterolabial wall of the metaconid, and inflected posteriorly at about its midline. The hypoconulid is taller and more distinct, positioned near the midline of the posterior cingulid (= posterolophid). The ectolophid is taller, straighter, and more complete, whereas those of Mysops and cf. Pareumys sp. are more convex (inflected), especially posteriorly. The metastylar crest is more distinct. The enamel is crenulated (although not heavily). UCM 95700 also exhibits some occlusal similarity to the m1-2 of certain species of the early Eocene (Wasatchian) cylindrodont Tuscahomys Dawson and Beard, 2007, which have a distinct hypoconulid and mesoconid, and commonly exhibit an incomplete or short hypolophid (e.g., T. ctenodactylops [Korth, 1984] and T. walshi Anemone et al., 2012). However, UCM 95700 can be easily distinguished from these species by the following (Korth, 1984; Dawson and Beard, 2007; Beard and Dawson, 2009; Anemone et al., 2012; Rose et al., 2012): 1) a significantly taller crown with deeper talonid and trigonid basins; 2) a relatively wider trigonid, more nearly equal in width to the talonid; 3) a much taller metalophulid II, connecting higher on the metaconid wall, and with a prominent posterior flexure at its midline; 4) a more distinct metastylid crest; 5) a much weaker hypolophid, barely extending labially into the talonid basin, and not directed towards or connected to the ectolophid or hypoconid; and 6) crenulated enamel.

Stock (1935) described three species of Eohaplomys from the late Uintan portion of the Sespe Formation of southern California and regarded his new genus as the then known earliest representative of the Aplodontidae. However, Rensberger (1975) provided convincing evidence that the dental similarities of Eohaplomys and prosciurine aplodontids (e.g., Spurimus Black, 1971, and Haplomys Miller and Gidley, 1918) represent convergence. Subsequently, Korth (1988) recognized that Eohaplomys along with Mytonomys Wood, 1956, actually represent ailuravine ischryomyids closely related the middle Eocene Ailuravus Rütimeyer, 1891, of Eurasia (see also Weitzel, 1949; Michaux, 1968; Wood, 1976; Hartenberger, 1995; Escarguel, 1999; Bernard et al., 2012).

In an attempt to further determine the familial status of UCM 95700, its dental characters were compared to those of the aplodontids Spurimus and Haplomys, along with the ailuravines Eohaplomys and Ailuravus, which exhibit some convergent occlusal similarity to early aplodontids (Table 9). Based on this comparison, UCM 95700 appears to have an occlusal morphology that is slightly more similar to the ailuravines Eohaplomys and Ailuravus (Ischyromyidae) than to Haplomys and the basal aplodontid Spurimus (Aplodontidae). Comparison of UCM 95700 to the aplodontid Prosciurus Matthew, 1903, which has many of the same dental character states as Haplomys (Rensberger, 1975), further indicates that it does not represent a basal aplodontid. UCM 95700 differs from late Uintan Eohaplomys by having a less lophate lower molar with the hypolophid incomplete, and with slightly less development of the metastylid crest and a weaker mesoconid. UCM 95700 is also significantly smaller than Eohaplomys. Moreover, no upper molars have been recovered from the TBM with the distinctive morphology seen in those of Eohaplomys or Ailuravus.

To summarize, UCM 95700 appears to represent a previously unknown rodent whose familial and generic allocations are uncertain. It could represent a cylindrodont or possibly a basal ailuravine.

\section{CONCLUSIONS}

The Bridger Formation in the type area of the Bridger Basin consists of three members (in ascending order); the Blacks Fork Member, the 
Twin Buttes Member, and the TBM. The Blacks Fork and Twin Buttes members contain mammalian faunas of the Blackforkian (biochron $\mathrm{Br} 2$ ) and Twinbuttean (biochron $\mathrm{Br} 3$ ) subages of the Bridgerian North American Land Mammal age. The TBM has been designated as the stratotype for the earliest Uintan (biochron Ui1a) of the Uintan North American Land Mammal age (Gunnell et al., 2009). As such, documenting the taxonomic composition of the TBM is important to better define this interval and further clarify our understanding of the Bridgerian-Uintan transition.

This report is the first in a series that provides detailed descriptions and taxonomic revisions of the mammals from the TBM. Here we document the occurrence of the following taxa in the TBM: Uintasorex parvulus; Microsyops annectans; Notharctus robustior, Omomys carteri; Trogolemur myodes; Washakius insignis; Thisbemys corrugatus; Microparamys minutus; Microparamys sp.; Sciuravus nitidus; Tillomys senex; Tillomys? parvidens; Taxymys lucaris; Pauromys sp., cf. $P$. perditus; three informal sciuravid species (sp. A, B and $\mathrm{C}$ ); cf. Pareumys sp.; Metanoiamys sp.; and Elymys? emryi new species.

Gunnell et al. (2009) listed two index species for the Ui1a; Hemiacodon engardae and Oromerycidae, new genus and species. With the discovery of Elymys? emryi from the TBM, a third index species is now recognized in the Ui1a. The new oromerycid of Gunnell et al. (2009) will be described and formally named in part two of this series of papers, along with a new species of Nyctitherium, both of which are known only from the TBM. Microparamys sp., Metanoiamys sp., cf. Pareumys sp., and sciuravid sp. A from the TBM also appear to represent new species restricted to the TBM, and thus additional Ui1a index species, but assigning formal names to them has been deferred until additional material of each is discovered to better characterize them. Whether the specimens assigned to the informal taxa sciuravid sp. B and sp. C represent new species, or instead belong to taxa known from lower in the Bridger Formation, cannot be determined until more complete specimens of each are available.

With the exception of Hemiacodon engardae, all of the primates from the TBM are holdover taxa from lower in the Bridger Formation, of which three (Uintasorex parvulus, Microsyops annectans, and Omomys carteri) range through to the Uintan biochron Ui1b or later. However, the rodents exhibit a modest diversification during the beginning of the earliest Uintan (Ui1a). Of the sixteen rodent taxa recognized from the TBM, at least four potential new species (Microparamys sp., sciuravid sp. A, cf. Pareumys sp., and Metanoiamys sp.), along with Elymys? emryi, make their first appearances in the TBM. In addition to the above rodent species, Triplopus and Epihippus first appear in the TBM, genera that are generally regarded as having their first appearances in the Uintan (e.g., Prothero, 1998; Flynn, 2008; MacFadden, 1998; Robinson et al., 2008; Gunnell et al., 2009). Additional taxa make their first appearances in the TBM, which we will document in the second part of this series of papers. These facts indicate a faunal turnover at the beginning of the Uintan, further supporting Gunnell et al.'s (2009) recognition of an earliest Ui1a biochron for the stratotype section of the TBM.

\section{ACKNOWLEDGMENTS}

We thank the U.S. Bureau of Land Management (BLM) for supporting our research by providing permits to complete our field work over the years. We are grateful to $B$. Breithaupt of the Wyoming BLM for facilitating the curation of TBM specimens at the DMNS, and to E.H. Lindsay of the University of Arizona for providing casts of Mysops from the Bridger Formation. We are greatly indebted to T.A. Deméré and K.A. Randall of the SDNHM, L. Ivy and J. Sertich of the DMNS, T. Culver and J. Eberle of the UCM, and J. Ming, R. O'Leary, and A. Gishlick of the American Museum of Natural History, for their considerate assistance in procuring loans of specimens for this study and assistance with locality and specimen numbers. Special thanks are extended to P. Robinson, E. Evanoff, P. Monaco, the late D. Engard, and all of the UCM students and volunteers who assisted with the recovery of the fossils from UCM Locality 92189; and P. Sena, M. Madsen, S. Madsen, H. Finalyson, and T. Temme, who assisted with quarrying and hauling and wet screening of matrix samples of the more recently discovered TBM localities. The music of Rush was an important source of inspiration during our field work including many long hours of wet screening and quarrying, so we'd like to say a special thanks and credit the musical genius of G. Lee, A. Lifeson, and N. Peart. Last but not least, we thank our late friend and colleague S.L. Walsh for his participation in the TBM field work, wet screening, heavy liquid separation, and fossil identifications; as well as his many contributions to middle Eocene mammalian paleontology, biostratigraphy and biochronology. $\mathrm{He}$ is sorely missed! R.J. Emry of the Smithsonian Insti- 
tution and an anonymous reviewer provided many constructive comments and suggestions on an earlier draft of this report, which significantly improved the final version.

\section{REFERENCES}

Alston, E.R. 1876. On the classification of the Order Glires. Proceedings of the Zoological Society of London, 1876:61-98.

Anderson, D.K. 2015. New specimens and neotype designation of Thisbemys brevicrista (Rodentia, Ischyromyidae) from the middle Eocene clarify the distinction between $T$. corrugatus and $T$. plicatus. Journal of Paleontology, 89:318-330.

Anemone, R.L., Dawson, M.R., and Beard, K.C. 2012. The early Eocene rodent Tuscahomys (Cylindrodontidae) from the Great Divide Basin, Wyoming: phylogeny, biogeography, and paleoecology. Annals of Carnegie Museum, 80:187-205.

Bengtson, P. 1988. Open nomenclature. Palaeontology, 31:223-227.

Beard, K.C. 1988. New notharctine primate fossil from the early Eocene of New Mexico and southern Wyoming and the phylogeny of Notharctinae. American Journal of Physical Anthropology, 75:439-469.

Beard, K.C. and Dawson, M.R. 2009. Early Wasatchian mammals of the Red Hot Local Fauna, uppermost Tuscahoma Formation, Lauderdale County, Mississippi. Annals of Carnegie Museum, 78:193-243.

Bernard, C., Sabatier M., Bernard, M., and Vianey-Liaud, M. 2012. Les rongeurs de Chery-Chartreuve et Rocourt-Saint-Martin (est du bassin de Paris; Aisne, France), leur place parmi les faunes de l'Eocene myoen d'Europe, Palaeovertebrata, 37:167-271. (In French)

Black, C.C. 1971. Paleontology and geology of the Badwater Creek area, central Wyoming, Part 7. rodents of the family Ischyromyidae. Annals of Carnegie Museum, 43:179-217.

Black, C.C. and Sutton, J.A. 1984. Paleocene and Eocene rodents of North America, p. 67-84. In R.M. Mengel (ed.), Papers in Vertebrate Paleontology Honoring Robert Warren Wilson. Carnegie Museum of Natural History Special Publication 9.

Bloch, J.I., Boyer, D.M., Gingerich, P.D., and Gunnell, G.F. 2010. New primitive paromomyid from the Clarkforkian of Wyoming and dental eruption in Plesiadapiformes. Journal of Vertebrate Paleontology, 22:366-379.

Bowdich, T.E. 1821. An Analysis of the Natural Classifications of Mammalia for the Use of Students and Travelers. J. Smith, Paris.

Bown, T.M. 1982. Geology, paleontology, and correlation of Eocene volcaniclastic rocks, southeast Absaroka Range, Hot Springs County, Wyoming. U.S. Geological Survey Professional Paper, 1201-A:1-75.

Brandt, J.F. 1855. Beiträge zur nähern Kenntnis der Säugethiere Russlands. Mémoires de l'Académie
Impériale des Sciences de Saint-Pétersbourg 6 séries, 9:1-375. (In German)

Burke, J.J. 1937. A new Sciuravus from Utah. Annals Carnegie Museum, 27:1-9.

Campisano, C.J., Kirk, E.C., Townsend, K.E.B., and Deino, A.L. 2014. Geochronological and taxonomic revisions of the middle Eocene Whistler Squat Quarry (Devil's Graveyard Formation, Texas) and implications for the early Uintan in Trans-Pecos Texas. PLOS ONE 9:e101516, doi:10.1371/journal.pone. 0101516 .

Chiment, J.J. and Korth, W.W. 1996. A new genus of eomyid rodent (Mammalia) from the Eocene (UintanDuchesnean) of southern California. Journal of Paleontology, 16:116-124.

Cope, E.D. 1883. On the mutual relations of the bunotherian Mammalia. Proceedings of the Academy of Natural Sciences, Philadelphia, 35:77-83.

Coues, E. 1875. Some account, critical, descriptive and historical, of Zapus. Bulletin of the U.S. Geological and Geographical Survey of the Territories, Series 2, 5:253-262.

Covert, H.H. 1990. Phylogenetic relationships among the Notharctinae of North America. American Journal of Physical Anthropology, 81:381-397.

Cuozzo, F.P. 2008. Using extant patterns of dental variation to identify species in the primate fossil record: a case study of middle Eocene Omomys from the Bridger Basin, southwestern Wyoming. Primates, 49:101-115.

Dawson, M.R. 1961. The skull of Sciuravus nitidus, a middle Eocene rodent. Postilla, 53:1-13.

Dawson, M.R. 1962. A sciuravid rodent from the middle Eocene of Wyoming. American Museum Novitates, 2075:1-5.

Dawson, M.R. 1966. Additional late Eocene rodents (Mammalia) from the Uinta Basin, Utah. Annals of Carnegie Museum, 38:97-114.

Dawson, M.R. 1968. Middle Eocene rodents (Mammalia) from northeastern Utah. Annals of Carnegie Museum, 39:327-370.

Dawson, M.R. and Beard, K.C. 2007. Rodents of the family Cylindrodontidae (Mammalia) from the earliest Eocene of the Tuscahoma Formation, Mississippi. Annals of Carnegie Museum, 76:135-144.

Dawson, M.R., Krishtalka, L. and Stucky, R.K. 1990. Revision of the Wind River faunas, early Eocene of central Wyoming. Part 9. the oldest known hystricomorphous rodent (Mammalia: Rodentia). Annals of Carnegie Museum, 59:135-147.

Emry, R.J. 1981. New material of the Oligocene muroid rodent Nonomys and its bearing on muroid origins. American Museum Novitates, 2712:1.1-4.

Emry, R.J. 2007. The middle Eocene North American myomorph rodent Elymys, her Asian sister Aksyiromys, and other Eocene Myomorphs. Bulletin Carnegie Mueseum of Natural History, 39:141-150.

Emry, R.J. and Dawson, M.R. 1973. Nonomys, new name for the cricetid (Rodentia, Mammalia) genus 
Nonomys Emry and Dawson. Journal of Paleontology, 47:1003.

Emry, R.J. and Korth, W.W. 1989. Rodents of the Bridgerian (middle Eocene) Elderberry Canyon local fauna of eastern Nevada. Smithsonian Contributions to Paleobiology, 67:1-14.

Emry, R.J., Tyutkova, L.A., Lucas, S.G., and Wang, B. 1998. Rodents of the middle Eocene Shinzhaly fauna of eastern Kazakhstan. Journal of Vertebrate Paleontology, 18:218-227.

Escarguel, G. 1999. Les rongeurs de l'Eocene inferieur et moyen d'Europe occidentale, systematique, phylogenie, biochronology et paleobiogeographie des niveaux-reperes MP 7 a MP 14. Palaeovertebrata, 28:89-351. (In French)

Evanoff, E., Brand, L.R., and Murphey, P.C. 1998. The lower Bridger Formation (middle Eocene) of southwest Wyoming: widespread marker units and subdivisions of Bridger B. Dakoterra, 5:115-122.

Evanoff, E., Robinson, P., Murphey, P.C., Kron, D.G., Engard, E., and Monaco, P. 1994. An early Uintan fauna from Bridger E. Society of Vertebrate Paleontology, Abstracts with Programs Supplement, 14:24A.

Fisher Von Waldheim, G. 1817. Adversaria zoological. Mémoires de la Société Imperiale des Naturalistes de Moscou, 5:368-428. (In Latin)

Flanagan, K.M. 1986. Early Eocene rodents from the San Jose Formation, San Juan Basin, New Mexico. Contributions to Geology, University of Wyoming, Special Paper, 3:197-220.

Flynn, L.J. 2008. Eomyidae, p. 415-427. In Janis, C.M., Gunnell, G.F., and Uhen, M.E. (eds.), Evolution of Tertiary Mammals of North America, Volume 2, Small Mammals, Xenarthans, and Marine Mammals. Cambridge, Cambridge University Press.

Gazin, C.L. 1934. On the priority of specific names for the upper Bridger Notharctus. Journal of Mammalogy, $15: 71$.

Gazin, C.L. 1946. Machaeroides eothen Matthew, the saber tooth creodont of the Bridger Eocene. Proceedings of the United States National Museum, 96:335-347.

Gazin, C.L. 1949. A leptictid insectivore from the middle Eocene Bridger Formation of Wyoming. Journal of the Washington Academy of Sciences, 39:220-223.

Gazin, C.L. 1952. The lower Eocene Knight Formation of western Wyoming and its mammalian faunas. Smithsonian Miscellaneous Collections, 117:1-82.

Gazin, C.L. 1955. A review of the Upper Eocene Artiodactyla of North America. Smithsonian Miscellaneous Collections, 281:1

Gazin, C.L. 1957. A skull of the Bridger middle Eocene creodont, Patriofelis ulta Leidy. Smithsonian Miscellaneous Collections, 134:1-112.

Gazin, C.L. 1958. A review of the middle and upper Eocene primates of North America. Smithsonian Miscellaneous Collections, 136:1-112.
Gazin, C.L. 1961. New sciuravid rodents from the lower Eocene Knight Formation of western Wyoming. Proceedings of the Biological Society of Washington, 74:193-194.

Gazin, C.L. 1962. A further study of the lower Eocene mammalian fauna of southwestern Wyoming. Smithsonian Miscellaneous Collections, 144:1-98.

Gazin, C.L. 1968. A study of the Eocene condylarthan mammal Hyopsodus. Smithsonian Miscellaneous Collections, 153:1-90.

Gazin, C.L. 1976. Mammalian faunal zones of the Bridgerian middle Eocene. Smithsonian Contributions to Paleobiology, 26:1-25.

Geoffroy Saint-Hilaire, É. 1812. Tableau des quadrumanes, ou des animaus composant le premier ordere de la classe des mamifères. Annales Muséum National d'Histoire Naturelle, Paris, 19:85-122. (In French)

Godinot, M. 1983. Contribution à l'étude des Primates Paléogenes d'Europe, Systématique, Locomotion. Thèse d'Etat, Université des Sciences et Techniques du Languedoc, Montpellier, France. (In French)

Golz, D.J. and Lillegraven, J.A. 1977. Summary of known occurrences of terrestrial vertebrates from Eocene strata of southern California. University of Wyoming Contributions in Geology, 15:43-65.

Granger, W. 1908. A revision of the American Eocene horse. Bulletin of the American Museum of Natural History, 24:221-264.

Granger, W. and Gregory, W.K. 1917. A revision of the Eocene primates of the genus Notharctus. Bulletin of the American Museum of Natural History, 37:841858.

Gregory, W.K. 1915. On the classification and phylogeny of the Lemuroidea. Geological Society of America Bulletin, 26:426-446.

Gunnell, G.F. 1997. Wasatchian-Bridgerian (Eocene) paleoecology of the western interior of North America; changing paleoenvironments and taxonomic composition of omomyid (Tarsiiformes) primates. Journal of Human Evolution, 32:105-132.

Gunnell, G.F. 1998. Mammalian fauna from the lower Bridger Formation (Bridger A, early middle Eocene) of the southern Green River Basin, Wyoming. Contributions to Geology, University of Wyoming, 30:57-70.

Gunnell, G.F. 2012. New uintasoricine (?Primates, Plesiadapiformes) from the earliest Bridgerian, latest early Eocene of Wyoming. Journal of Paleontology, 86:973-978

Gunnell, G.F. and Bartels, W.S. 1994. Early Bridgerian (middle Eocene) vertebrate paleontology and paleoecology of the southern Green River Basin, Wyoming, p. 404-432. In Gunnell, G.F. (ed.), Eocene Biodiversity: Unusual Occurrences and Rarely Sampled Habitats. Kluwer Academic/Plenum Press, New York.

Gunnell, G.F, Murphey, P.C., Stucky, K.R., Townsend, K.E.B., Robinson, P., Zonneveld, J-P., and Bartels, W.S. 2009. Biostratigraphy and biochronology of the 
latest Wasatchian, Bridgerian, and Uintan North American Land Mammals "Ages," p. 279-330. In Albright III, L.B. (ed.), Papers on Geology, Vertebrate Paleontology, and Biostratigraphy in Honor of Michael O. Woodburne. Museum of Northern Arizona Bulletin 65, Flagstaff, Arizona.

Gunnell, G.F., Rose, K.D., and Rasmussen, D.T. 2008. Euprimates, p. 239-261. In Janis, C.M., Gunnell, G.F., and Uhen, M.E. (eds.), Evolution of Tertiary Mammals of North America. Cambridge University Press, Cambridge.

Gunnell, G.F. and Yarborough, V.L. 2000. Brontotheriidae (Perissodactyla) from the late early and middle Eocene (Bridgerian), Wasatch and Bridger Formations, southern Green River Basin, southwestern Wyoming. Journal of Vertebrate Paleontology, 20:349-368.

Hartenberger, J.-L. 1995. Place des Ailuravinae dans la radiation initiale des rongeurs en Europe. Comptes Rendus de l'Académie des Sciences, Série Ila, 321:631-637. (In French)

Illiger, C. 1811. Prodromus systematis mammalium et avium additis terminis zoographicis utriusqued classis. C. Salfeld, Berlin. (In Latin)

Ivy, L.D. 1990. Systematics of late Paleocene and early Eocene Rodentia (Mammalia) from the Clark's Fork Basin, Wyoming. University of Michigan, Contributions of the Museum of Paleontology, 28:21-70.

Kelly, T.S. 1992. New Uintan and Duchesnean (middle and late Eocene) rodents from the Sespe Formation, Simi Valley, California. Southern California Academy of Sciences Bulletin, 91:97-120.

Kelly, T.S. 2010. New records of Marsupialia, Lipotyphla, and Primates from the Duchesnean (middle Eocene) Simi Valley Landfill Local Fauna, Sespe Formation, California. Paludicola, 7:158-169.

Kelly, T.S., Murphey, P.C., and Walsh, S.L. 2012. New records of small mammals from the middle Eocene Duchesne River Formation, Utah, and their implications for the Uintan-Duchesnean North American Land Mammal Age transition. Paludicola, 8:194-237.

Kelly, T.S. and Whistler, D.P. 1994. Additional Uintan and Duchesnean (middle and late Eocene) mammals from the Sespe Formation, Simi Valley, California. Contributions in Science, 439:1-29.

Kelly, T.S. and Whistler, D.P. 1998. A new eomyid rodent from the Sespe Formation of southern California. Journal of Vertebrate Paleontology 18:440-443.

Korth, W.W. 1984. Earliest Tertiary evolution and radiation of rodents in North America. Bulletin of the Carnegie Museum of Natural History, 24:1-71.

Korth, W.W. 1988. The rodent genus Mytonomys from the Uintan and Duchesnean (Eocene) of Utah, and the content of the Ailuravinae (Ischyromyidae, Rodentia). Journal of Vertebrate Paleontology, 8:290294.

Korth, W.W. 1994. The Tertiary record of rodents in North America. Topics in Geobiology, Vol. 12. Plenum Press, New York.
Krishtalka, L. 1978. Paleontology and geology of the Badwater Creek area, central Wyoming. Part 15. Review of the late Eocene primates from Wyoming and Utah, and the Plesitarsiiformes. Annals of Carnegie Museum, 47:335-360.

Krishtalka, L. and West, R.M. 1977. Paleontology and geology of the Bridger Formation, southern Green River Basin, southwestern Wyoming, Part 2, the Bridgerian insectivore Entomolestes grangeri. Contributions in Biology and Geology, Milwaukee Public Museum, 14:1-11.

Krishtalka, L. and West, R.M. 1979. Paleontology and geology of the Bridger Formation, southern Green River Basin, southwestern Wyoming, Part 4, the Geolabididae (Mammalia, Insectivora). Contributions in Biology and Geology, Milwaukee Public Museum, 27:1-10.

Kuiper, K.F., Deino, A., Hilgen, F.J., Krijgsman, W., Renne, P.R., and Wijbrans, J.R. 2008. Synchronizing rock clocks of Earth history. Science, 320:500-504.

Leidy, J. 1869. Notice of some extinct vertebrates from Wyoming and Dakota. Proceedings, Academy of Natural Sciences of Philadelphia, 23:230-232.

Leidy, J. 1870. Descriptions of Palaeosyops paludosus, Microsus cuspidatus, and Notharctus tenebrosus. Proceedings of the Academy of Natural Sciences, Philadelphia, 21:113-114.

Leidy, J. 1871. Notice of some extinct rodents. Proceedings of the Academy of Natural Sciences Philadelphia, 23:230-232.

Leidy, J. 1872. Remarks on fossils from Wyoming. Proceedings of the Academy of Natural Sciences, Philadelphia, 24:19-21.

Leidy, J. 1873. Contributions to the extinct vertebrate fauna of the western Territories, p. 14-358. In Hayden, F.V. (ed.), U.S. Geological and Geographical Survey of the Territories Report, Volume 1. U.S. Government Printing Office, Washington D.C.

Lillegraven, J.A. 1976. Didelphids (Marsupialia) and Uintasorex (?Primates) from later Eocene sediments of San Diego County, California. Transactions of the San Diego Natural History Society, 18:85-112.

Lillegraven, J.A. 1977. Small rodents (Mammalia) from Eocene deposits of San Diego County, California. Bulletin of the American Museum of Natural History, 158:221-262.

Lillegraven, J.A. and Wilson, R.W. 1975. Analysis of Simimys simplex, an Eocene rodent (?Zapodidae). Journal of Paleontology, 49:856-874.

Lindsay, E.H. 1968. Rodents from the Hartman Ranch local fauna, California. PaleoBios, 6:1-22.

Lindsay, E.H. 1977. Simimys and origin of the Cricetidae (Rodentia: Muroidea). Géobios, 10:597-623.

Linnaeus, C. 1758. Systema Naturae per Regna Tria Naturae, Secundum Classes, Ordines, Genera, Species, cum Characteribus, Differntiis, Synonymis, Locis, Volume 1: Regnum Animale. Editio Decima, Reformata. Laurentii Salvia, Stockholm. (In Latin) 
Loomis, F.B. 1907. Wasatch and Wind River rodents. American Journal of Science, 4:123-130.

Marsh, O.C. 1871. Notice of some new fossil mammals from the Tertiary formation. American Journal of Science, Series 3, 2:15-19.

Marsh, O.C. 1872. Preliminary description of new Tertiary mammals. American Journal of Science, Series 3, 4:202-224.

Marsh, O.C. 1886. Dinocerata, a monograph of an extinct order of gigantic mammals. U.S. Geological Survey Monograph, 10:1- 243.

Matthew, W.D. 1903. The fauna of the Titanotherium beds at Pipestone Springs, Montana. Bulletin of the American Museum of Natural History, 19:197-226.

Matthew, W.D. 1909. The Carnivora and Insectivora of the Bridger Basin, middle Eocene. American Museum of Natural History Memoirs, 9:289-567.

Matthew, W.D. 1910. On the osteology and relationships of Paramys and the affinities of the Ischyromyidae. Bulletin of the American Museum of Natural History, 28:43-71.

Matthew, W.D. and Granger, W. 1921. New genera of Paleocene mammals. American Museum Novitates, 13:1-17.

McGrew, P.O. 1959. The geology and paleontology of the Elk Mountain and Tabernacle Butte area, Wyoming. Bulletin of the American Museum of Natural History, 117:121-176.

McGrew, P.O. and Sullivan, R. 1970. The stratigraphy and paleontology of Bridger A. Contributions to Geology, University of Wyoming, 9:66-85.

McKenna, M.C., Robinson, P., and Taylor, W.D. 1962. Notes on Eocene Mammalia and Mollusca from Tabernacle Butte, Wyoming. American Museum Novitates, 2102:1-33.

Michaux, J. 1968. Les Paramyidae (Rodentia) de l'Eocéne inférieur du bassin de Paris. Palaeovertebrata, 1:135-193.

Miller, G.S. and Gidley, J.W. 1918. Synopsis of the supergeneric groups of rodents. Journal of the Washington Academy of Science, 8:431-448.

Murphey, P.C. 1995. Paleontology, sedimentology, and depositional history of a middle Eocene lacustrine deposit in the Bridger Formation, southwest Wyoming. Unpublished MS Thesis, University of Colorado at Boulder, Colorado, USA.

Murphey, P.C. 2001. Stratigraphy, fossil distribution, and depositional environments of the upper Bridger Formation (middle Eocene) of southwestern Wyoming, and the taphonomy of an unusual Bridger microfossil assemblage. Unpublished PhD Thesis, University of Colorado, Denver, Colorado, USA.

Murphey, P.C. and Dunn, R.H. 2009. Hemiacodon engardae, a new species of omomyid primate from the earliest Uintan Turtle Bluff Member of the Bridger Formation, southwestern Wyoming, USA. Journal of Human Evolution, 57:123-130.

Murphey, P.C. and Evanoff, E. 2007. Stratigraphy, fossil distribution, and depositional environments of the upper Bridger Formation (middle Eocene), southwestern Wyoming. Wyoming State Geological Survey, Report of Investigations, 57:1-107.

Murphey, P.C., Lester, A., Bohor, B., Robinson, P., Evanoff, E., and Larson, E. 1999. ${ }^{40} \mathrm{Ar} / 39 \mathrm{Ar}$ dating of volcanic ash deposits in the Bridger Formation (middle Eocene), southwesternWyoming. Geological Society of America Abstracts with Programs, 31:233.

Murphey, P.C., Torick, L.L., Bray, E.S., Chandler, R., and Evanoff, E. 2001. Taphonomy, fauna, and depositional environment of the Omomys Quarry, and unusual accumulation from the Bridger Formation (middle Eocene) of southwestern Wyoming, p. 361402. In Gunnell, G.F. and Alexander, J.P. (eds.), Eocene biodiversity; unusual occurrences and rarely sampled habitats. Topics in Geobiology Volume 18, Plenum Press, New York.

Murphey, P.C. and Townsend, K.E. 2005. Ecological diversity analysis applied to facies faunas in the Twin Buttes Member, middle Eocene Bridger Formation, southwestern Wyoming, USA. Society of Vertebrate Paleontology, Abstracts with Programs, 25:95A.

Murphey, P.C., Townsend, K.E., Friscia, A.R., and Evanoff, E. 2011. Paleontology and stratigraphy of middle Eocene rock units in the Bridger and Uinta Basins, Wyoming and Utah, p. 125-166. In Lee, J. and Evans, J.P. (eds.), Geologic Field Trips to the Basin and Range, Rocky Mountains, Snake River Plain, and Terranes of the U.S. Cordillera. Geological Society of American Field Guide 21, Boulder, Colorado.

Murphey, P.C. and Walsh, S.L. 2007. Shoshonian revisited: documenting the Bridgerian-Uintan faunal transition in the Turtle Bluff Member of the Bridger Formation, middle Eocene, southwestern Wyoming. Geological Society of America, Abstracts with Programs, 39:418.

Nelson, M.E. 1974. Middle Eocene rodents (Mammalia) from southwestern Wyoming. Contributions to Geology, University of Wyoming, 13:1-10.

Nelson, M.E. 1977. Middle Eocene primates (Mammalia) from southwestern Wyoming. The Southwestern Naturalist, 22:487-493.

Osborn, H.F. 1929. The titanotheres of ancient Wyoming, Dakota, and Nebraska. U.S. Geological Survey Monograph, 1:1-701.

Osborn, H.F. and Wortman, J.L. 1892. The American Eocene primates and the supposed rodent family Mixodectidae. Bulletin of the American Museum of Natural History, 4:80-147.

Ostrander, G.E. 1986. A new species of the early Tertiary rodent Thisbemys. Transactions of the Kansas Academy of Science, 89:45-48.

Peterson, O.A. 1919. Report upon the material discovered in the upper Eocene of the Uinta Basin by Earl Douglass in the years 1908-1909, and by O.A. Peterson in 1912. Annals Carnegie Museum, 12:71-105.

Porter, R. 2001. A cladistic analysis of the Sciuravidae (Mammalia: Rodentia) and implications for rodent 
phylogeny. Unpublished Senior Thesis, Amherst College, Amherst, Massachusetts, USA.

Qian, L. 2012. Middle Eocene cricetids (Rodentia, Mammalia) from the Erlian Basin, Nei Mongol, China. Vertebrata PalAsiatica, 50:237-244.

Rasmussen, D.T., Hamblin, A.H., and Tabrum, A.R. 1999. The mammals of the Eocene Duchesne River Formation, p. 421-427. In Gillette, D.D. (ed.), Vertebrate Paleontology in Utah. Utah Geological Survey, Miscellaneous Publication 99-1.

Renne, P.R., Swisher, C.C., Deino, A.L., Karner, D.B., Owens, T.L., and DePaolo, D.J. 1998. Intercalibration of standards, absolute ages and uncertainties in 40Ar/39Ar dating. Chemical Geology, 145:117-152.

Rensberger, J.M. 1975. Haplomys and its bearing on the origin of the aplodontid rodents. Journal of Mammalogy, 56:1-14.

Robinson, P. 1957. The species of Notharctus from the middle Eocene. Postilla, 28:1-27.

Robinson, P. 1968a. Nyctitheriidae (Mammalia, Insectivora) from the Bridger Formation of Wyoming. Contributions to Geology, University of Wyoming, 7:129138.

Robinson, P. 1968b. The paleontology and geology of the Badwater Creek area, central Wyoming. Part 4. Late Eocene Primates from Badwater, Wyoming with a Remarks of material from Utah. Annals of Carnegie Museum, 39:307-326.

Robinson, P., Gunnell, G.F., Walsh, S.L., Clyde, W.C., Storer, J.E., Stucky, R.K., Froehlich, D.J., Villafranca, I.F., and McKenna, M.C. 2004. Wasatchian through Duchesnean biochronology, p. 106-155. In Woodburne, M.O. (ed.), Late Cretaceous and Cenozoic Mammals of North America. Columbia University Press, New York.

Rodrigues, H.G., Marivaux, L., and Vianey-Liaud, M. 2010. Phylogeny and systematic revision of Eocene Cricetidae (Rodentia, Mammalia) from central and east Asia: on the origin of cricetid rodents. Journal of Zoological Systematics and Evolutionary Research, 48:259-268.

Rose, K.D., Chew, A.E., Dunn, R.H., Kraus, M.J., Fricke, H.C., and Zack, S.P. 2012. Earliest Eocene mammalian fauna from the Paleocene-Eocene thermal maximum at Sand Creek Divide, southern Bighorn Basin, Wyoming. University of Michigan, Papers on Paleontology 36:1-122.

Rose, K.D., Rana, R.S., Sahni, A., Kumar, K., Missiaen, P., Singh, L., and Smith, T. 2009. Early Eocene Primates from Gujarat, India. Journal of Human Evolution, 56:366-404.

Rudman, S.M. 1981. Observations on Uintasorex parvulus (Mammalia, Primates) from the Bridger Formation, southwestern Wyoming. Unpublished MA Thesis, University of Wisconsin at Milwaukee, Wisconsin, USA.

Rütemeyer, C.L.1891. Die Eocäne Saugetier, Welt von Egerkingen. Gesammt dartellung un deitter Nachtrag zu den Eocänen Säugetieren aus dem Gebiet des schweizeuschen Jura (1862). Abhandlungen Schweizerische Paläontologische Gessellschaft, 16:153. (In German)

Silcox, M.T. and Gunnell, G.F. 2008. Plesiadapiformes, p. 89-125. In Janis, C.M., Gunnell, G.F., and Uhen, M.E. (eds.), Evolution of Tertiary Mammals of North America. Cambridge University Press, Cambridge.

Simons, E.L. 1972. Primate Evolution-An Introduction to Man's Place in Nature. The MacMillan Company, New York.

Smith, M.E., Carroll, A.R., and Singer, B.S. 2008. Synoptic reconstruction of a major ancient lake system: Eocene Green River Formation, western United States. Geological Society of America Bulletin, 120:54-84.

Smith, M.E., Chamberlain, K.R., Singer, B.S., and Carroll, A.R. 2010. Eocene clocks agree; coeval $40 \mathrm{Ar} /$ ${ }^{39} \mathrm{Ar}, \mathrm{U}-\mathrm{Pb}$, and astronomical ages from the Green River Formation. Geology, 124:527-530.

Stehlin, H.G. and Schaub, S. 1951. Die Trigondontie der simplicidentalen Nager. Schweizerische Palaeontologische Abhandlungen, 67:1-385. (In German)

Stock, C. 1935. A new genus of rodent from the Sespe Eocene. Bulletin of the Geological Society of America, 46:61-68.

Storer, J.E.1984. Mammals of the Swift Current Creek Local Fauna (Eocene: Uintan), Saskatchewan. Natural History Contributions, Saskatchewan Museum of Natural History, 7:1-158.

Storer, J.E. 1987. Dental evolution and radiation of Eocene and early Oligocene Eomyidae (Mammalia: Rodentia) of North America, with new material from the Duchesnean of Saskatchewan. Dakoterra, 3:108117.

Szalay, F.S. 1969a. Mixodectidae, Microsyopidae and the insectivore-Primate transition. Bulletin of the American Museum of Natural History, 140:1-330.

Szalay, F.S. 1969b. Uintasoricinae, a new subfamily of early Tertiary mammals (?Primates). American Museum Novitates, 2363:1-36.

Szalay, F.S. 1976. Systematics of the Omomyidae (Tarsiiformes, Primates) taxonomy, phylogeny, and adaptations. Bulletin of the American Museum of Natural History, 156:1-449.

Szalay, F.S. and Delson, E. 1979. Evolutionary History of the Primates. Academic Press, New York.

Thaler, L. 1966. Les rongeurs fossiles du BasLanguedoc dans leurs rapports avec l'histoire des faunes et la stratigraphie du Tertiaire d'Europe. Mémoires du Muséum of National d'Histoire Naturelle, 17:1-295. (In French)

Tong, Y.S. 1992. Pappocricetodon, a pre-Oligocene cricetid genus (Rodentia) from central China. Vertebrata PalAsiatica, 30:1-16. (In Chinese with English summary)

Tornow, M.A. 2005. Phylogenetic systematics of the Eocene primate superfamily Omomyoidea: an investigation using dental and postcranial data. Unpub- 
lished PhD Thesis, Southern Illinois University at Carbondale, Illinois, USA.

Trouessart, E.L. 1879. Catalogue des Mammifères vivants et fossiles. Revue et Magazine de Zoologie Pure et Appliquée, Séries 3, 7:219-285. (In French)

Troxell, E.L. 1923a. Pauromys perditus, a small rodent. American Journal of Science, 5:155-156.

Troxell, E.L. 1923b. The Eocene rodents Sciuravus and Tillomys. American Journal of Science, 5:383-396.

Tsukui, K. and Clyde, W.C. 2012. Fine-tuning the calibration of the early to middle Eocene geomagnetic polarity time scale: paleomagnetism of radioisotopically date tuffs from Laramide foreland basins. Geological Society of America Bulletin, 124:870-885.

Vianey-Liaud, M. 1985. Possible evolutionary relationships among Eocene and lower Oligocene rodents of Asia, Europe, and North America, p. 277-309. In Luckett, W.P. and Hartenberger, J.L. (eds.), Evolutionary relationships among rodents: a multidisciplinary analysis. NATO Advanced Science Series, Series A, Life Sciences, Volume 92, Plenum Press, New York.

Walsh, S.L.1991. Eocene mammal faunas of San Diego County, p. 161-177. In Abbott, P.L. and May, J.A. (eds.), Eocene Geologic History San Diego Region. Pacific Section, Society of Economic Paleontologists and Mineralogists Book 68.

Walsh, S.L.1996. Middle Eocene mammalian faunas of San Diego County, California, p. 75-119. In Prothero, D.R. and Emry, R.J. (eds.), The Terrestrial EoceneOligocene Transition in North America. Cambridge University Press, New York.

Walsh, S.L.1997. New specimens of Metanoiamys, Pauromys, and Simimys (Rodentia: Myomorpha) from the Uintan (middle Eocene) of San Diego County, California, and comments on the relationships of selected Paleogene Myomorpha. Proceedings of the San Diego Society of Natural History, 32:1-20.

Walsh, S.L. and Storer, J.E. 2008. Cylindrodontidae, p. 336-354. In Janis, C.M., Gunnell, G.F., and Uhen, M.E. (eds.), Evolution of Tertiary Mammals of North America, Volume 2, Small Mammals, Xenarthans, and Marine Mammals. Cambridge, Cambridge University Press.

Walton, A.H. 1993. Pauromys and other small Sciuravidae (Mammalia: Rodentia) from the middle Eocene of Texas. Journal of Vertebrate Paleontology, 13:243261.

Walton, A.H. and Porter, R.M. 2008. Sciuravidae, p. 326335. In Janis, C.M., Gunnell, G.F., and Uhen, M.E. (eds.), Evolution of Tertiary Mammals of North America, Volume 2, Small Mammals, Xenarthans, and Marine Mammals. Cambridge University Press, Cambridge.

Wang, B.-Y. and Dawson, M.R.. 1994. A primitive cricetid (Mammalia: Rodentia) from the middle Eocene of Jiangsu Province, China. Annals of Carnegie Museum, 63:239-256.
Wang, B.-Y. and Meng, J. 1986. Eucricetodon (Rodentia, Mammalia) from the lower Oligocene of Qujing, Yunnan, China. Vertebrata PalAsiatica, 24:110-120.

Weitzel, K. 1949. Neue Wirbeltiere (Rodentia, Insectivora, Testudinata) aus dem Mittelozan von Messel bei Darmstadt. Abhandlungen Senckenbergischen Naturforschende Gesselschaft, 480:1-24. (In German)

West, R.M. 1969. Geology and vertebrate paleontology of the northeastern Green River Basin, Wyoming, p. 77-92. In Barlow, Jr., J.A. (ed.), Symposium of Tertiary rocks of Wyoming. Wyoming Geological Association 21st Field Conference Guidebook.

West, R.M. 1973. Geology and mammalian paleontology of the New Fork-Big Sandy area, Sublette County, Wyoming. Fieldiana Geology, 29:1-193.

West, R.M. 1979. Paleontology and geology of the Bridger Formation, southern Green River Basin, southwestern Wyoming, Part 3, notes on Hyopsodus. Contributions in Biology and Geology, Milwaukee Public Museum, 25:1-52.

West, R.M. 1981. Paleontology and geology of the Bridger Formation, southern Green River Basin, southwestern Wyoming, Part 5, Harpagolestes macrocephalus and comments on structure, function and diversity of middle Eocene to early Oligocene large mesonychids. Contributions in Biology and Geology, Milwaukee Public Museum, 43:1-17.

West, R.M. 1984. Paleontology and geology of the Bridger Formation, southern Green River Basin, southwestern Wyoming, Part 7, survey of Bridgerian Artiodactyla, including description of a skull and partial skeleton of Antiacodon pygmaeus. Contributions in Biology and Geology, Milwaukee Public Museum, $56: 1-47$.

West, R.M. and Akins, E.G. 1970. Additional middle Eocene (Bridgerian) mammals from Tabernacle Butte, Sublette County, Wyoming. American Museum Novitates, 2404:1-26.

West, R.M. and Hutchison, J.H. 1981. Paleontology and geology of the Bridger Formation, southern Green River Basin, southwestern Wyoming, Part 6, the fauna and correlation of Bridger E. Contributions in Biology and Geology, Milwaukee Public Museum, 46:1-8.

Wilson, R.W. 1935a. Cricetine-like rodents from the Sespe Eocene of California. Proceedings of the National Academy of Sciences, 21:26-32.

Wilson, R.W. 1935b. Simimys, a new name to replace Eumysops Wilson, preoccupied-A correction. Proceedings of the National Academy of Sciences, 21:179-180.

Wilson, R.W. 1937. Two new Eocene rodents from the Green River Basin, Wyoming. American Journal of Science, 34:447-456.

Wilson, R.W. 1938a. Review of some rodent genera from the Bridger Eocene. American Journal of Science, 35:123-137. 
Wilson, R.W. 1938b. Review of some rodent genera from the Bridger Eocene, Part II. American Journal of Science, 35:207-222.

Wilson, R.W. 1938c. Review of some rodent genera from the Bridger Eocene, Part III. American Journal of Science, 35:297-304.

Wilson, R.W. 1940. Two new Eocene rodents from California. Carnegie Institute of Washington Publication, 514:85-95.

Winge, H. 1887. Jordfundne og nulevende gnavere (Rodentia) fra lagoa Santa, Minas Geraes, Brasilien: med udsigt over gnaveines indbyrdes Slaegtskab. $E$ Mueso Lundii 1:1-178. (In Danish)

Wood, A.E. 1937. The mammalian fauna of the White River Oligocene, Part II. Rodentia. Transactions of the American Philosophical Society, New Series, 28:155-269.

Wood, A.E. 1956. Mytonomys, a new genus of paramyid rodent from the upper Eocene. Journal of Paleontology, 30:753-755.

Wood, A.E. 1959a. Rodentia, p. 157-169. In The geology and paleontology of the Elk Mountain and Tabernacle Butte area, Wyoming. Bulletin of the American Museum of Natural History, 117:123-176.

Wood, A.E. 1959b. A new sciuravid rodent of the genus Pauromys from the Eocene of Wyoming. American Museum Novitates, 1978:1-6.
Wood, A.E. 1962. The early Tertiary rodents of the family Paramyidae. Transactions of the American Philosophical Society, 52:1-261.

Wood, A.E. 1965. Small rodents from the early Eocene Lysite Member, Wind River Formation of Wyoming. Journal of Paleontology, 39:124-134.

Wood, A.E. 1973. Eocene rodents, Pruett Formation, southwest Texas; their pertinence to the origin of the south American Caviomorpha. Pearce-Sellards Series, Texas Memorial Museum, 20:1-40.

Wood, A.E. 1974. Early Tertiary vertebrate faunas Vieja Group, Trans-Pecos Texas: Rodentia. Bulletin Texas Memorial Museum, 21:1-112.

Wood, A.E. 1976. The paramyid rodent Ailuravus from the middle and late Eocene of Europe and its relationships. Palaeovertebrata, 7:117-149.

Wood, A.E. and Wilson, R.W. 1936. A suggested nomenclature for the cusps of the cheek teeth of rodents. Journal of Paleontology, 10:388-391.

Wood, H.E. 1934. A revision of the Hyrachyidae. Bulletin of the American Museum of Natural History, 67:182295.

Wortman, J.L. 1903. Studies of Eocene Mammalia in the Marsh collection, Peabody Museum. American Journal of Science, 95:345-368. 